Portland State University

PDXScholar

$7-27-2020$

\title{
Statistical Modeling of Historical Daily Water Temperatures in the Lower Columbia River
}

Malia Hanae Scott

Portland State University

Follow this and additional works at: https://pdxscholar.library.pdx.edu/open_access_etds

Part of the Environmental Engineering Commons

Let us know how access to this document benefits you.

\section{Recommended Citation}

Scott, Malia Hanae, "Statistical Modeling of Historical Daily Water Temperatures in the Lower Columbia River" (2020). Dissertations and Theses. Paper 5594.

https://doi.org/10.15760/etd.7466

This Thesis is brought to you for free and open access. It has been accepted for inclusion in Dissertations and Theses by an authorized administrator of PDXScholar. Please contact us if we can make this document more accessible: pdxscholar@pdx.edu. 


\title{
Statistical Modeling of Historical Daily Water Temperatures in the Lower Columbia River
}

by

\author{
Malia Hanae Scott
}

A thesis submitted in partial fulfillment of the requirements for the degree of

\author{
Master of Science \\ in \\ Civil and Environmental Engineering
}

\author{
Thesis Committee: \\ David A. Jay, Chair \\ Stefan A. Talke \\ Scott B. Wells \\ Heida Diefenderfer
}

Portland State University

2020 


\begin{abstract}
Water temperature affects numerous aspects of aquatic life, and its stability is critical to cold water fish such as salmonids. With rising anthropogenic influence in natural environments, the future existence of these organisms is becoming less certain. In this study, I examined the evolution of historical water temperatures in the lower Columbia River by creating a statistical model to estimate daily historical water temperatures between the 1850s and 2010s. Daily air temperature and river flow measurements were used as inputs to the model, which estimated daily water temperatures at Bonneville Dam. The model used time lags between air temperature and water temperature to determine how the river's "memory," or capacitance, has changed over time. Since the 1850 s, there has been an increase of $2.2 \pm 0.2^{\circ} \mathrm{C}$ in mean annual water temperature in the lower Columbia River. The largest seasonal rate of increase of about $2.0 \pm 0.2^{\circ} \mathrm{C} /$ century occurs in the fall and early winter while the smallest seasonal increase rate of about $0.04 \pm 0.2^{\circ} \mathrm{C} /$ century occurs in the spring. Furthermore, I sought to identify and quantify the causes of these long-term changes by distinguishing what fraction of the water temperature changes were due to climate effects and how much of the changes were due to the reservoir system and irrigation withdrawals. I found the hydropower and reservoir system has contributed approximately twice as much as climate change to warming river temperatures. While these are simplified approximations of attribution, they have important implications for conservation management.
\end{abstract}




\section{Acknowledgements}

I would like to acknowledge and thank my advisors, Stefan Talke and David Jay, and my committee members, Scott Wells and Heida Diefenderfer, for their invaluable guidance and support throughout this project. 


\section{Table of Contents}

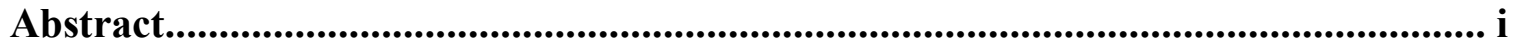

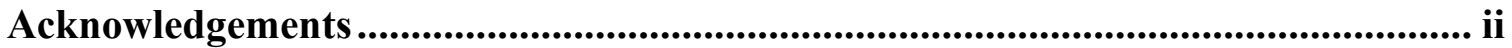

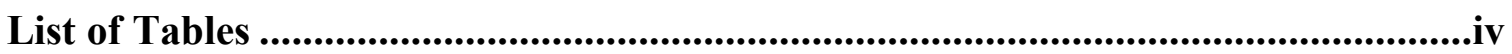

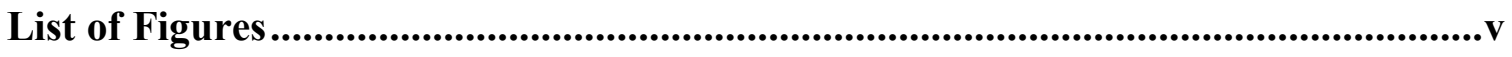

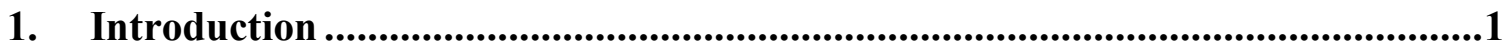

1.1. Background on the Columbia River Basin ............................................5

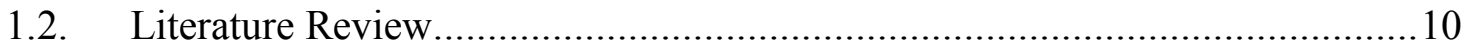

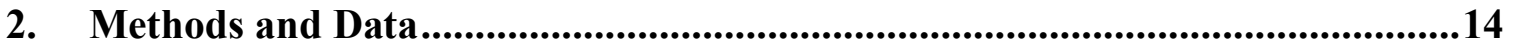

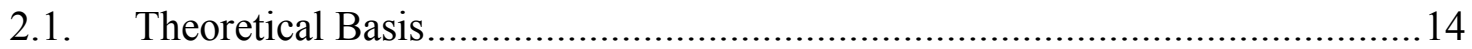

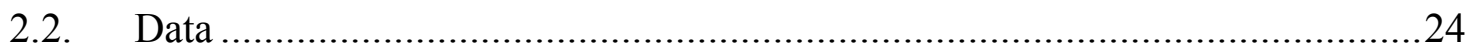

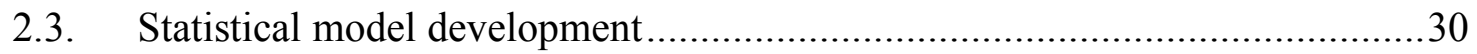

2.4. Models using Empirical Orthogonal Functions (EOFs) ..............................49

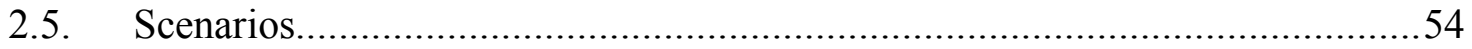

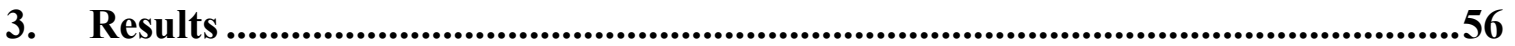

3.1. Measured and Modeled Water Temperature Changes ................................56

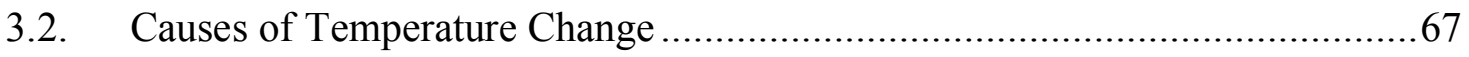

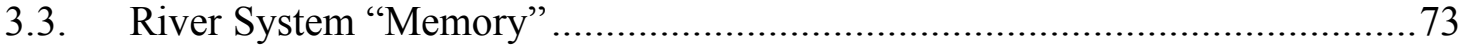

3.4. Multiple Model Comparison and an Average Model ...................................76

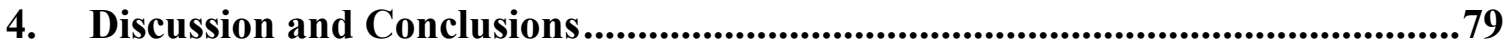

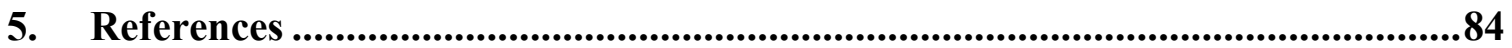




\section{List of Tables}

Table 1: Summary of air temperature data used in water temperature models. All air temperature data used were daily maximum values. And all datasets were used to produce a Pre-Dam (1940s) and Modern (2000s) model. The Vancouver dataset was also used to produce a Historical (1850s) model.

Table 2: The $\mathrm{T}_{\mathrm{a}}$ time lag structures for the Historical 1850s, Pre-Dam 1940s, and Modern 2000 s models. The values in bold indicate the number of days prior to the desired modeled day $(\mathrm{t}=0)$. The corresponding values below the bolded numbers indicate the

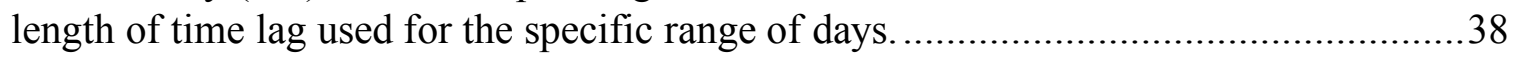

Table 3: Datasets used for the independent and composite Vancouver models.

Table 4: Scenario inputs and outputs for analysis of climate change and reservoir effects

Table 5: The RMSE statistic and estimated change per decade statistic are shown below for each composite model using different $\mathrm{T}_{\mathrm{a}}$ inputs. All models used $\mathrm{T}_{\mathrm{a}}$ from NOAA's NCEI unless otherwise noted. 


\section{List of Figures}

Figure 1: A map of the Columbia River basin showing the mainstem river and tributaries.

Figure 2: Annual hydrograph of the Lower Columbia River showing the change in river flow between the beginning of the $20^{\text {th }}$ century and the end of the $20^{\text {th }}$ century. The data has been smoothed with a 30 -day moving average. ...............................................

Figure 3: Diagram of flux into and out of a water column..................................... 14

Figure 4: The various heat fluxes between a stream and its surrounding environment are shown. Solar radiation is synonymous with incoming shortwave radiation. Convective heat flux is also called sensible heat exchange, and evaporative flux is the same as evaporative heat loss (Caissie et al. 2014).

Figure 5: A map of the stations within the Columbia River Basin used in developing our statistical model. The green pins indicate air temperature stations, blue pins are water temperature stations, and the red pin represents the river flow station data.

Figure 6: The air temperature deviations (or anomalies) for the Spokane International Airport station. The changes in the estimated station mean bias shows the bias in the raw data.

Figure 7: An overview of the statistical model development process.

Figure 8: Monthly linear correlation estimated between Bonneville and Astoria water temperatures based on data between 1950 and 1980. The black line shows a reference 1:1 correlation. The green line shows the actual monthly correlation.

Figure 9: Calibration of 1850s Historical model using Vancouver air temperature data. RMS error was used to compare seasonal vs. full year (annual) models and river flow (w/Q) vs. no river flow (no Q) models.

Figure 10: Calibration of 1940s Pre-Dam model using Vancouver air temperature data. RMS error was used to compare seasonal vs. full year (annual) models and river flow (w/Q) vs. no river flow (no Q) models.

Figure 11: Calibration of 2000s Modern model using Vancouver air temperature data. RMS error was used to compare seasonal vs. full year (annual) models and river flow (w/Q) vs. no river flow (no Q) models.

Figure 12: Vancouver 1940s (Pre-Dam) model coefficients plotted against time lags (in days). The decrease in magnitude of Ta coefficients (red line) as the time lags increase 
indicates the correlation between air temperature and water temperature decreases as the number of days between measurements increases.

Figure 13: Vancouver 1850s (Historical) model coefficients plotted against time lags (in days)

Figure 14: Seasonal and annual models are combined together to produce a full-year model.

Figure 15: A comparison of the measured data (in blue) to the final modeled results (in red) after the climatology was added back in, for the years from 1944 to 1945.

Figure 16: A comparison of the measured data (in blue) to the final modeled results (in red) after the climatology was added back in, for the years from 2010 to 2011 .

Figure 17: The Spokane composite model spans from 1880 to 2018 and is comprised of two individual models stitched together (the 1940s and 2000s models)

Figure 18: The Portland composite model spans from 1872 to 2018 and is comprised of two individual models stitched together (the 1940s and 2000s models). The Portland $\mathrm{T}_{\mathrm{a}}$ dataset is missing a few years around 2006 - 2010 which is why there are some gaps in the model output.

Figure 19: The Vancouver composite model showing how individual models were stitched together to obtain a single, fairly continuous model spanning from $1850-2018$. The blue model uses Vancouver $\mathrm{T}_{\mathrm{a}}$ and estimated Bonneville $\mathrm{T}_{\mathrm{w}}$. The orange model uses Fort Colville $\mathrm{T}_{\mathrm{a}}$ and estimated Bonneville $\mathrm{T}_{\mathrm{w}}$. The yellow and purple models use Vancouver $\mathrm{T}_{\mathrm{a}}$ and Bonneville $\mathrm{T}_{\mathrm{w}}$

Figure 20: From EOF analysis, the weighting of each air temperature input from mode 1 for 1940 s data. The air temperature inputs are plotted by approximate geographical location with the left most points representing the westernmost part of the Columbia River basin, and the rightmost points representing the easternmost part of the basin......52

Figure 21: From EOF analysis, the weighting of each air temperature input from mode 2 for 1940s data. The air temperature inputs are plotted by approximate geographical location with the left most points representing the westernmost part of the Columbia River basin, and the rightmost points representing the easternmost part of the basin......53

Figure 22: Measured change in water temperature at Bonneville between 1938 and 2018. A river climatology was calculated based on thirty-day averaged temperature between 1938 to 1952 (red line) and 2004 to 2018 (black line). The estimated change in temperature is based on the difference between the specified time periods. 
Figure 23: Estimated measured change in water temperature at Bonneville between 1855 to 1952. A river climatology was calculated based on thirty-day averaged temperature between 1855 to 1875 (blue line) and 1938 to 1952 (red line). The data from the 1800s is estimated Bonneville temperatures based on measured water temperature data from Astoria. The estimated change in temperature is based on the difference between these two time periods

Figure 24: Annual mean, minimum, and maximum water temperature trends are shown. The red line is the measured data from Bonneville, the grey line is the modeled water temperature, and the cyan line is the estimated water temperatures at Bonneville based on data from Astoria.

Figure 25: Annual seasonal trends are shown. The red line is the measured data from Bonneville and the grey line is the modeled result. The measured water temperature from the 1800s shown in blue is estimated Bonneville temperatures based on measurements from Astoria.

Figure 26: Modeled number of days over $20{ }^{\circ} \mathrm{C}$ for water temperature. The + sign indicates when the maximum water temperature for the year occurred.

Figure 27: The decadally averaged number of days above and under various thresholds. (a) shows the number of cold days (below 2 and $4{ }^{\circ} \mathrm{C}$ ) is decreasing. (b) shows the number of warm days (above 18,20 , and $22^{\circ} \mathrm{C}$ ) is increasing. The ridged circles indicate Bonneville approximated measurements, the squares indicate true Bonneville measurements.

Figure 28: The modeled change in water temperature based solely on the changing climate (air temperature). We used the 1940s (historical) Vancouver model for this simulation. (a) The change in air temperature climatology from1880 to 1910 and 1988 to 2018. (b) The modeled change in water temperature from 1880 to 2018.

Figure 29: The estimated modeled change in water temperature based solely on changes to the river due to the reservoir system. This figure shows the difference in the Pre-Dam Vancouver model (1940V) and Modern Vancouver model (2000V) when applied to the same set of air temperature and river flow data.

Figure 30: Measured water temperatures from Rock Island Dam (blue) and Bonneville Dam (orange) over time. The measurements are averaged over a two year time period. .72

Figure 31: The air temperature coefficients plotted as a function of number of days lagged. The change in the magnitude of coefficients from 0 lag days to 60 lag days shows how the correlation between air temperature and water temperature decreases as the time between measurements increases. The red line is the 1940s Vancouver (1940V) decorrelation structure and the black line is the 2000s Vancouver (2000V) correlation structure. 
Figure 32: Five-year averaged modeled water temperature from various models (light grey lines) compared with the ensemble average of all model results (black line) and fiveyear averaged measured water temperature (blue line). The various models shown used different air temperature inputs from different locations (Table 1)................................77 


\section{Introduction}

Water temperature is a common and important measure of water quality in streams, rivers, and lakes. It plays a role in numerous biological processes such as nutrient cycling and solute chemistry, which subsequently influence aquatic food webs and ecosystems (ISAB 2011-1). Water temperature affects species abundance, distribution, dynamics, productivity, feeding, and growth and metabolism rates (ISAB 2011-1, McCullough et al. 2009). The timing of important life events in anadromous fish species such as migration and spawning are triggered by water temperature (Carter 2005, Caldwell et al. 2013). Water temperature also impacts predator-prey interactions and other ecosystem processes such as competition, community composition, and spread of disease and parasites (McCullough et al. 2009).

Water temperature guides metabolic and life cycle processes for native, endangered fish such as salmon, bull trout, and steelhead of the Columbia River Basin (U.S. Dept. of the Interior, Bureau of Reclamation 2016). In 1998, under the Clean Water Act, the states of Washington and Oregon listed parts of the Columbia and Snake Rivers as impaired waterbodies because the temperatures consistently exceeded the states' water quality standards of $20^{\circ} \mathrm{C}$ (Columbia Riverkeeper v. Pruitt 2018). Since then, temperatures have continued to surpass the threshold set by the states, especially in the summer. In 2015 , an estimated 250,000 migrating sockeye salmon died because of dangerously warm temperatures in the Columbia and Snake Rivers (Columbia Riverkeeper v. Pruitt 2018). 
Total Maximum Daily Loads (TMDL) for temperature are a regulatory concept, the maximum amount of heat (i.e., maximum temperature) allowed in a water body. The Environmental Protection Agency (EPA) had started work on temperature TMDLs for the Columbia and Snake Rivers in 2003; however, after producing a preliminary draft, it stopped its work and left the project unfinished (Columbia Riverkeeper v. Pruitt 2018, U.S. EPA 2003). Because there were no temperature TMDL's for the Columbia and Snake Rivers, the Columbia Riverkeeper, a non-profit organization based in Portland, OR, filed a lawsuit against the U.S. EPA for not finishing its work on the TMDLs back in 2003.

In its preliminary draft on TMDL, the EPA cited the dams as a significant contributor to warming river temperatures, particularly in the late summer and early fall. It found that the dams extended the length of time the river may be above $20^{\circ} \mathrm{C}$ because the rivers did not cool as quickly in the fall as they did prior to the dams' existence. It estimated the impact of each individual dam and found some to have caused an increase of up to $6^{\circ} \mathrm{C}$. In addition to the dams, the report also cited climate change as a potential contributor to warmer water temperatures (U.S. EPA 2003). Additional research has also shown that climate change impacts water temperature regimes in streams and rivers and will likely have a significant impact in the future (Isaak et al. 2012, Wagner et al. 2011). A combination of both rising air temperatures and potentially decreased river flows points to warmer river temperatures (van Vliet et al. 2011). In the Pacific Northwest in particular, snow dominant streams will likely be more affected by climate change compared to other stream types due to lower summer stream flows and warmer summer air temperatures (Wu et al. 2012). These changes suggest an increase in thermal stress on fish in future summers. 
Because water temperature is a crucial component to organism and ecosystem functioning, it is important to study this parameter in an anthropogenically-altered environment, in which temperature has changed. To examine changes over time, and what the impacts of these changes might be, one must know what temperatures were like prior to any ecological disturbance. Therefore, a long-term understanding of water temperature is important. Weitkamp (1994) sought to identify the biological and physical effects of the dams along the Columbia River; however, determining the potential effects proved quite difficult due to the lack of historical data prior to the existence of dams. This is one example highlighting the importance and need for a study such as this one.

In the Columbia River, Bottom et al. (2011) used a statistical model and estimated that annual average water temperatures have increased by 2 to $3^{\circ} \mathrm{C}$ from 1890 to 2002 , with over half of this increase $\left(0.8^{\circ} \mathrm{C}\right.$ to $\left.2.0^{\circ} \mathrm{C}\right)$, attributable to the reservoir system. Similarly, Overman (2017), estimated that water temperatures from 1938 to 2003 increased by about $1.5^{\circ} \mathrm{C}$ between May and October, with $1.3^{\circ} \mathrm{C}$ of the total increase attributable to the reservoir system.

The purpose of this study is to revisit and improve upon the statistical models of Bottom et al. (2011) and Overman (2017). These previous studies used bi-weekly or monthly time resolution in their models. This study develops a daily water temperature model. Daily temperatures have more relevance for management purposes and for studying the ecological impacts of exposure to temperatures near and above species' limits. Another novelty of this study is the use of historical air and water temperature measurements dating 
back to the 1850s. These data allowed me to produce a long-term model that covers more than 160 years. I also incorporated air temperature data from multiple stations throughout the Columbia River Basin to construct multiple models that could be compared, and to increase the robustness of results. The final composite model spans from 1850 to 2018; it is composed of three different models across three time periods and provides estimates of long term trends in river temperature. Specifically, I created a Historical 1850s model, a Pre-Dam 1940s model, and a Modern 2000s model that could distinguish and estimate water temperature changes due to climate change and changes due to the reservoir system. This work allows for a better understanding of the thermal regime of the lower Columbia River, which has implications for future river management and ultimately the ecosystems that depend on the river.

The following study is outlined as follows. A description and brief history of the Columbia River Basin is covered, followed by the development of statistical models for water temperature, and concluded with an analysis and interpretation of results. 


\subsection{Background on the Columbia River Basin}

The Columbia River Basin spans across seven states and part of British Columbia, Canada and is the fourth largest river in the United States by volume (Figure 1). The mainstem river originates in the Rocky Mountains in Canada and flows through Washington and Oregon before reaching the Pacific Ocean. As the largest river in the Pacific Northwest, the Columbia River not only provides vital habitat to various species, it also provides resources such as energy, water, and food, for the growing human population in the region (US Dept. of the Interior, Bureau of Reclamation 2016). The river itself is about 2,000 km long and has a drainage area of about 668,000 square kilometers. The basin consists of a variety of climates and ecosystems including desert, forest, shrubland and riparian zones (National Research Council 2004). There is significant seasonal precipitation that primarily falls as snow during the winter months, while summers are dry. Prior to European settlement and modification of the river basin, peak flows in the river occurred in May and

June and were driven primarily by snowmelt, though some major floods, e.g., the flood of record in 1894, were enhanced by very heavy rainfall on the snowmelt. 


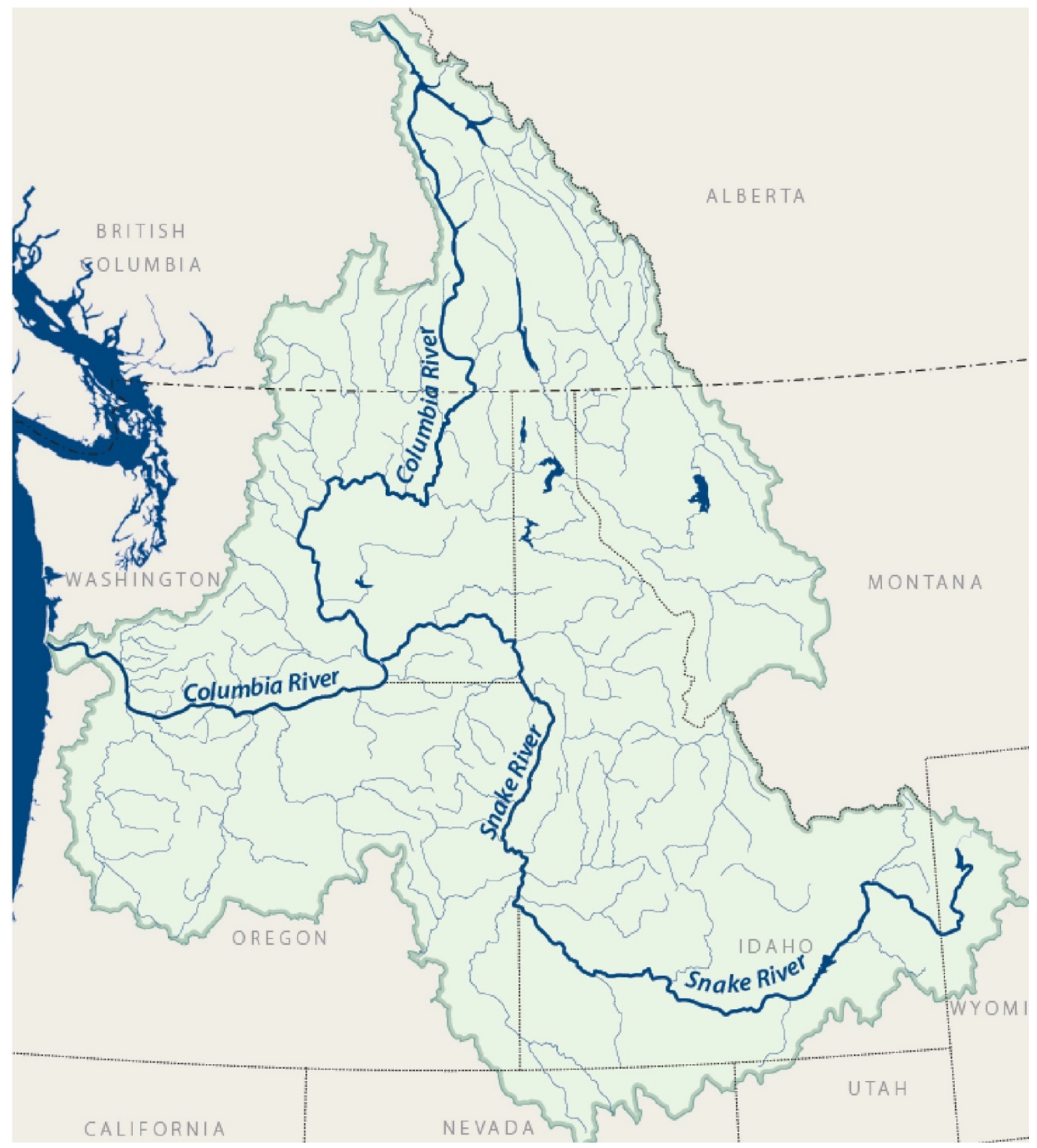

Figure 1: A map of the Columbia River basin showing the mainstem river and tributaries.

Human activities have affected the timing and magnitude of the peak and lowest flows, particularly since about 1970 (Figure 2, National Research Council 2004, Naik and Jay 2011). Irrigated agriculture diverts water from the river, largescale logging has altered the 
vegetation and landscape, and the hydroelectric power system has changed the volume and seasonality of the river's original flows. Between irrigation withdrawals, changes in climate, and deforestation, annual flows have decreased by about $15 \%$. Additionally, the decrease in magnitude of the spring freshet is largely attributable to flow regulation; and the timing of peak flows have been affected by both human-caused and climate changes (Naik and Jay 2011). European settlers first started bringing livestock and agricultural practices to the region in the mid-1 $19^{\text {th }}$ century, while irrigation diversion began around 1840. However, it was only after the beginning of the $20^{\text {th }}$ century that these activities occurred on a large enough scale to have a significant impact on the river system (National Research Council 2004, Bottom et al. 2005). The timing of peak flows are thought to have been more influenced by climate prior to about 1920, while human activities have more significantly affected flows after about 1970 (Naik and Jay 2011). 

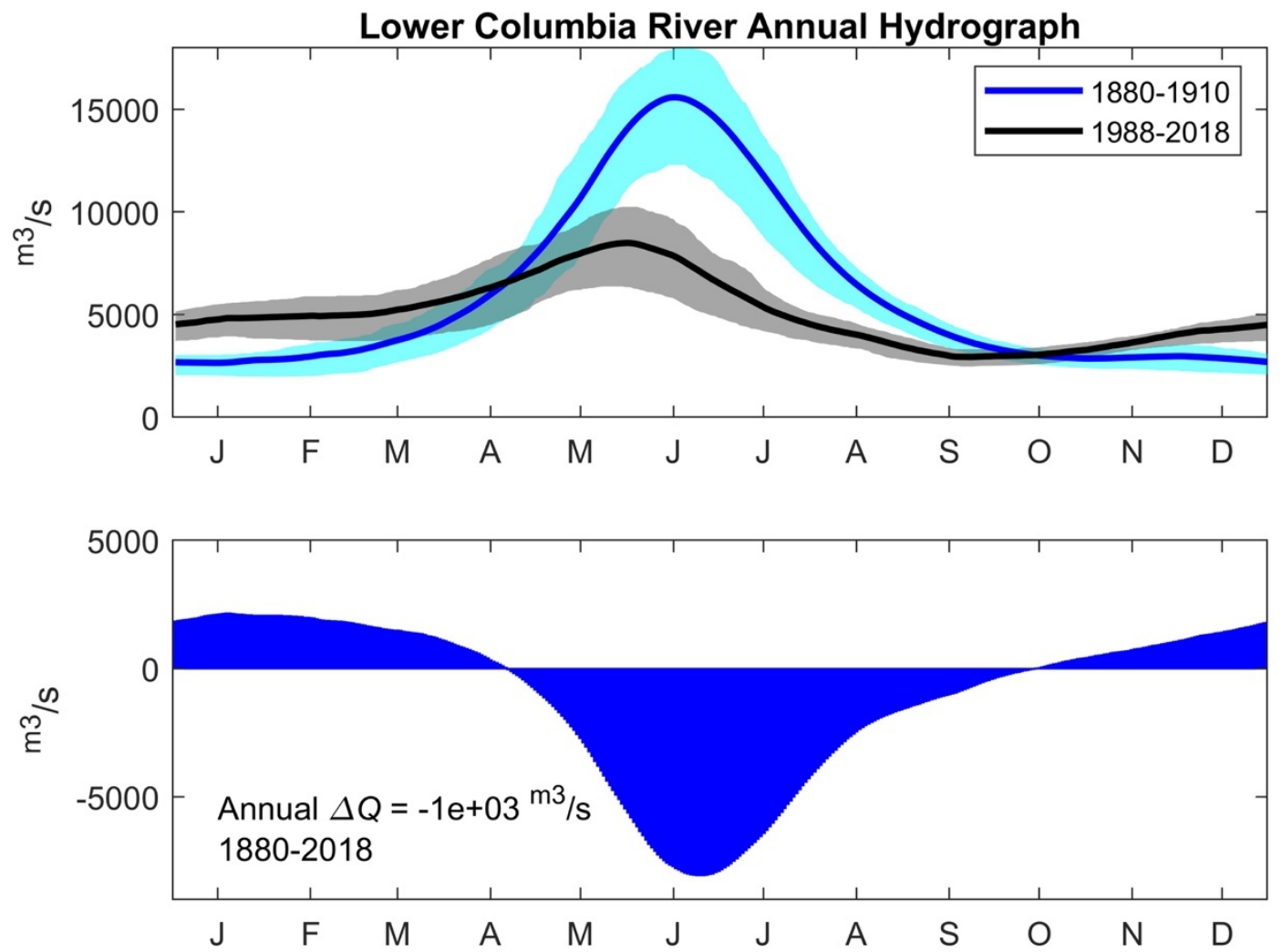

Figure 2: Annual hydrograph of the Lower Columbia River showing the change in river flow between the beginning of the $20^{\text {th }}$ century and the end of the $20^{\text {th }}$ century. The data have been smoothed with a 30-day moving average.

One of the most significant alterations to the river has been the construction of dams and reservoirs. These structures provide hydropower and account for up to $80 \%$ of the total energy production in the Pacific Northwest (US Dept. of the Interior, Bureau of Reclamation 2016). In total, there are 31 large dams along the Columbia River and its tributaries that make up the Federal Columbia River Power System (FCRPS). The first mainstem dam built was Rock Island Dam in 1933, with Bonneville Dam following in 1938 (National Research Council 2004). In addition to the hydropower system, humans have also altered the natural river system through other activities such as agriculture, 
ranching, timber harvesting, and water diversions (National Research Council 2004). Humans first inhabited the region about 15,000 years ago, and while they did have some impact on the river system, the industrial based economic activities along with increased settlement starting around the $19^{\text {th }}$ century has led to much more substantial changes regarding land use and basin hydrology (National Research Council 2004).

In addition to the reservoirs and dams, multiple nuclear reactors at the Hanford Site $(\sim \mathrm{rkm}$ 600) had a significant effect on the river during its peak production from about 1955 to 1965. During its operation, water from the Columbia River was used to cool the reactors and then returned directly to the mainstem river. A study done in 1968 showed a 1.5 to $2^{\circ} \mathrm{F}$ $\left(\sim 0.8\right.$ to $\left.1^{\circ} \mathrm{C}\right)$ increase in water temperatures at Bonneville Dam during the fall and winter months from 1941 to 1966; furthermore it showed that this change was caused by the Hanford nuclear site and not meteorological forcing (Moore 1968). 


\subsection{Literature Review}

Human-related activities have had a large impact on the Columbia River and its temperature. We, as humans, have contributed to an overall warming trend over time, as well as altered the natural thermal gradients across space and time in the river (ISAB 20111, Sauter et al. 2011). Warming trends have been influenced by decreased summer peak flows due to the reservoirs and water extraction, warm irrigation return flows, and climate change. Changes in spatial and temporal variability can be attributed to the reservoir system which holds and releases cold or warm water, as well as largescale timber harvesting and grazing which has impacted the vegetation and shading around the river and its tributaries (ISAB 2011-1, National Research Council 2004).

The altered variability in temperatures along with an overall trend of warming temperatures has potentially serious consequences for cold water fish such as salmonids. The temperature tolerance range of salmonids is approximately $5^{\circ} \mathrm{C}$ to $20^{\circ} \mathrm{C}$ (National Research Council 2004). Water temperatures above $20^{\circ} \mathrm{C}$ are known to negatively impact salmonids (National Research Council 2004, Sauter et al. 2011, Carter 2006, Benyahya et al. 2007, Bottom et al. 2005, Bottom et al. 2011). Increased energy expenditure in juvenile fish, decreased growth rates, and increased disease prevalence are a few of the impacts of high temperatures (National Research Council 2004). Increasing water temperature has also led to a decrease in cold water refugia for fish (ISAB 2011-1). These areas of colder water have been shown to be critical for migrating salmonids in warmer waters (Keefer et al. 2018). When salmonids migrate in higher water temperatures, they use cold water refuges 
extensively, from hours up to days. Furthermore, Keefer et al. (2018) found a positive correlation between thermal exposure and migration duration, which suggests an increased used of cold water refugia in warmer temperatures.

Temperature changes may also affect the migration timing of salmonids (Quinn and Adams 1996, Keefer et al. 2008). Quinn and Adams (1996) found that shad (an introduced species) are migrating much earlier in the year, about 38 days earlier since 1938, while the native salmon are migrating only about 6 days earlier since 1949. Because they are migrating earlier in the year, the shad are experiencing a lower mean water temperature, while the salmon are experiencing a higher mean water temperature. The salmon's adaptation rate is therefore slower than the rate of environmental change. The difference in the two species' responses may be due to the difference in distance and duration of migratory patterns as well as innate factors such as genetics (Quinn and Adams 1996).

In modeling river and stream temperatures, there are two main approaches, deterministic, and statistical or stochastic models. Deterministic models are based on the underlying physics of heat exchange in a river. They typically perform better than a statistical model for a given scenario, however they require extensive and detailed input data such as stream geometry, meteorology, and hydrology that are typically not available, except in the modern period. Statistical models are advantageous because of their simplicity and because they usually require fewer types of data and much less time to run compared to deterministic models (Benyahya et al. 2007). Statistical models also are better for larger spatial and temporal time scales because of their minimal data requirement (Caldwell et al. 
2013). The correlation between various environmental variables and water temperature is the driving mechanism behind these statistical models. Air temperature and river flow are the two most common variables used in modeling river temperature, with air temperature being the primary independent variable used (Benyahya et al. 2007, Caldwell et al. 2013, Neumann et al. 2003, Gu 1998, Bottom et al. 2011, Webb et al. 2003). Models have been created at various time scales from hourly to annually, with the best statistical model performance somewhere in the middle between daily to monthly (Benyahya et al. 2007, Webb et al. 2003, Erickson and Stefan 2000).

Among statistical models, there are various types. They can first be divided into parametric and non-parametric models. Parametric models assume an underlying model structure while non-parametric models do not, and instead rely on the data to determine the appropriate structure (Benyahya et al 2007). Parametric models can be further classified into regression and stochastic models. Regression models have been used frequently to model water temperatures on the weekly to yearly scale (Stefan and Preud'homme 1993, Webb et al. 2003, Erickson and Stefan 2000). Their success relies on the strong correlation between water and air temperatures. While a linear regression is often used for modeling river temperatures, some work has also been done using non-linear regression, indicating the water and air temperature relationship is not always linear (Mohseni and Stefan 1999).

In stochastic statistical models, the seasonal or annual variation is removed from the data and the remaining deviations from the mean (the residuals) are modeled (Benyahya et al. 2007, Caissie et al. 1998). This approach accounts for the autocorrelation, or time- 
dependence, of water temperature. Autocorrelation is common in time series data and occurs when the data collected for a given day is influenced by conditions from previous days, thus the data is correlated with itself from a previous timestep. By using the daily deviations from the mean, the autocorrelation inherent in environmental variables such as temperature is removed and thus the assumption of time-independence in statistical regression analysis is not violated.

Additionally, it has been shown that including air temperature from previous days can help improve the water temperature model's performance (Stefan and Preud'homme 1993, Webb et al. 2003, Erickson and Stefan 2000). A direct relationship between river depth and time lag length has been found, where the larger the river depth, the longer the time lag that water temperature responds to air temperature (Stefan and Preud'homme 1993). Adding these time lags to the model can especially help with large river systems where the thermal inertia of the water is higher compared to smaller streams (Webb et al. 2003). 


\section{Methods and Data}

Temperature is a measure of heat, and similarly, the change in temperature is a measure of the amount of heat transfer. Heat transfer in a system is driven by spatial and temporal temperature differences. The processes that describe these energy imbalances and transfers are described by the advection-diffusion equation, as derived in the following section.

\subsection{Theoretical Basis}

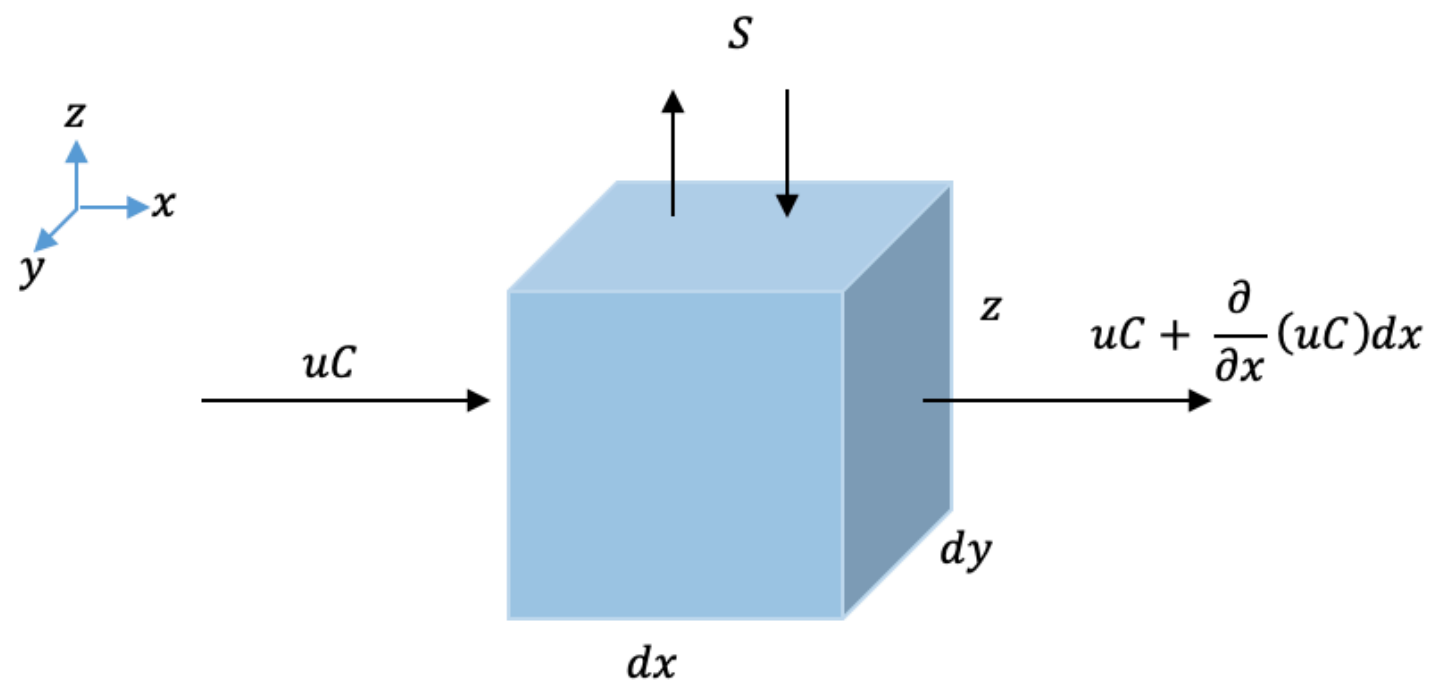

Figure 3: Diagram of flux into and out of a water column.

The advection-diffusion equation is derived in terms of the scalar fluxes into $\left(J_{\text {in }}\right)$ and out of $\left(J_{\text {out }}\right)$ a water column in a stream, where $u$ is the cross-sectionally averaged velocity in the $\mathrm{x}$ (along-channel) direction, $C$ is a cross-sectionally averaged scalar property, and $\mathrm{S}$ represents sources or sinks (Figure 3). The control volume chosen is a water column with the height, $z$, equal to river depth. While there are sources/sinks into and out of the bottom 
of the water column, they are considered negligible here compared to the flux at the top of the water column. The flux into the water column on the left facing side can be described by:

$$
J_{\text {in }}=(u C) z d y
$$

$z d y$ is the cross sectional area of the left and right faces of the water column. The flux out of the water column on the right facing side can be described by:

$$
J_{\text {out }}=-\left(u C+\frac{\partial}{\partial x}(u C) d x\right) z d y
$$

The second part of the 'flux out' term represents any internal changes in concentration within the control volume and comes from a Taylor series expansion where the higher order terms are neglected. The mean and deviation components of the 'flux in' term are then separated, a step analogous to Reynolds decomposition.

$$
(u C) z d y=\left(\overline{u C}+u^{\prime} C^{\prime}\right) z d y
$$

Next, I took a one-day time average of all components. The time averaging of the equation, also known as Reynolds averaging, allows use of a gradient diffusion assumption to approximate the deviation component from (3):

$$
(\overline{u C}) z d y=\left(\overline{u C}+\overline{u^{\prime} C^{\prime}}\right) z d y
$$


by:

$$
\overline{u^{\prime} C^{\prime}}=-K \frac{\partial C}{\partial x}
$$

where $K$, is a dispersion coefficient based on a spatially and temporally averaged system. The 'flux in' term can then be written as:

$$
J_{\text {in }}=\left(u C-K \frac{\partial C}{\partial x}\right) z d y
$$

Applying the same steps to the 'flux out' term, it becomes:

$$
J_{o u t}=-\left(u C-K \frac{\partial C}{\partial x}\right) z d y-\left[\frac{\partial}{\partial x}(u C)-\frac{\partial}{\partial x}\left(K \frac{\partial C}{\partial x}\right)\right] z d x d y
$$

The total rate of change of concentration in the water column control volume is the net flux through the water column in the x-direction plus additional heat sources from the top of the water column represented as $S$ :

$$
\frac{\partial C}{\partial t} z d x d y=\left(u C-K \frac{\partial C}{\partial x}\right) z d y-\left(u C-K \frac{\partial C}{\partial x}\right) z d y-\left[\frac{\partial}{\partial x}(u C)-\frac{\partial}{\partial x}\left(K \frac{\partial C}{\partial x}\right)\right] z d x d y \pm S
$$

Eliminating terms that cancel out and describing the net flux per water column:

$$
\frac{\partial C}{\partial t}=-\frac{\partial}{\partial x}(u C)+\frac{\partial}{\partial x}\left(K \frac{\partial C}{\partial x}\right) \pm \frac{\sum S}{z}
$$

To use equation (9) to describe heat transfer, $C$ is replaced with energy content, $U$ :

$$
U=\rho_{w} c_{p} T_{w}
$$


where $\rho_{w}$, is the density of water, $c_{p}$, is the specific heat of water, and $T_{w}$, is the water temperature. The source/sink at the water surface $S$, is the interfacial heat flux, $H$, that occurs between the water and air at the top of the water column. Thus:

$$
\frac{\partial\left(\rho_{w} c_{p} T\right)}{\partial t}+\frac{\partial}{\partial x}\left(u \rho_{w} c_{p} T\right)=\frac{\partial}{\partial x}\left(K \frac{\partial \rho_{w} c_{p} T}{\partial x}\right)+\frac{\Sigma H}{z}
$$

Assuming $\rho_{w}$ and $c_{p}$ are constant along the river channel:

$$
\rho_{w} c_{p} \frac{\partial T}{\partial t}+\rho_{w} c_{p} \frac{\partial}{\partial x}(u T)=\rho_{w} c_{p} \frac{\partial}{\partial x}\left(K \frac{\partial T}{\partial x}\right)+\frac{\Sigma H}{z}
$$

Lastly, the spatially and temporally averaged velocity term, $u$, can be rewritten as:

$$
u=\frac{Q}{A}
$$

where $Q$ is the volumetric flow and $A$ is the cross-sectional area of the river. This substitution allows one to see the relevance of $Q$ for heat transfer more easily. After dividing through by $\rho_{w} c_{p}$, the end result is:

$$
\underbrace{\frac{\partial T}{\partial t}}_{1}+\underbrace{\frac{\partial}{\partial x}\left(\frac{Q}{A} T\right)}_{2}=\underbrace{\frac{\partial}{\partial x}\left(K \frac{\partial T}{\partial x}\right)}_{3}+\underbrace{\frac{\sum H}{\rho_{w} c_{p} Z}}_{4}
$$

Equation (13) describes one dimensional heat transfer for a river (Wagner et al. 2011). The leftmost term (13-1) describes the local change in $T$, the second term (13-2) describes heat transfer by advection, the third term (13-3) describes heat transfer by dispersion, and the fourth term (13-4) describes heat fluxes between the air and water. Note that the last term 
(13-4) varies inversely with the depth of the river, $z$, which is in turn influenced by flow rate.

By scaling equation (13), one can more easily identify which terms in the equation dominate and which terms could be considered negligible. When scaling, each variable is written as a product of a characteristic length scale and a non-dimensional variable. For example along-channel velocity, $u$, becomes defined as $U=U \hat{u}$, where, $U$, is the static characteristic velocity scale and, $\hat{u}$, is the non-dimensional, dynamic variable. Similarly:

$$
t=\tau \hat{t} \quad X=L \hat{x} \quad K=K \hat{k} \quad Z=H \hat{z} \quad T=T \hat{t}
$$

The characteristic scales and parameter estimates used were:

$$
\begin{aligned}
& U \sim 1 \frac{m}{s} \quad \tau \sim 10^{5} \mathrm{~s} \quad L \sim 10^{6} \mathrm{~m} \quad K \sim 10^{2} \frac{\mathrm{m}^{2}}{\mathrm{~s}} \quad H \sim 10 \mathrm{~m} \quad T \sim 1{ }^{\circ} \mathrm{C} \\
& \sum H \sim 4 \times 10^{2} \frac{\mathrm{J}}{\mathrm{m}^{2} \mathrm{~s}} \quad \rho_{w} \sim 10^{3} \frac{\mathrm{kg}}{\mathrm{m}^{3}} \quad c_{p} \sim 4 \times 10^{3} \frac{\mathrm{J}}{\mathrm{kg}{ }^{\circ} \mathrm{C}}
\end{aligned}
$$

The characteristic scale for the longitudinal dispersion coefficient, $K$, was estimated based on a study from the middle Columbia River (Sonnichsen et al. 1970). Measurements of total heat flux can vary greatly depending on geographical and meteorological factors. For a sunny day in the Pacific Northwest, average incoming solar radiation can reach up to $400 \frac{J}{m^{2} s}$ (Johnson 2000 and Whiteman 2000). 
The heat budget equation is written in terms of these scaling and non-dimensional variables, and then multiplied through by $\frac{t}{T}$ in order to non-dimensionalize the entire equation:

$$
\begin{aligned}
& \frac{T}{\tau} \frac{\partial T}{\partial t}+U \frac{T}{L} u \frac{\partial T}{\partial x}=\frac{K T}{L^{2}}\left(\frac{\partial}{\partial x}\left(K \frac{\partial T}{\partial x}\right)\right)+\frac{\Sigma H}{\rho_{w} c_{p} z} \\
& \underbrace{1 \frac{\partial T}{\partial t}}+\underbrace{U \frac{\tau}{L} u \frac{\partial T}{\partial x}}=\frac{K \tau}{L^{2}} \underbrace{\left(\frac{\partial}{\partial x} K\left(\frac{\partial T}{\partial x}\right)\right)}+\frac{\tau}{T} \underbrace{\frac{\Sigma H}{\rho_{w} c_{p} Z}} \\
& 1 \sim 0.1 \sim 10^{-5} \sim 1
\end{aligned}
$$

Within large rivers, this scaling exercise suggests that the dispersion term is negligible compared to the other terms. Often, advection can also be considered negligible when considering large distances where the longitudinal temperature gradient is small $(\partial \mathrm{T} / \partial \mathrm{x}$ $\rightarrow 0$ ). Some of the scaling parameters vary depending on the season. The advection term varies such that the longitudinal temperature gradient can be smaller in the late winter and spring than in the summer. With higher flows in the late winter and springtime, the river's temperature is less sensitive to various weather conditions because it has a higher thermal inertia compared to late summer and fall, when flows are lower, and the system is more sensitive to varying local weather patterns. Decreased thermal sensitivity in the winter suggests a decreased longitudinal temperature gradient. This suggests that $Q$ may be more important in the summer and fall than winter and spring when attempting to model temperature. 
From the scaling exercise, I was left with a simplified version of the advection diffusion equation:

$$
\frac{\partial T}{\partial t}=\frac{\Sigma H}{\rho_{w} C_{p} z}
$$

The heat flux terms are more specifically defined as:

$$
\sum H=H_{s}+H_{e}+H_{l w}+H_{s w}
$$

The air-water heat fluxes in (16) include sensible heat exchange $\left(H_{s}\right)$, evaporative heat loss $\left(H_{e}\right)$, longwave radiation $\left(H_{l w}\right)$, and shortwave radiation $\left(H_{s w}\right)$ (Figure 4$)$. Sensible heat exchange is the heat exchange that occurs between two substances of different temperatures, where the rate of heat exchange depends on the temperature gradient, wind speed, wave height and other factors. Evaporative heat loss is the heat lost during the evaporation of water from the river into the atmosphere. Shortwave radiation is the incoming heat from the sun. Some of that incoming radiation is remitted back into the atmosphere, known as longwave radiation. For a large, predominantly snow-fed river such as the Columbia River, the most important heat fluxes in the river are those that occur between the air and water boundary, while the ground to water boundary fluxes are typically much smaller. Thus, the latter were neglected in (16). 


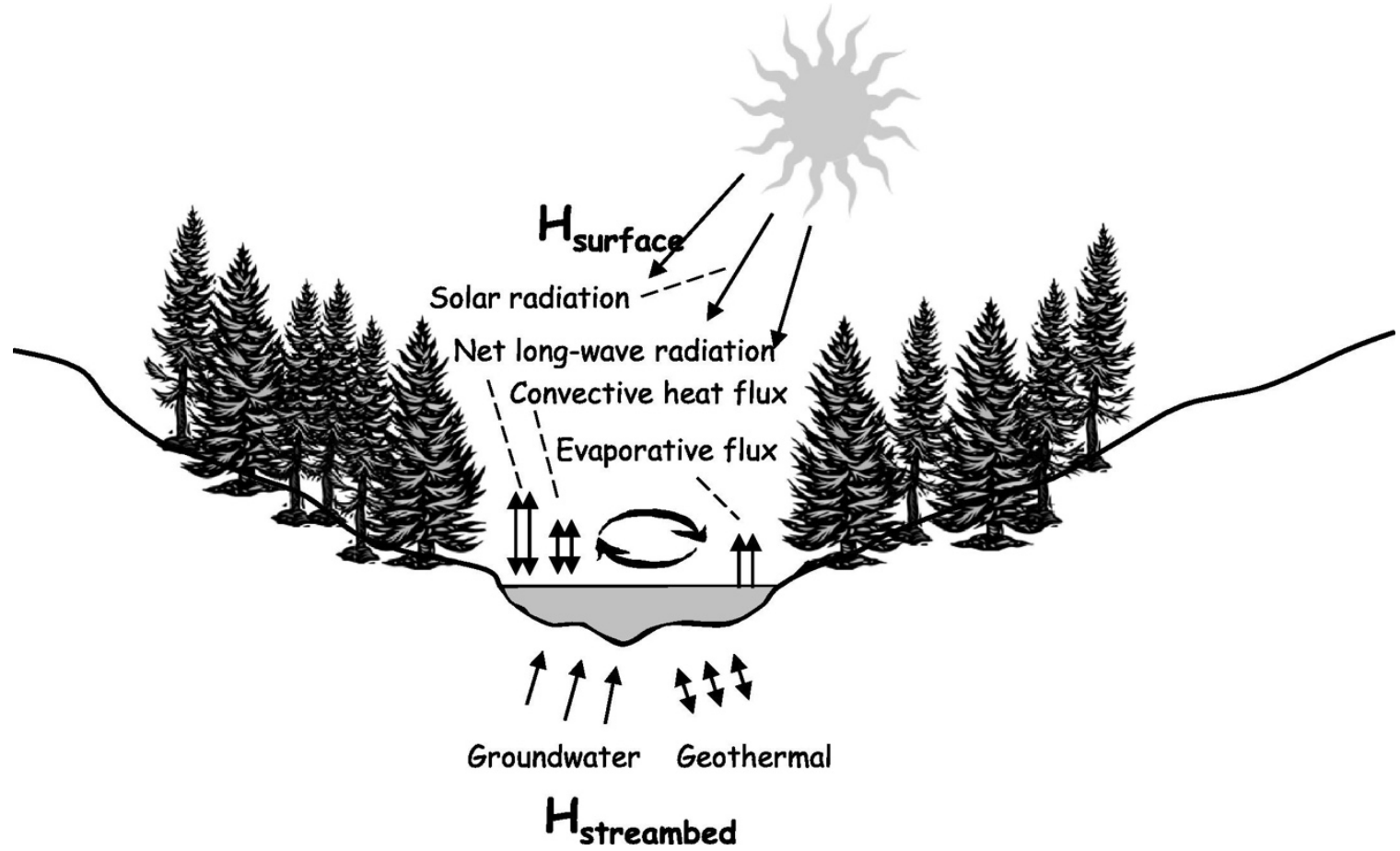

Figure 4: The various heat fluxes between a stream and its surrounding environment are shown. Solar radiation is synonymous with incoming shortwave radiation. Convective heat flux is also called sensible heat exchange, and evaporative flux is the same as evaporative heat loss (Caissie et al. 2014).

Of these fluxes, incoming shortwave radiation and longwave radiation are typically the largest (Sinokrot and Stefan 1993, Johnson 2004). Measurements of shortwave and longwave radiation are not very common; however, air temperature measurements can be found very easily. While air temperature does not have a significant influence on water temperature directly (via the sensible heat flux), both air temperature and water temperature are affected by solar and longwave radiation and are often highly correlated (Johnson 2004). Because of this correlation, I use air temperature as a proxy for the surface heat flux terms when estimating or predicting water temperature (Wagner et al. 2011, Overman 2011). 
River discharge, $Q$, has also been shown to influence water temperature (Gu et al. 2009, Webb et al. 2003, Overman 2017). For summer river temperatures, a negative correlation between river discharge, $Q$, and water temperature, $T_{w}$, exists (Gu et al. 2009, Overman 2017). This relationship occurs, because as water levels rise and river flow increases, the water body response time increases so that it is not as responsive to changes in meteorological conditions. From equation (15), one can see that increasing river flow, and thus increasing the river depth, $\mathrm{z}$, results in a decrease of the time rate of change of temperature. In other words, the river discharge typically has a negative correlation with water temperature.

From these theoretical concepts and observational factors, I formulated a statistical model to estimate water temperature, $T_{w}$, as a function of air temperature, $T_{a}$, and river discharge, $Q$. The relationship between water temperature and air temperature is quite linear for temperatures greater than $0^{\circ} \mathrm{C}$ and less than $25^{\circ} \mathrm{C}$, but becomes less linear outside of this range (Webb et al. 2003). Since the majority of temperatures that I was working with fell within this range, I did not have any reason to adopt a non-linear approach. Thus, the basis for the statistical linear model for water temperature was:

$$
T_{w}(t)=\mathrm{a}+b * T_{a}(t)+\mathrm{c} * Q(t)
$$

Where, $a, b$, and, $c$, are regression coefficients generated from a linear least-squares regression. Because the Columbia River has very high flow volumes and subsequently a large thermal capacity, water temperature tends to lag behind air temperature fluctuations. The performance of my model was therefore improved by incorporating time lags on the 
$T_{a}$ and $Q$ terms in equation (17) (Webb et al. 2003, Erickson and Stefan 2000). Generalizing my approach for $n$ number of time lags on $T_{a}$ and $m$ number of time lags on $Q$ :

$$
T_{w}(t)=a+\sum_{1}^{n} b_{n} * T_{a}(t-n)+\sum_{1}^{m} c_{m} * Q(t-m)
$$

Equation (18) represents the general model form that I used to estimate water temperature in this study. The first term is a regression constant, the second term is the summation of $n$ number of $T_{a}$ terms with time lags, and the third term is the summation of $m$ number of $Q$ terms with time lags.

There remains, given the general form, the problem of how to choose the lags. For example, the model could include time lags on air temperature for one, two, and three days, and also include time lags of larger durations, between 3 - 30 days. By applying a moving average filter to these longer time lags on the weekly and monthly scale, these smaller but still important time lags could be considered while still maintaining statistical significance. To determine the number and lengths of time lags used in each model, I employed a trial and error approach. The time lag structures were chosen based on the significance of the regression coefficients with at least $95 \%$ confidence, as well as minimizing the root-meansquared-error. 


\subsection{Data}

Three types of data, discussed individually below, were used to construct and validate the statistical model. The data used included air temperature, river flow, and water temperature from stations located throughout the basin (Figure 5).

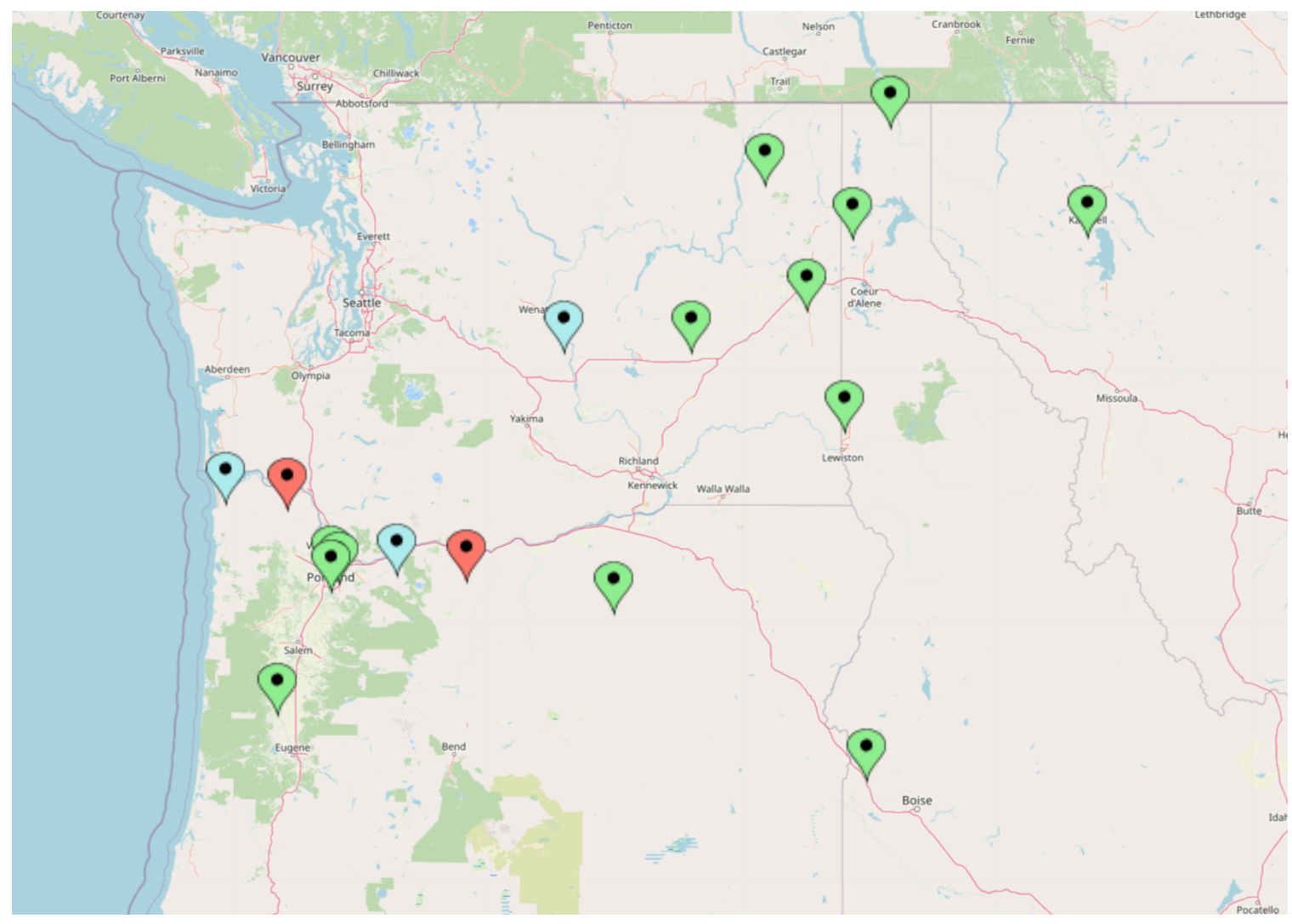

Figure 5: A map of the stations within the Columbia River Basin used in developing the statistical models. The green pins indicate air temperature stations, blue pins are water temperature stations, and the red pin represents the river flow station data.

\section{Water temperature}

The primary daily water temperature measurements used in this study were from Bonneville Dam, with some additional data used from Astoria, OR and Rock Island Dam. 
For Bonneville Dam-located at river kilometer 235 and about $64 \mathrm{~km}$ upstream of Portland, Oregon - the data came from two sources. For the period between 1938 and 1990, daily water temperature data was provided by the Northwest Power Planning Council (http://www.streamnet.org/files/407/StuTempData.html). For the period between 1990 and 2018, data was provided by the United States Army Corps of Engineers (USACE http://www.nwd-wc.usace.army.mil/dd/common/dataquery/www/). The USACE data did not always consist of one measurement per day. Sometimes there were no measurements and other times there were multiple measurements per day. To convert the measurements to a consistent time scale, multiple measurements in a day were averaged. For days that were missing measurements, a $\mathrm{NaN}$ (not a number) was used as a place holder. Additionally, any extreme values based on visual inspection were removed.

I also used water temperature data from Astoria, OR from 1855 to 1876 and from 1950 to 1995 (Talke et al. 2020, NOAA via email). While the model was built to predict water temperatures at Bonneville Dam, the historical data from Astoria allowed for model comparison and validation. It was also used to estimate a monthly correlation of water temperatures between the two locations, which were then used to estimate historical Bonneville temperatures based on the historical Astoria data (Figure 8).

Lastly, I used water temperature data from Rock Island Dam, located at river kilometer 729, from the US Army Corps of Engineers (USACE http://www.nwdwc.usace.army.mil/dd/common/dataquery/www/). The data spanned from 1933 to 2018 and were used to compare how the temperature difference between 
Bonneville Dam and Rock Island Dam has changed over time, especially as additional dams were constructed along the river.

\section{Air temperature}

Daily maximum air temperatures were used from various locations and from various sources throughout the basin between 1850 and 2018 (Figure 5). Because one of the main goals of this study was to estimate water temperatures back to the $19^{\text {th }}$ century, I focused on air temperature datasets that spanned at least most of the $20^{\text {th }}$ century, if not longer. The air temperature datasets used were primarily obtained from NOAA's National Centers for Environmental Information (Table 1). The longest datasets that started in the late 1800s were for Spokane, WA, Vancouver, WA, and Portland, OR. Other stations used were not quite as long as these three, but still spanned nearly all of the $20^{\text {th }}$ century (Table 1 ). I included all of these records to better understand how air temperature from an individual station can influence the statistical model of water temperature, and more generally for model comparison. 
Table 1: Summary of air temperature data used in water temperature models. All air temperature data used were daily maximum values. And all datasets were used to produce a Pre-Dam (1940s) and Modern (2000s) model. The Vancouver dataset was also used to produce a Historical (1850s) model.

\begin{tabular}{|c|c|c|c|c|}
\hline Station Name & $\begin{array}{l}\text { Period of } \\
\text { Record }\end{array}$ & $\begin{array}{l}\text { Complete- } \\
\text { ness }\end{array}$ & Source & Network: Station ID \\
\hline Spokane, WA & $\begin{array}{l}1881- \\
1892\end{array}$ & $97 \%$ & $\begin{array}{l}\text { U.S. Army Signal } \\
\text { Service via the } \\
\text { MRCC }\end{array}$ & Coop ID: 457938 \\
\hline $\begin{array}{l}\text { Fort Colville, } \\
\text { WA }\end{array}$ & $\begin{array}{l}1860- \\
1880\end{array}$ & $89 \%$ & $\begin{array}{l}\text { U.S. Army Signal } \\
\text { Service via the } \\
\text { MRCC }\end{array}$ & $\begin{array}{l}999999 \\
\text { https://mrcc.illinois.edu/FO } \\
\text { RTS/inventory3.jsp?state= } \\
\underline{\text { WA\&city=Fort_Colville }}\end{array}$ \\
\hline $\begin{array}{l}\text { Spokane } \\
\text { International } \\
\text { Airport, WA }\end{array}$ & $\begin{array}{l}1889- \\
2018\end{array}$ & $100 \%$ & NOAA NCEI & GHCND:USW00024157 \\
\hline $\begin{array}{l}\text { Vancouver, } \\
\text { WA }\end{array}$ & $\begin{array}{l}1856- \\
2018\end{array}$ & $97 \%$ & NOAA NCEI & GHCND:USC00458773 \\
\hline Portland, OR & $\begin{array}{l}1875- \\
2018\end{array}$ & $96 \%$ & NOAA NCEI & $\begin{array}{l}\text { GHCND:USW00024274 } \\
\text { GHCND:USC00356749 }\end{array}$ \\
\hline $\begin{array}{l}\text { Portland } \\
\text { International } \\
\text { Airport, OR }\end{array}$ & $\begin{array}{l}1936- \\
2018\end{array}$ & $100 \%$ & NOAA NCEI & GHCND:USW00024229 \\
\hline $\begin{array}{l}\text { Kalispell } \\
\text { Glacier } \\
\text { Airport, MT }\end{array}$ & $\begin{array}{l}1896- \\
2018\end{array}$ & $99 \%$ & NOAA NCEI & GHCND:USC00244558 \\
\hline $\begin{array}{l}\text { Moscow U of } \\
\text { I, ID }\end{array}$ & $\begin{array}{l}1893- \\
2018\end{array}$ & $99 \%$ & NOAA NCEI & GHCND:USC00106152 \\
\hline $\begin{array}{l}\text { Priest River } \\
\text { Experimental } \\
\text { Station, ID }\end{array}$ & $\begin{array}{l}1898- \\
2018\end{array}$ & $94 \%$ & NOAA NCEI & GHCND:USC00107386 \\
\hline Payette, ID & $\begin{array}{l}1892- \\
2018\end{array}$ & $95 \%$ & NOAA NCEI & GHCND:USC00106891 \\
\hline $\begin{array}{l}\text { Waterville, } \\
\text { WA }\end{array}$ & $\begin{array}{l}1893- \\
2018\end{array}$ & $95 \%$ & NOAA NCEI & GHCND:USC00459012 \\
\hline Odessa, WA & $\begin{array}{l}1902- \\
2018\end{array}$ & $98 \%$ & NOAA NCEI & GHCND:USC00456039 \\
\hline Porthill, ID & $\begin{array}{l}1892- \\
2018\end{array}$ & $97 \%$ & NOAA NCEI & GHCND:USC00107264 \\
\hline Heppner, OR & $\begin{array}{l}1893- \\
2018\end{array}$ & $95 \%$ & NOAA NCEI & GHCND:USC00353827 \\
\hline $\begin{array}{l}\text { Corvallis State } \\
\text { University, } \\
\text { OR }\end{array}$ & $\begin{array}{l}1893- \\
2018\end{array}$ & $97 \%$ & NOAA NCEI & GHCND:USC00351862 \\
\hline
\end{tabular}


Although these stations provide plenty of data, they have also been subject to relocations and significant elevation changes. Consequently, there are biases inherent in many of the raw data. Because it is difficult to precisely quantify and correct for these biases that elevation changes produce, I also incorporated daily air temperature from Berkeley Earth's daily gridded datasets (http://berkeleyearth.org/data/). This data is not raw and has been reconstructed in an attempt to remove station biases and missing data; for example, see Figure 6, which illustrates numerous shifts in the Spokane data. They provided daily maximum air temperature with a $1^{\circ} \times 1^{\circ}$ latitude-longitude grid resolution from 1880 to 2018. These reconstructed temperatures were based on over 30,000 stations. To account for biases in the raw data, they developed a program to automatically identify breakpoints or discontinuities in the data and then split the single record into two separate records. They then applied calculated weights to the newly created records to generate a single estimated value for a particular location. By using this method, they avoided introducing further bias by attempting to manually correct for apparent changes in a record, and instead treated a given biased station as two or more separate records. To obtain the grid of temperatures, they used Kriging estimation to interpolate temperatures where there were not nearby stations (Rohde et al., 2013). By using the dataset from Berkeley Earth, I could compare the results of models that used raw air temperature to those that used adjusted air temperature. And because the dataset was gridded, it provided the option of using air temperature from throughout the Columbia River Basin. 


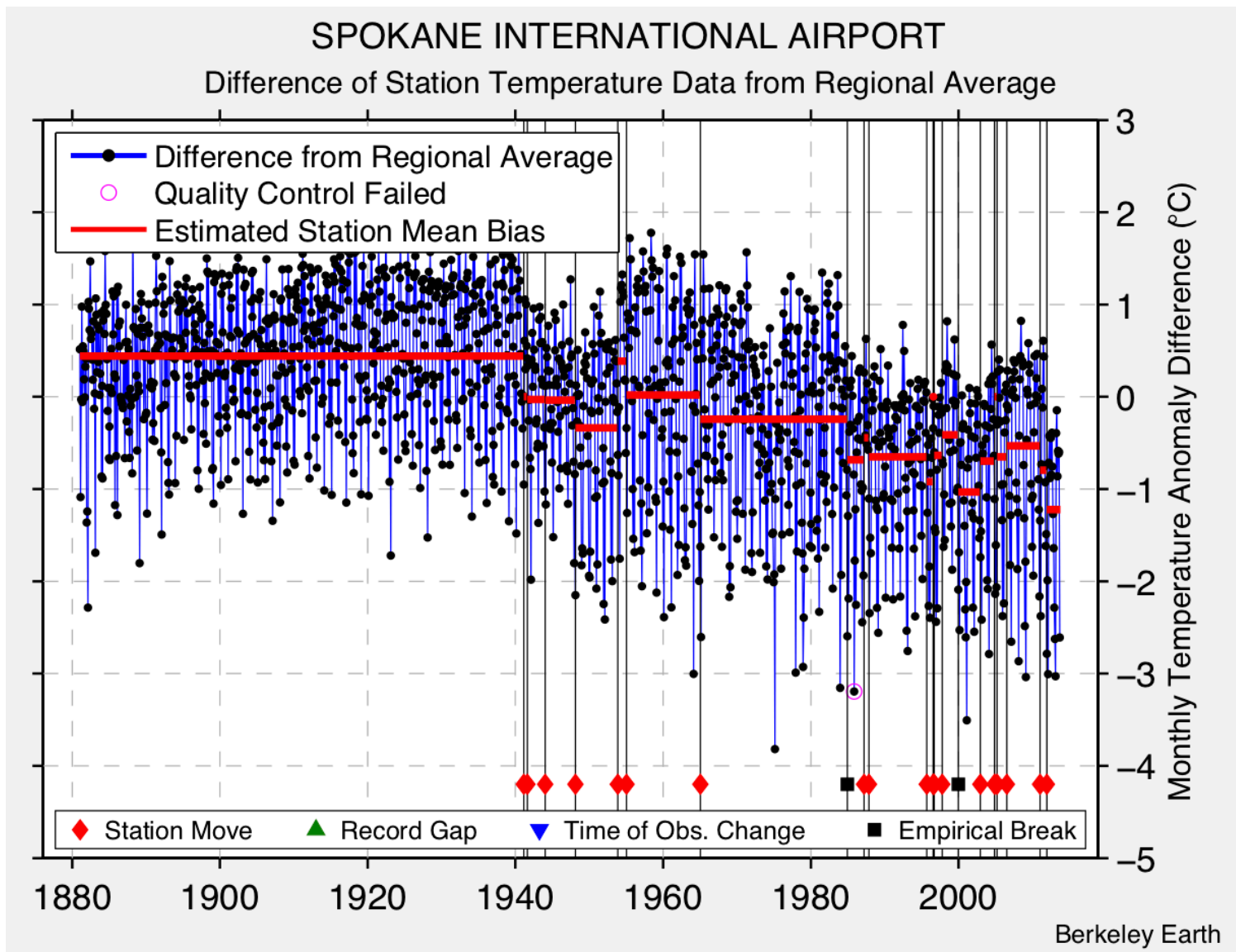

Figure 6: The air temperature deviations (or anomalies) for the Spokane International Airport station. The changes in the estimated station mean bias shows the bias in the raw data. Image taken from: berkeleyearth.lbl.gov/stations/170156.

\section{$\underline{\text { River flow }}$}

For river flow data, I used daily measurements taken from the Dalles, OR from 1878 to 2018 (USGS 14105700 Columbia River at the Dalles, OR). Between 1853 and 1876 I used estimates of flow at Quincy, OR (also known as Port Westward and Beaver Army Terminal), because there are no direct measurements from this time period (Talke et al. 2019). 


\subsection{Statistical model development}

In order to model and hindcast water temperatures at Bonneville Dam back to the $19^{\text {th }}$ century, three separate statistical models were developed by regressing measured water temperature against air temperature and river discharge based on Equation (18):

- A Pre-Dam model from 1938 to 1952

- A Modern model from 2004 to 2018

- A Historical model from 1855 to 1868

All together, these models span more than 160 years and allowed for determination of how water temperatures have changed over time (Figure 7). 


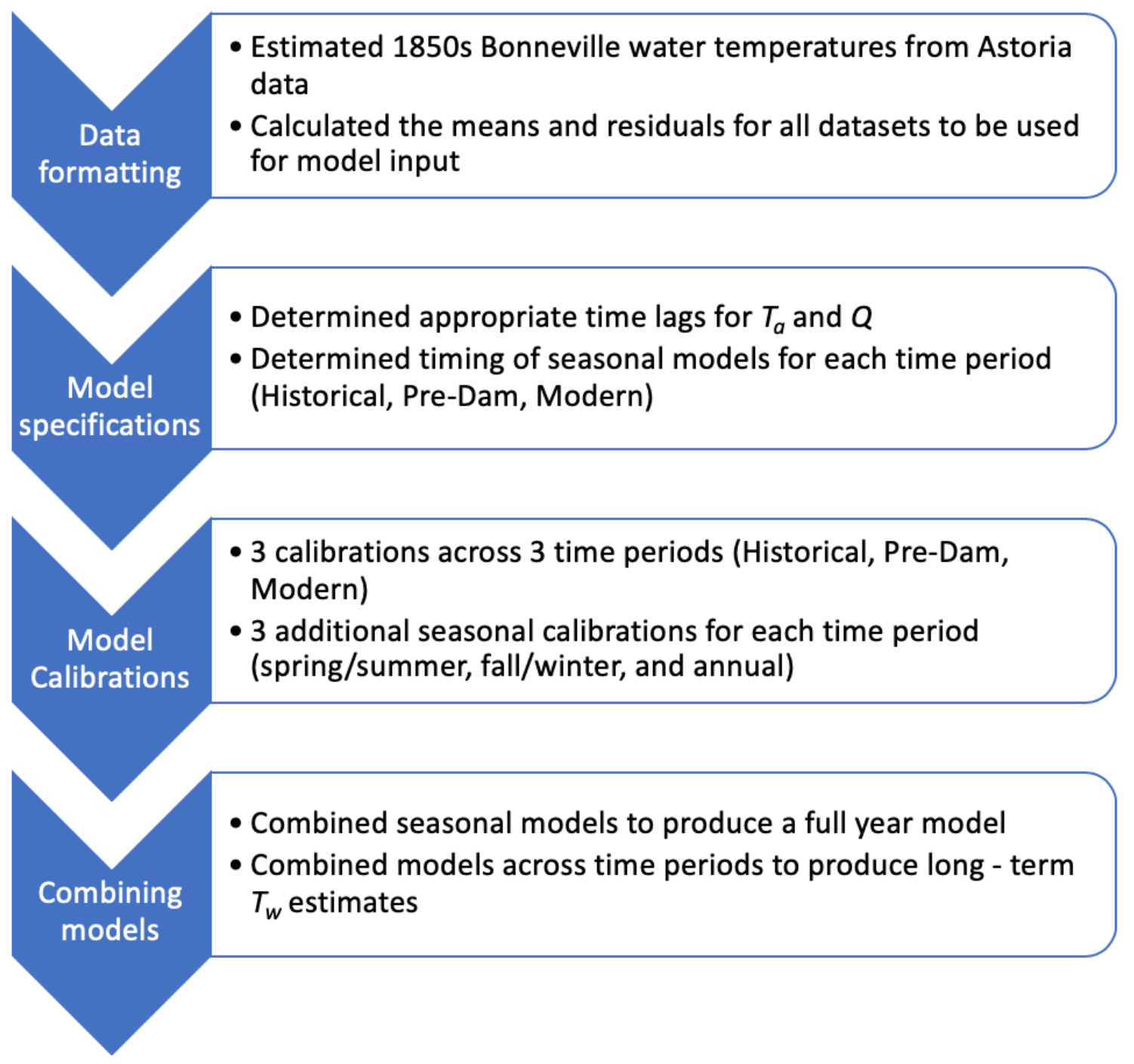

Figure 7: An overview of the statistical model development process.

The years 1938 to 1952 were chosen for the Pre-Dam model years because it covers the time before most of the dams were built, it is prior to the peak operation at the Hanford Nuclear site around 1956, and 1938 is the first year of existing water temperature measurements at Bonneville Dam. For the Modern model, the years 2004 to 2018 were 
used because not only do they represent the most recent 15 years, it also includes both rainy $(2011,2017)$ and dry $(2011,2013)$ years as well as hot $(2015,2017)$ and cold $(2008)$ conditions (PRISM Climate Group). Lastly, the years 1855 to 1868 were used for the Historical model based on data availability, with available air temperature data spanning from 1850 to 1868 and water temperature data from 1855 to 1875 . None of the models span more than 15 years to minimize non-stationary trends in the data.

A robust linear regression was used for the statistical models because it is less influenced by outliers in the data compared to ordinary least squares regression. For model generation, residual data — the deviations from the seasonal mean — were used for all inputs and outputs rather than the raw, absolute data. To do this, I calculated the mean air temperature, water temperature, and river flow, for each day of the year within the model calibration periods then subtracted it from each daily observation to obtain the residuals. The calculated means were first smoothed by applying a 30-day moving average filter before obtaining the residuals. Finally, the residuals were normalized by their respective standard deviations in order to non-dimensionalize the inputs.

For the 1850s Historical model (1855 to 1868), estimates of water temperatures at Bonneville Dam were used. These estimates were based on water temperature measurements at Astoria, OR. Using a time period (1950 to 1982) with overlapping Bonneville and Astoria water temperature measurements, a correlation was drawn between the two on a monthly basis (Figure 8). It is important to note that the construction of the dams after the 1930s may have altered the original correlation that existed in the $1850 \mathrm{~s}$, 
but as there are no major dams along the river between the two points and the Astoria dataset was the only available water temperature dataset for this time period, this method was a simple and easy way to obtain rough estimates. The results of this method revealed the seasonality of the relationship between these two locations. In the winter, the river is colder than the ocean because of the colder interior basin temperatures, which makes measurements at Astoria slightly warmer than Bonneville measurements. In the summer, the ocean is colder than the river because of the warmer interior basin temperatures so the measurements at Bonneville are slightly warmer than the Astoria measurements. The difference in air temperatures between the coast and interior basin is what drives the difference in seasonal river temperatures between the river and ocean (Figure 8). 

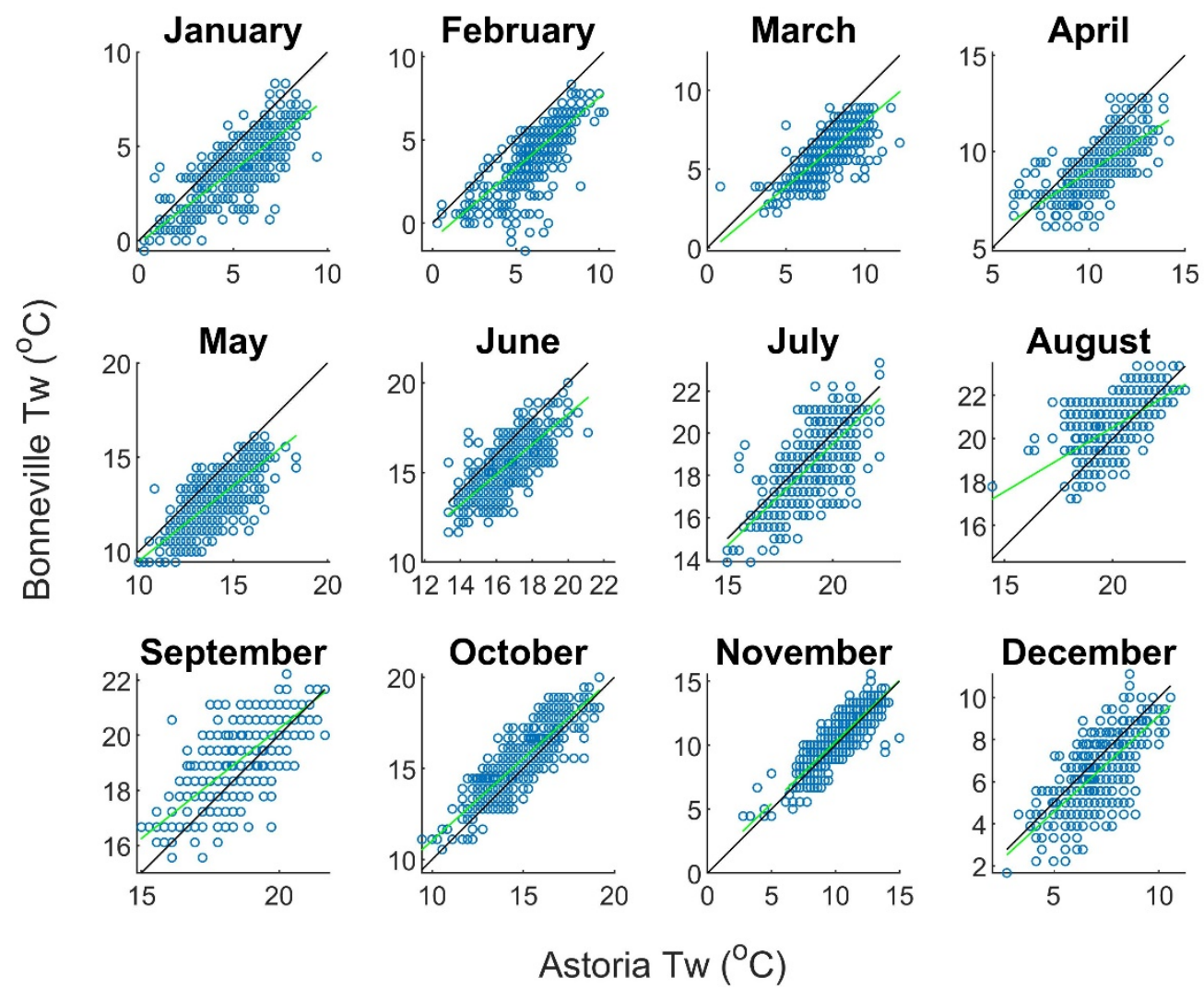

Astoria $\operatorname{Tw}\left({ }^{\circ} \mathrm{C}\right)$

Figure 8: Monthly linear correlation estimated between Bonneville and Astoria water temperatures based on data between 1950 and 1980. The black line shows a reference 1:1 correlation. The green line shows the actual monthly correlation.

I created an annual model variation and two seasonal model variations for each distinct time period. The annual models included all months of the year throughout the entire calibration period while the seasonal models spanned 4-5 months of each year. I chose the seasonal models based on trial and error and observing which combination of months produced the lowest root mean squared error (RMSE) when compared to the measured water temperatures. For the Historical 1850s model, the chosen seasons were from April to July and from October to January (Figure 9). For the Pre-Dam 1940s model, the seasons 
were March to June, and September to December (Figure 10), and for the Modern 2000s model, the chosen seasons were from January to April and from July to October (Figure 11). Across all models, including river flow as an input improved the RMSE of the model; thus river flow was included in the final versions of the models.

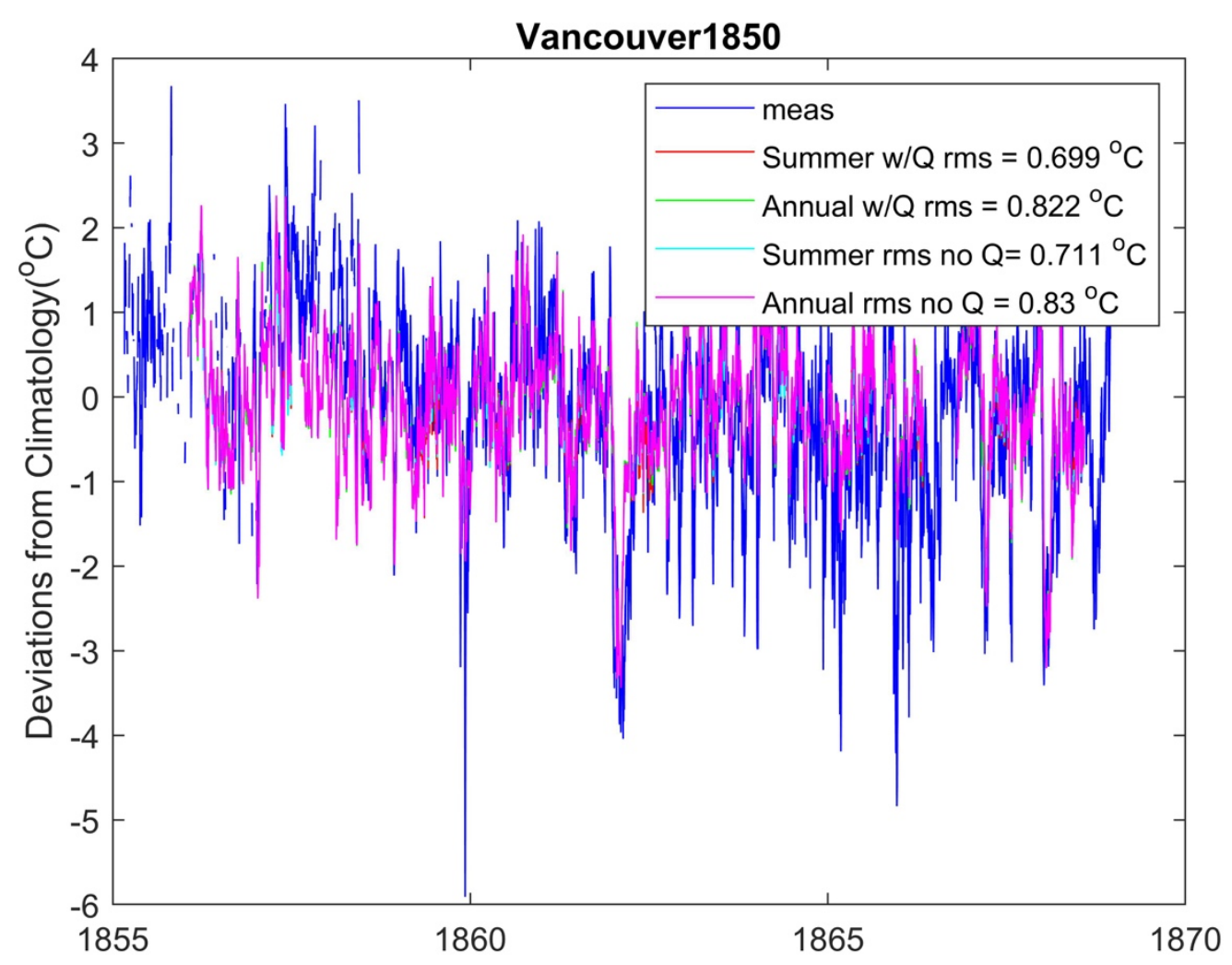

Figure 9: Calibration of 1850s Historical model using Vancouver air temperature data. RMS error was used to compare seasonal vs. full year (annual) models and river flow (w/Q) vs. no river flow (no $Q$ ) models. 


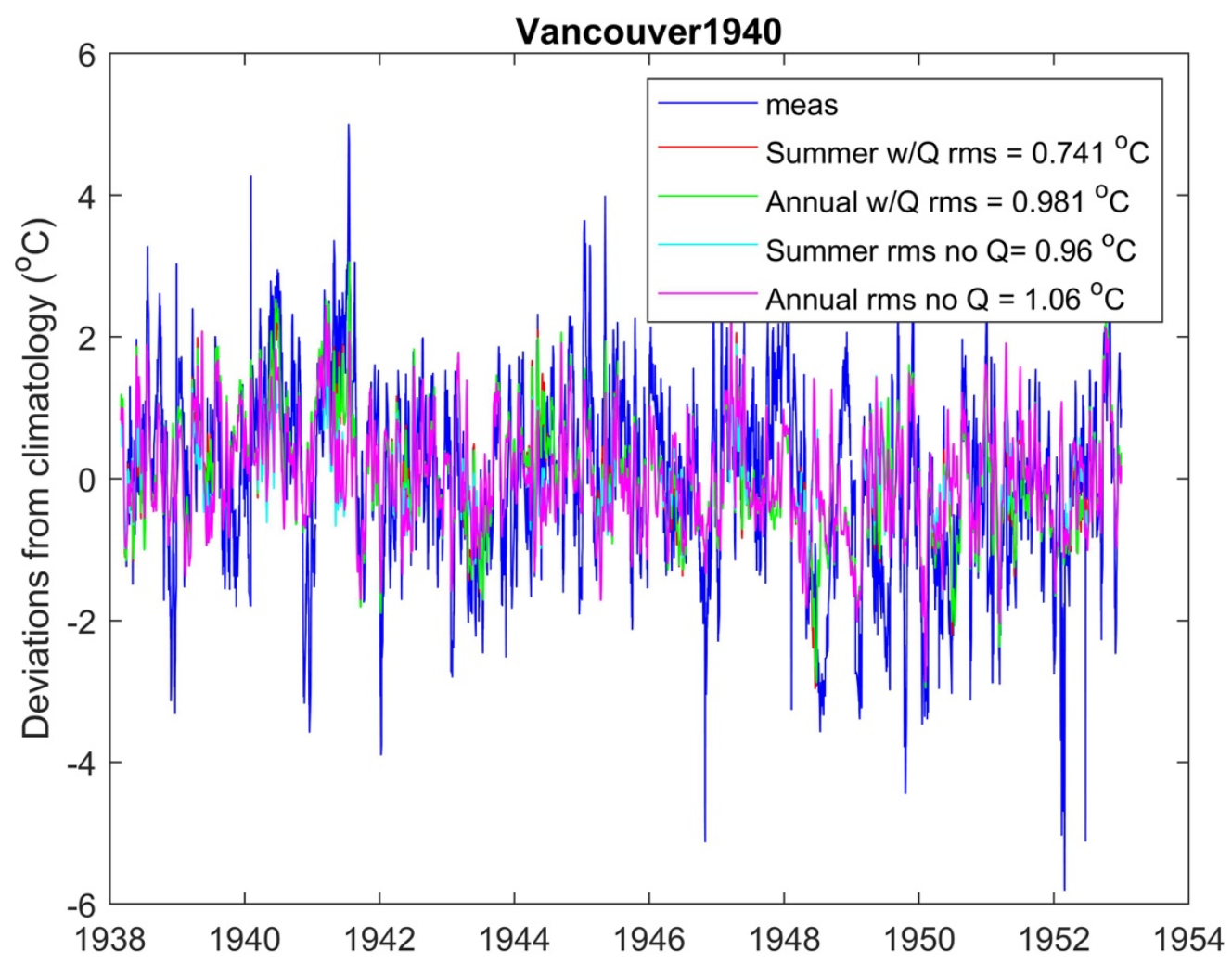

Figure 10: Calibration of 1940s Pre-Dam model using Vancouver air temperature data. RMS error was used to compare seasonal vs. full year (annual) models and river flow ( $w / Q)$ vs. no river flow (no $Q$ ) models. 


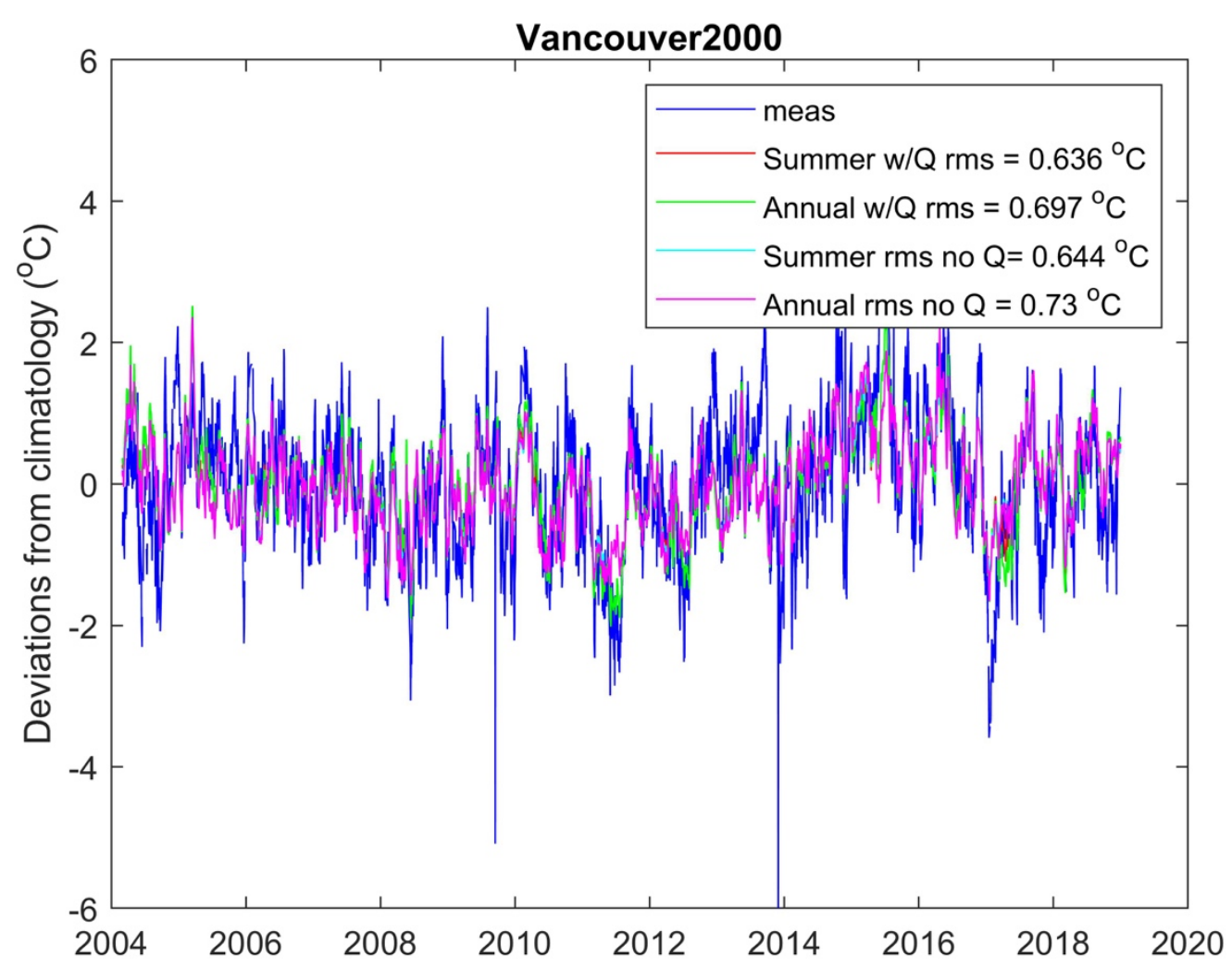

Figure 11: Calibration of 2000s Modern model using Vancouver air temperature data. RMS error was used to compare seasonal vs. full year (annual) models and river flow $(w / Q)$ vs. no river flow (no $Q$ ) models.

As stated earlier, I included multiple time lags on air temperature and river flow for all models in order to obtain a more thorough understanding of the Columbia River as a system and obtain a stronger understanding of the river's "memory". To examine the latter, the coefficients corresponding to air temperature lags were plotted, and it was noted how the magnitudes changed as the time lags increased (e.g. Figure 12).

A trial and error approach was used to determine appropriate time lags for each model. The resulting time lag structure for the Pre-Dam 1940s model included three 1-day time lags, 
then two 3-day-averaged time lags, followed by one 5-day-averaged time lag, and one 7day-averaged time lag (Table 2 and Figure 12). This structure accounts for up to 21 days, or three weeks difference between water and air temperatures. Time lags beyond this length did not yield significant model coefficients, indicating that the correlation between air and water temperature up to about three weeks difference was substantial. The resulting time lag structure for the Modern 2000s model included three 3-day-averaged time lags, followed by one 5-day-averaged time lag, two 7-day-averaged time lags, and finally one 30-day-averaged time lag (Table 2). This structure accounts for up to 58 days, or roughly two months, difference between water and air temperatures; it indicates that the correlation between air and water temperature up to about two months' difference was significant. The Historical 1850s model had the same time lag structure as the Pre-Dam 1940s model (Table 2). Because the location of the raw water temperature measurements for the 1850 s model was not the same as the 1940s and 2000s model, the magnitudes of the time lag coefficients for the 1850 s model are noticeably different (Figure 13). Overall, coefficients from all models were significant at a $95 \%$ confidence level.

Table 2: The Ta time lag structures for the Historical 1850s, Pre-Dam 1940s, and Modern 2000s models. The values in bold indicate the number of days prior to the desired modeled day $(t=0)$. The corresponding values below the bolded numbers indicate the length of time lag used for the specific range of days.

\begin{tabular}{|l|l|l|l|l|l|l|l|}
\hline Days before $\boldsymbol{T}_{\boldsymbol{w}}(\boldsymbol{t}=\mathbf{0})$ & $\mathbf{1}$ & $\mathbf{2}$ & $\mathbf{3}$ & $\mathbf{4 - 6}$ & $\mathbf{7 - 9}$ & $\mathbf{1 0 - 1 4}$ & $\mathbf{1 5 - 2 1}$ \\
\hline Length of time lag & 1 & 1 & 1 & 3 & 3 & 5 & 7 \\
\hline Days before $\boldsymbol{T}_{\boldsymbol{w}}(\boldsymbol{t}=\mathbf{0})$ & $\mathbf{1 - 3}$ & $\mathbf{4 - 6}$ & $\mathbf{7 - 9}$ & $\mathbf{1 0 - 1 4}$ & $\mathbf{1 5 - 2 1}$ & $\mathbf{2 2 - 2 8}$ & $\mathbf{2 9 - 5 8}$ \\
\hline Length of time lag & 3 & 3 & 3 & 5 & 7 & 7 & 30 \\
\hline
\end{tabular}




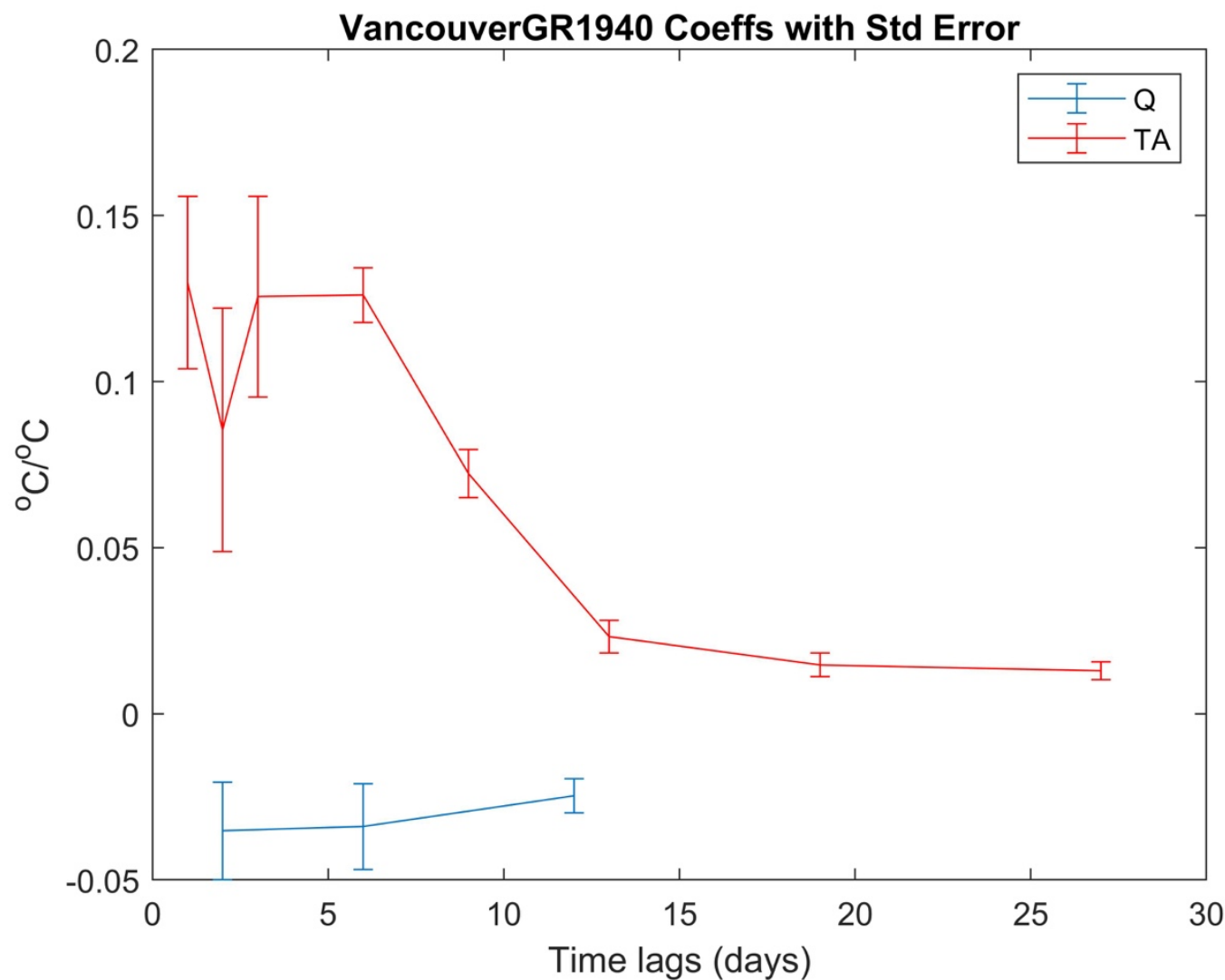

Figure 12: Vancouver 1940s (Pre-Dam) model coefficients plotted against time lags (in days). The decrease in magnitude of $T_{a}$ coefficients (red line) as the time lags increase indicates the correlation between air temperature and water temperature decreases as the number of days between measurements increases. The Q coefficients (blue line) often (especially in the spring and summer) produced a negative correlation with $T_{w}$. 


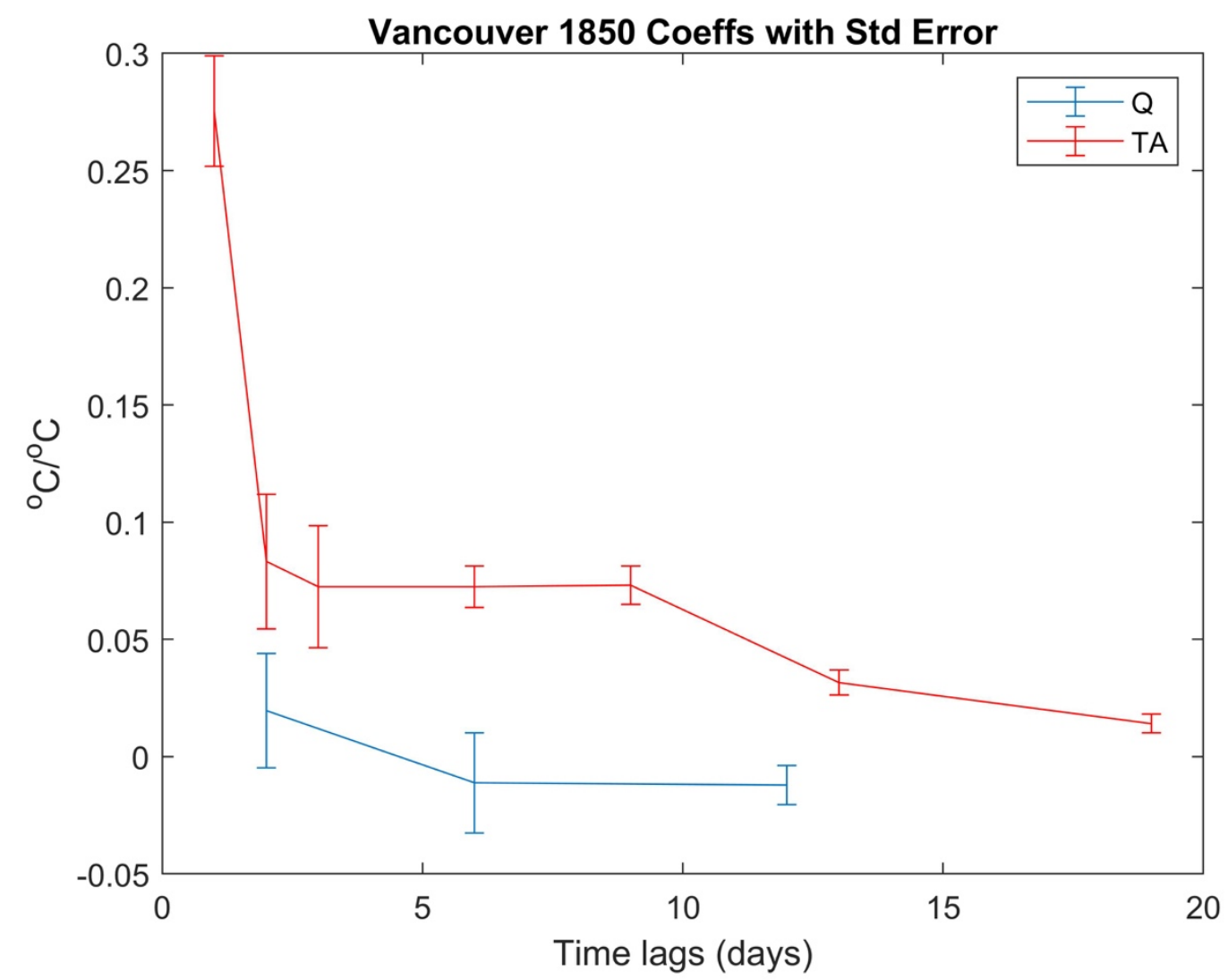

Figure 13: Vancouver 1850s (Historical) model coefficients plotted against time lags (in days).

I also used time lags on river flow. For the Historical and Pre-Dam model, the resulting time lag structure included one 3-day-averaged lag, followed by one 5-day-averaged lag and one 7-day-averaged lag. For the Modern model, the time lag structure included three 10-day-averaged lags. In general, the regression coefficients for time-lagged river flow were significant for spring/summer seasonal models and not significant for fall/winter models. This may be in part due to seasonal changes in longitudinal temperature gradients. However, when these models were compared to models with no time lags on river flow, the models with river flow and time lags produced a lower RMSE. 


\section{Composite model}

The seasonal models were combined with the annual models to produce a full year model. For the months that fell within one of the specified seasonal models, those seasonal model results were used, and for the months that did not fall within either of the specified seasonal models, the annual model results were used. The resulting model consisted of a combination of the two seasonal models stitched together with the annual model (Figure 14). The differences in how the seasons were defined between models could be a reflection of the changes in relationships between air temperature, river flow, and water temperature. However, it is also possible that there is no physical explanation as these seasons were chosen based on RMSE.

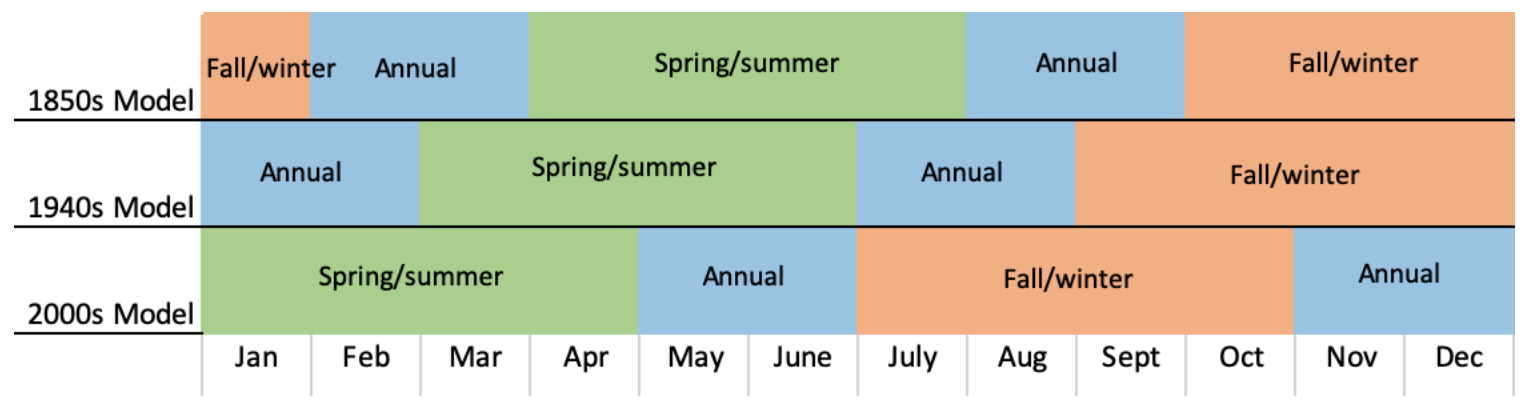

Figure 14: Seasonal and annual models are combined together to produce a full-year model.

Next, I applied the full air temperature and river flow datasets to all models to get estimates of water temperatures before there were measurements. For the final step in the model generation, I added the climatology back with the deviations in order for the model to predict the absolute temperature (Figure 15, Figure 16 and Figure 17). 


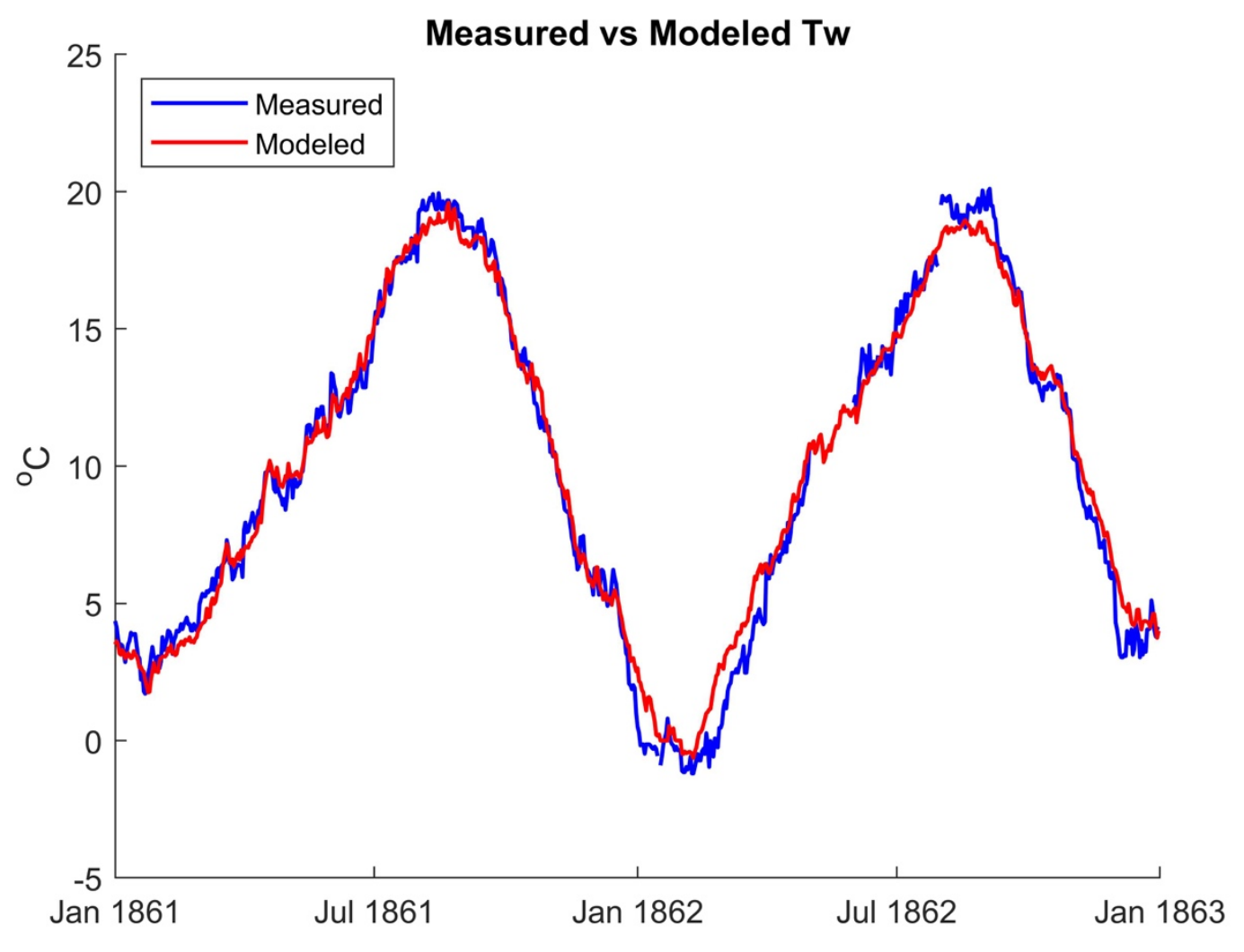

Figure 15: A comparison of the estimated measured data (in blue) at Bonneville to the modeled results (in red) after the climatology was added back in, for the years 1861 to 1863. The estimated measured data was based on Astoria $T_{w}$ data. 


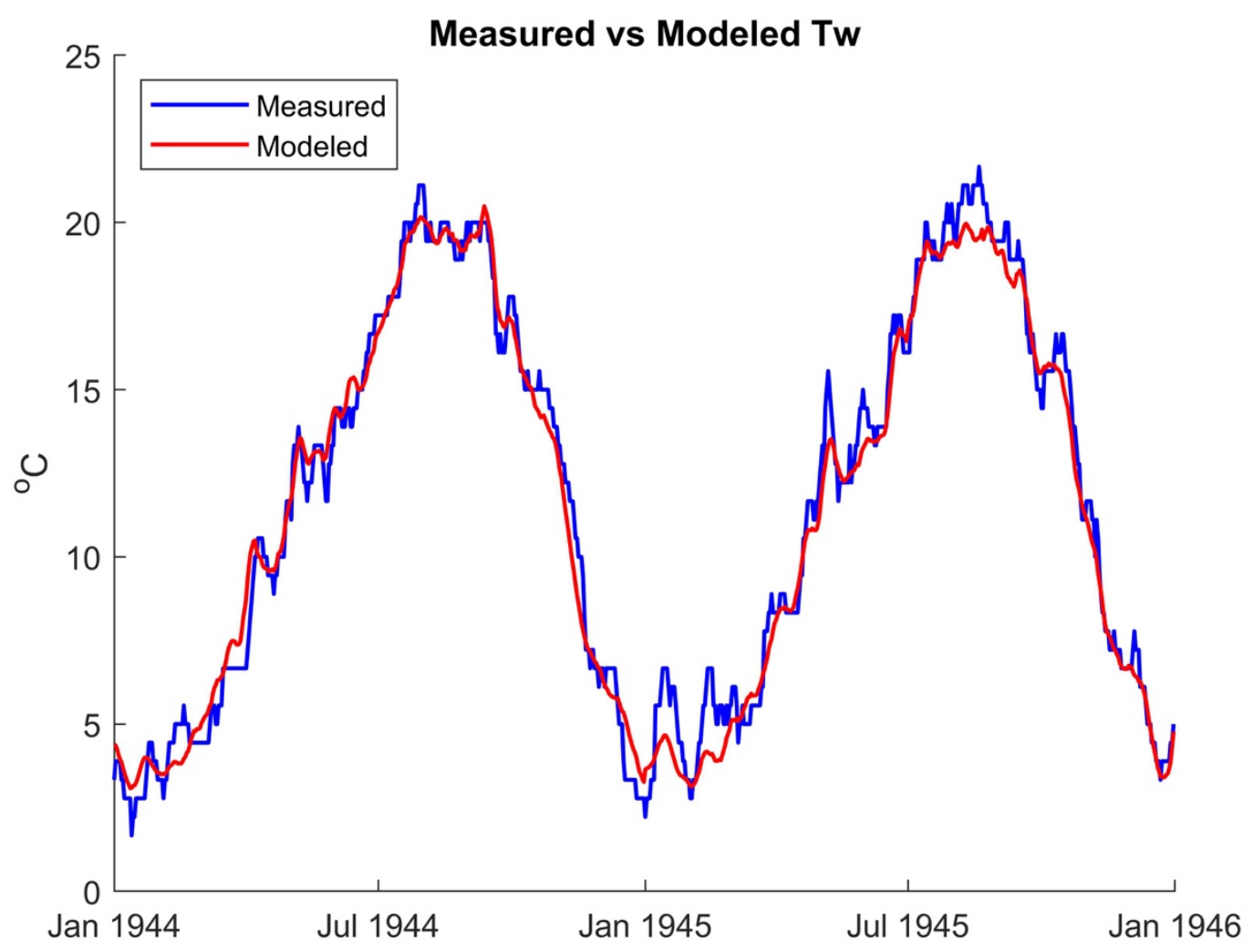

Figure 16: A comparison of the measured data (in blue) to the final modeled results (in red) after the climatology was added back in, for the years from 1944 to 1945. 


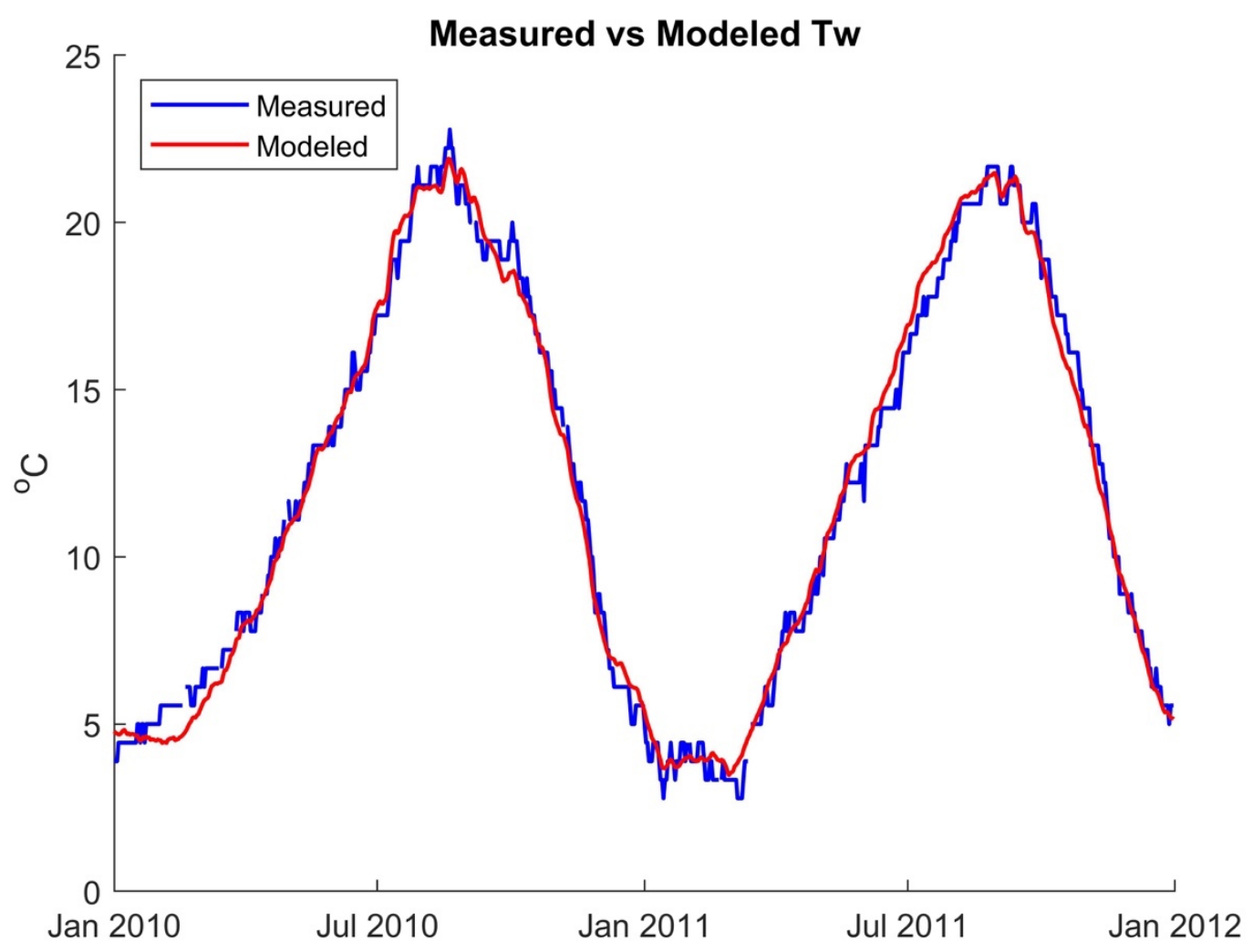

Figure 17: A comparison of the measured data (in blue) to the final modeled results (in red) after the climatology was added back in, for the years from 2010 to 2011.

Further, I constructed composite models for each of the listed air temperature datasets (Table 1). The composite models involved combining the Pre-Dam and Modern models together. The Pre-Dam model was applied from approximately 1880 to 1969 , and the Modern model from 1970 to 2018. The year 1970 was used for the first year for the Modern model because by 1970 most of the present dams along the Columbia River had been completed, and 1970 has been identified as approximately the beginning of modern management (Sherwood et al., 1990). The start year for each of the composite models depended on the start year of available air temperature data, which ranged from 1875 to 
1936 (Figure 18 and Figure 19). By merely stitching the two models together, this introduced the possibility of a discontinuity in temperatures at 1970. This is visible in the composite model plots (Figure 18, Figure 19, and Figure 20). Including a way to more smoothly transition from one model to the next would be one consideration for future work.

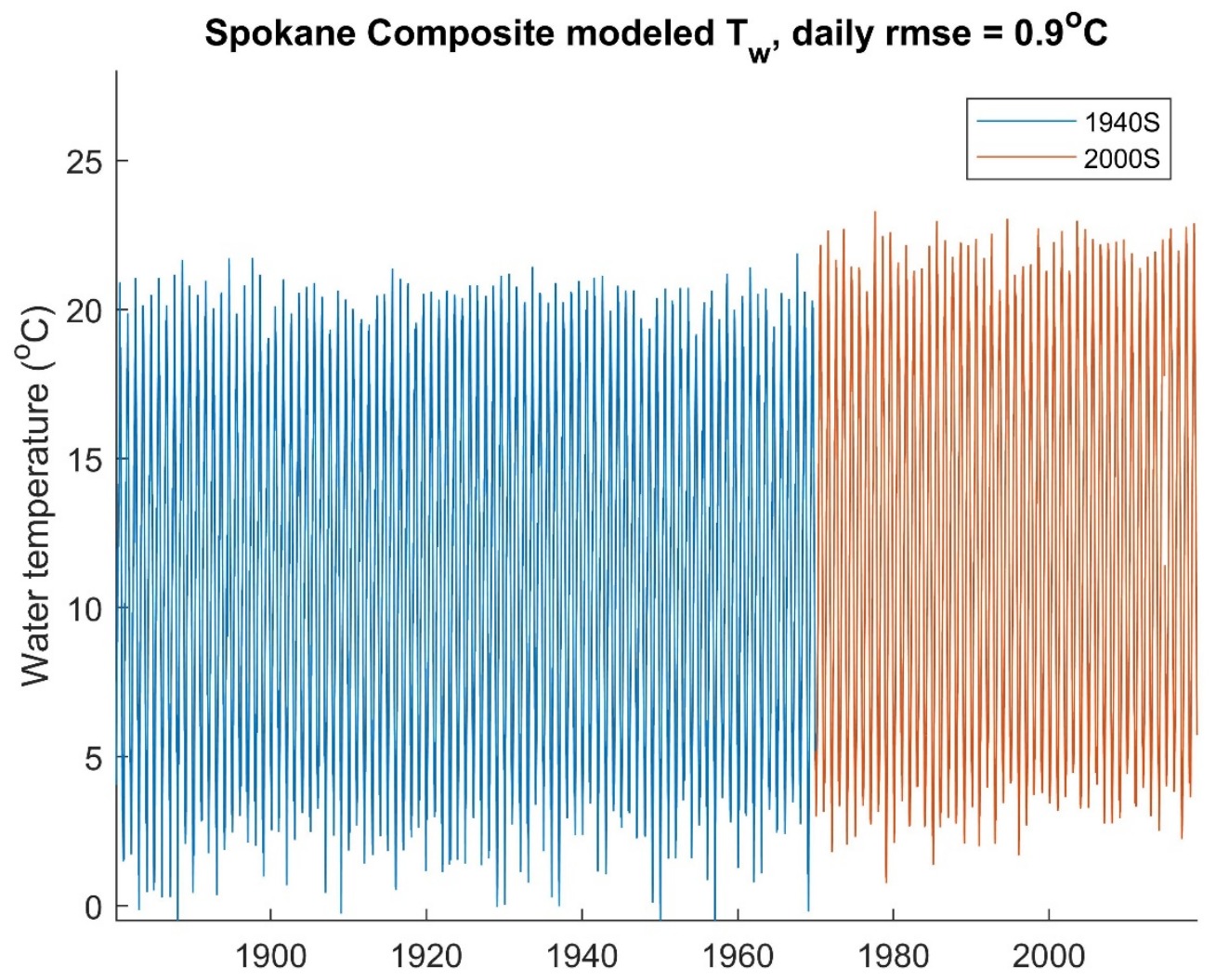

Figure 18: The Spokane composite model spans from 1880 to 2018 and is comprised of two individual models stitched together (the 1940s and 2000s models). 


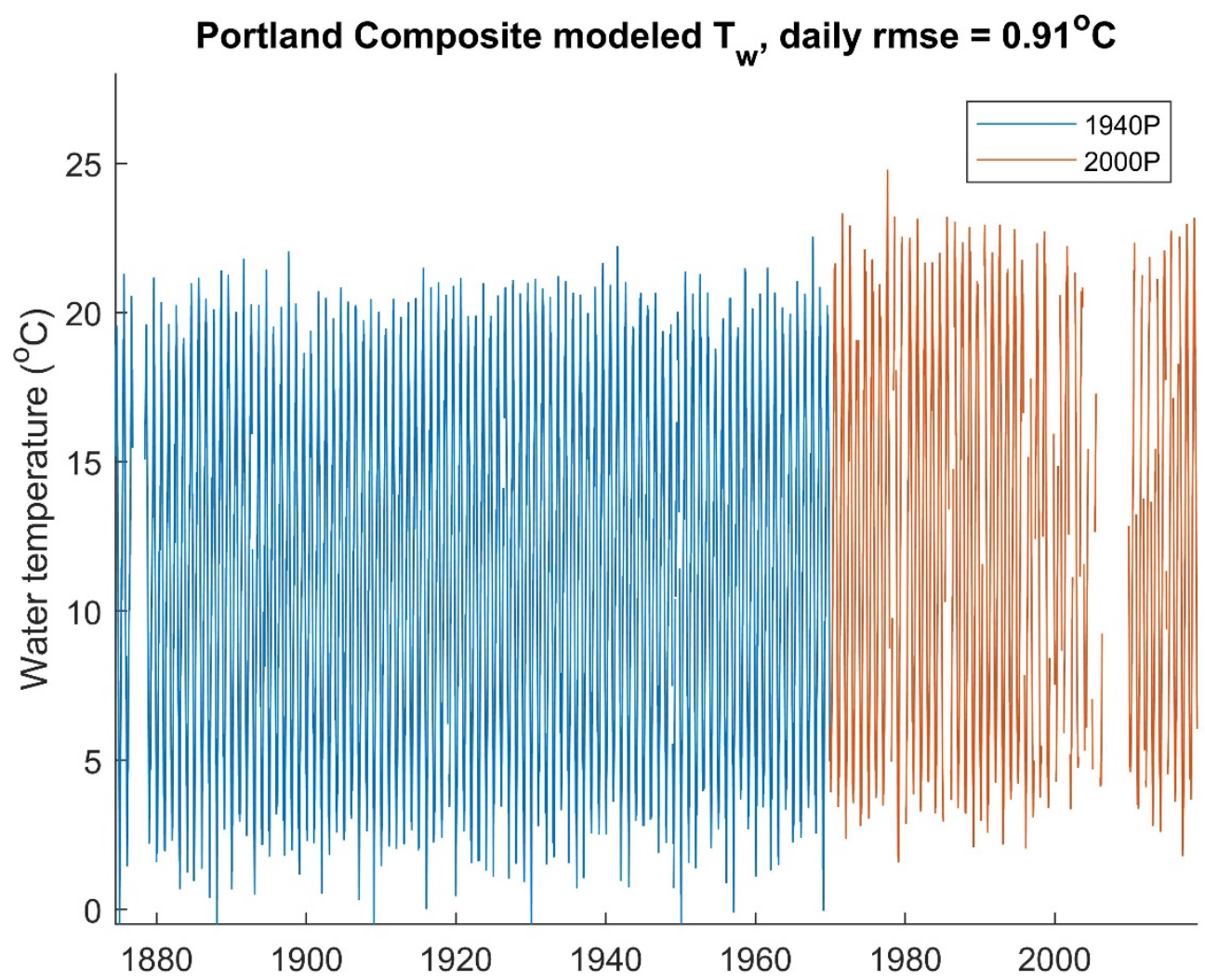

Figure 19: The Portland composite model spans from 1872 to 2018 and is comprised of two individual models stitched together (the 1940s and 2000s models). The Portland $T_{a}$ dataset is missing a few years around 2006 - 2010 which is why there are some gaps in the model output.

For the composite model based on air temperature data from Vancouver, WA, I combined the 1850s Historical model with the other two models to create a composite model spanning the period from 1850 to 2018 (Table 3 and Figure 20). The Historical 1850s model was applied from 1850 to 1880 . Since air temperature from Vancouver was only available from 1850 to 1868 , air temperature data from Fort Colville, WA for 1860 to 1880 were also used. I chose this particular station because it had fairly continuous air temperature measurements for the period when Vancouver lacked data (from 1869 to 1879). Thus, the final composite Vancouver model included a Historical model from 1850 to 1868 , a second 
Historical model using Fort Colville air temperature from 1869 to 1879, a Pre-Dam model applied to 1880 to 1969 , and a Modern model applied to 1970 to 2018 .

Table 3: Datasets used for the independent and composite Vancouver models.

\begin{tabular}{|c|c|c|c|}
\hline & $T_{a}$ & $Q$ & $\boldsymbol{T}_{w}$ \\
\hline \multicolumn{4}{|c|}{ Independent Vancouver Model Calibration Datasets } \\
\hline $\begin{array}{l}\text { Historical (1855 - } \\
\text { 1868) }\end{array}$ & Vancouver, WA & $\begin{array}{l}\text { Port Westward, OR } \\
\text { (previously Beaver } \\
\text { Army Terminal) }\end{array}$ & $\begin{array}{l}\text { Estimated Bonneville } \\
\text { (from Astoria } T_{w} \text { ) }\end{array}$ \\
\hline $\begin{array}{l}\text { Pre-Dam Model } \\
(1938-1952)\end{array}$ & Vancouver, WA & The Dalles, OR & Bonneville Dam, OR \\
\hline $\begin{array}{l}\text { Modern Model } \\
(2004-2018)\end{array}$ & Vancouver, WA & The Dalles, OR & Bonneville Dam, OR \\
\hline \multicolumn{4}{|c|}{ Composite Vancouver Model Datasets } \\
\hline From $1850-1868$ & Vancouver, WA & $\begin{array}{l}\text { Port Westward, OR } \\
\text { (previously Beaver } \\
\text { Army Terminal) }\end{array}$ & \\
\hline From $1869-1879$ & Fort Colville, WA & $\begin{array}{l}\text { Port Westward, OR } \\
\text { (previously Beaver } \\
\text { Army Terminal) }\end{array}$ & \\
\hline From $1880-1969$ & Vancouver, WA & The Dalles, OR & \\
\hline From 1970 - 2018 & Vancouver, WA & The Dalles, OR & \\
\hline
\end{tabular}




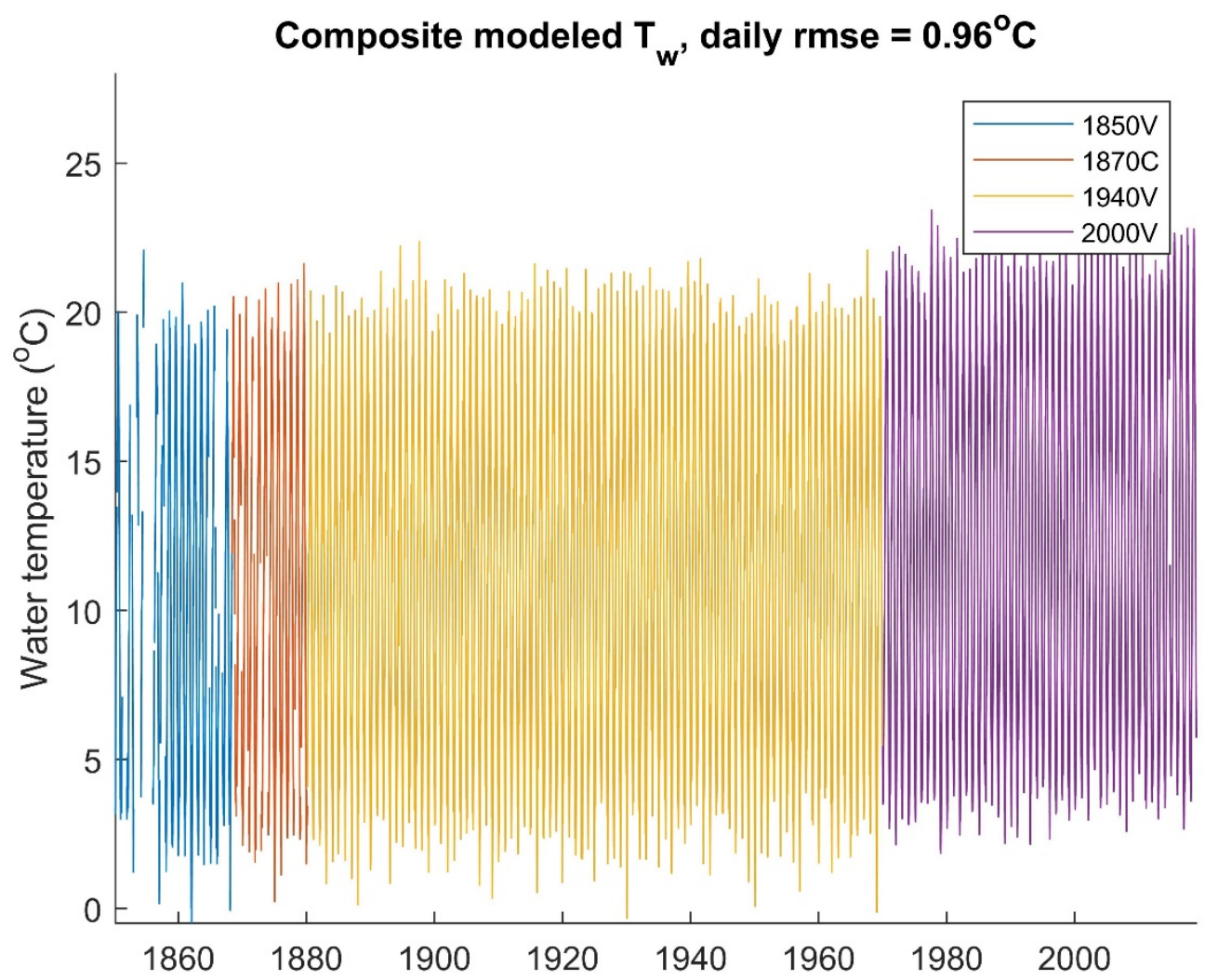

Figure 20: The Vancouver composite model showing how individual models were stitched together to obtain a single, fairly continuous model spanning from 1850 - 2018. The blue model uses Vancouver $T_{a}$ and estimated Bonneville $T_{w}$. The orange model uses Fort Colville $T_{a}$ and estimated Bonneville $T_{w}$. The yellow and purple models use Vancouver $T_{a}$ and Bonneville $T_{w}$. 


\subsection{Models using Empirical Orthogonal Functions (EOFs)}

From all of the air temperature datasets used in this study, I used a subset of them for principal component analysis (PCA), also called empirical orthogonal functions (EOF) analysis. EOF analysis is often used to reduce a set of many variables to only a few, while maintaining as much of the variance from the original set as possible (Hannachi 2004). In this study, the primary purpose for using EOF analysis was to explore putting more air temperature inputs into the statistical model and thus account for more variance. The analysis produces a set of principal components, also called modes. The first principal component or mode, explains the maximum amount of variance from the original data. The second mode explains the remaining maximum amount of variance after the variance from the first mode is removed. All subsequent modes follow the same guidelines, and all modes are mutually orthogonal to each other. This last feature is important for the statistical model, because if I had simply included multiple air temperature datasets as inputs for my model, it might have violated a statistical model assumption that all inputs are independent of each other. By using EOF analysis on the air temperature datasets, I hoped to capture more spatiotemporal variability in air temperature and ultimately improve the model performance.

Through use of EOF analysis, I also hoped to address a few limitations in my statistical model. First, all models used so far have been based off of air temperature as point measurements from a single station that have unknown amounts of bias. By using EOF analysis, I hoped to reduce the effect of this bias by incorporating data from multiple 
stations rather than just one. A second limitation this analysis addressed was whether air temperature from a single station could be considered representative of the entire Columbia River Basin. By creating a model that uses air temperatures from multiple stations, I could be more confident in the amount of air temperature variability incorporated into the model.

From the various sets of air temperature data, I chose eight locations for my EOF analysis model. These locations were scattered throughout the Columbia Basin in order to best capture the spatial variability. As with all other models, I used the air temperature deviations rather than the absolute temperatures. I also chose to use air temperatures from the Berkeley Earth gridded dataset, as that data set is 100\% complete and therefore doesn't affect the results of the EOF analysis. Based on the way the modes are calculated in MATLAB, if any of the input datasets were missing a measurement for a given day, all of the output time-series would also have a missing value for the corresponding day. If I had used eight raw station datasets for this analysis, the number of missing values for each output mode would be the sum of all the missing values of the raw datasets used. By using the gridded dataset, the EOF modes were 100\% complete. From the Pre-Dam 1940s model, the amount of variance explained by the first and second mode was $87.5 \%$ and $7.2 \%$, respectively, while the variance explained in the 2000 s model was $88.4 \%$ and $6.7 \%$. Thus, about $95 \%$ of the total variance was explained by the top two modes in both Pre-Dam and Modern models, and no further modes were used in the modeling.

Several patterns emerged when the weights applied to each station from the first and second modes were plotted against their geographical location. For the Pre-Dam model mode 1 
coefficients, I found that stations located in the northeastern parts of the river basin were more heavily weighted and the western stations were weighted less (Figure 21). The mode 2 coefficients for the Pre-Dam model showed an opposite pattern where the western stations were weighted more than the eastern stations (Figure 22). Additionally, the magnitude of variation in mode 2 (between -0.2 and +0.5 ) was much than in mode 1 (between +0.28 and +0.38 ).

The modes probably denote the difference between the cold/hot interior basin and the milder, coastally influenced Willamette Valley. Mode 1 might be caused by weather systems - when a cold snap happens, it gets much colder inland than near the coast, and vice versa for a heat wave. The inland temperatures tend to be more variable than the coastal temperatures and thus are weighted higher in mode 1 . Mode 2 suggests a slight tendency for the coast and interior to be anti-correlated — when one is warmer, the other is cooler, and vice versa - with a spatial change in the sign of the weights. The coastal regions are typically warmer in the winter and cooler in the summer compared to the inland regions. These interpretations are only speculation at this point and more work would be needed to be done to support them. 


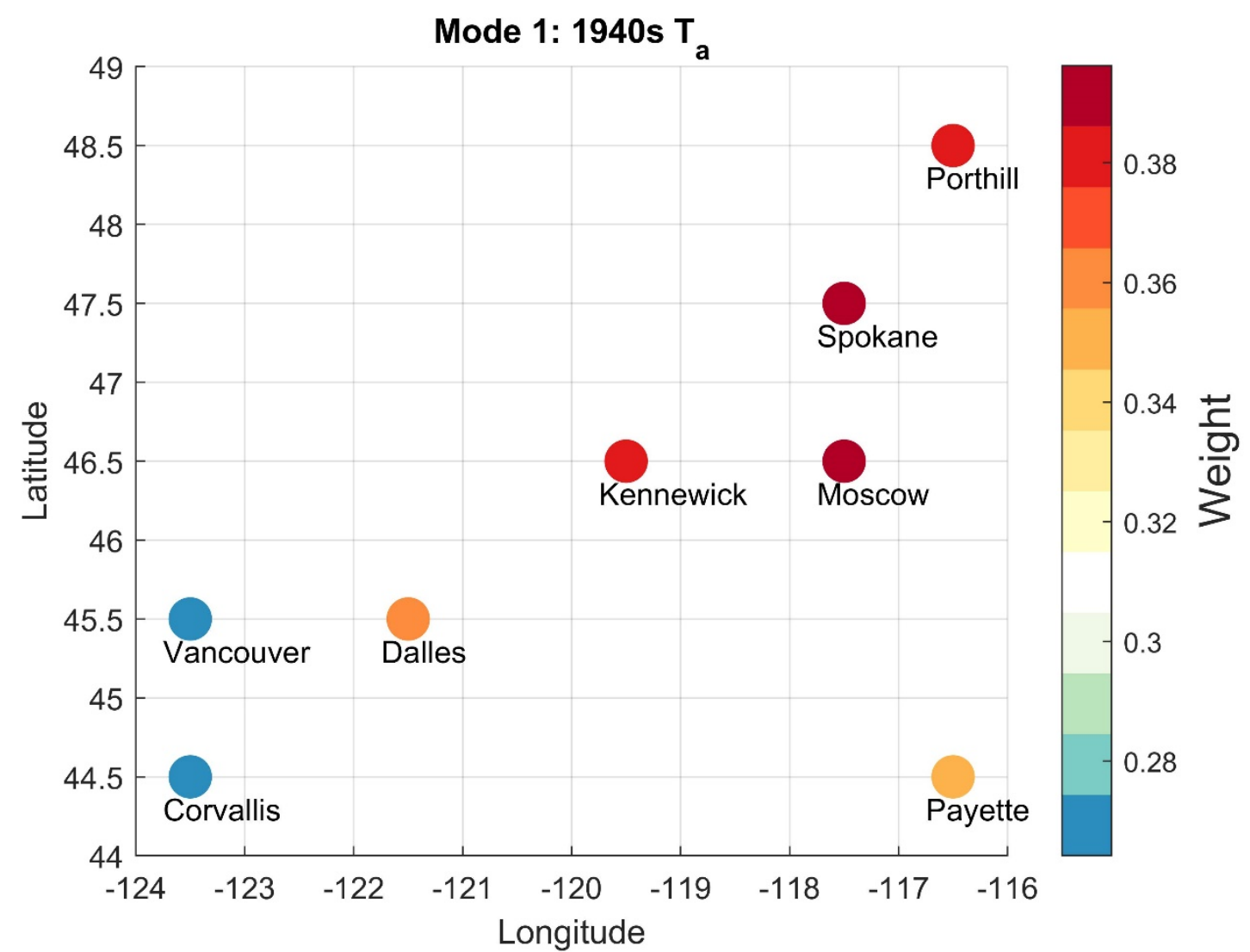

Figure 21: From EOF analysis, the weighting of each air temperature input from mode 1 for 1940s data. The air temperature inputs are plotted by approximate geographical location with the left most points representing the westernmost part of the Columbia River Basin, and the rightmost points representing the easternmost part of the basin. 


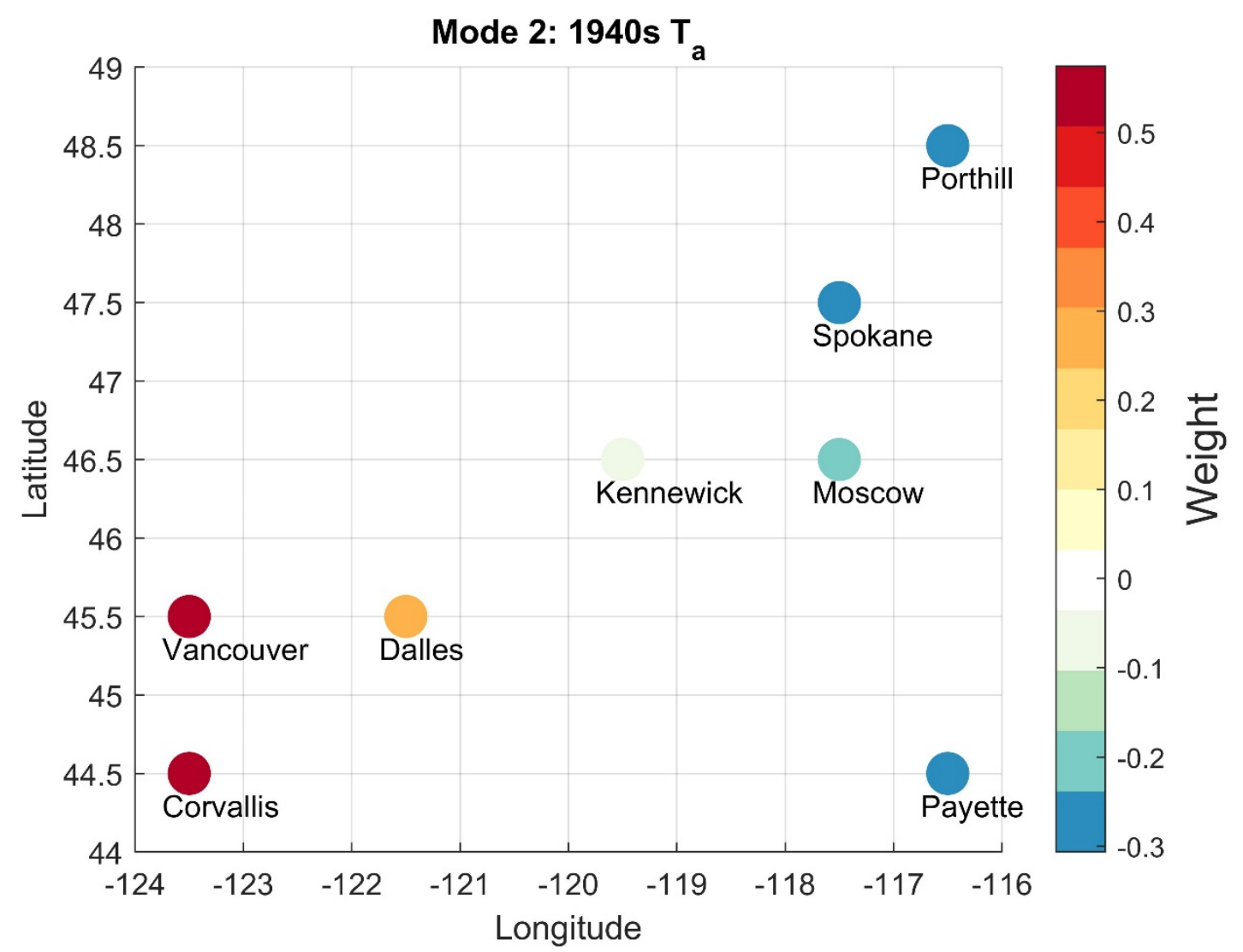

Figure 22: From EOF analysis, the weighting of each air temperature input from mode 2 for 1940s data. The air temperature inputs are plotted by approximate geographical location with the left most points representing the westernmost part of the Columbia River Basin, and the rightmost points representing the easternmost part of the basin. 


\subsection{Scenarios}

To estimate the effects of climate change on Columbia River water temperatures, I first calculated air temperature climatologies (Table 4). The longest air temperature records in this study were from Spokane, WA, Vancouver, WA, and Portland, OR and were used to estimate climate change effects separately, using two 30-year periods (1880 to 1910 and 1988 to 2018). For this scenario, the model regression coefficients and the river flows were kept constant at pre-dam levels, while only the air temperature was changed in order to best isolate and identify the effects of climate change. By applying the difference in climatology for the air temperature input and keeping the same river flow, the result showed the changes in water temperature between 1880 and 2018 as a function of air temperature change. This analysis quantifies effects caused solely by air temperature changes and may oversimplify and underestimate total climate change impacts because it does not account for other ways in which the climate is changing, such as altered river flows.

To estimate the effects of the dams and reservoirs along the river, I applied the Pre-Dam and Modern models to the same time period (2000 to 2018) and calculated the difference in their results (Table 4). For this analysis, air temperature and river flow were kept constant, while the model coefficients changed. I assumed the difference between the two model results to be the estimated change in water temperature between 1938 to 2018 solely as a function of reservoir construction and management. 
Table 4: Scenario inputs and outputs for analysis of climate change and reservoir effects

\begin{tabular}{|l|l|l|l|l|}
\hline & $\boldsymbol{T}_{\boldsymbol{a}}$ & $\boldsymbol{Q}$ & $\boldsymbol{T}_{\boldsymbol{w}}$ & Output \\
\hline $\begin{array}{l}\text { Model inputs } \\
\text { for climate } \\
\text { change effects }\end{array}$ & $\begin{array}{l}\text { Difference in } \\
1988-2018 \text { and } \\
1880-1910 \\
\text { climatology }\end{array}$ & $\begin{array}{l}\text { No difference }(0 \\
\left.\mathrm{m}^{3} / \mathrm{s}\right) \text { between } \\
1880-2018\end{array}$ & $\begin{array}{l}\text { No difference }(0 \\
\left.{ }^{\circ} \mathrm{C}\right) \text { between } \\
1880-2018\end{array}$ & $\begin{array}{l}\text { Estimated } \\
\text { changing } T_{w} \\
\text { based on } \\
\text { changing } T_{a} \text { and } \\
\text { constant } Q\end{array}$ \\
\hline $\begin{array}{l}\text { Model inputs } \\
\text { for reservoir } \\
\text { effects }\end{array}$ & $\begin{array}{l}\text { From } \\
\text { Vancouver, WA } \\
\text { between 2000- } \\
2018\end{array}$ & $\begin{array}{l}\text { From the Dalles, } \\
\text { OR between } \\
2000-2018\end{array}$ & $\begin{array}{l}\text { From Bonneville } \\
\text { Dam, OR } \\
\text { between 2000 }- \\
2018\end{array}$ & $\begin{array}{l}\text { Difference } \\
\text { between } 2000 \mathrm{~s} \\
\text { modeled } \mathrm{T}_{\mathrm{w}} \text { and } \\
1940 \mathrm{~s} \text { modeled } \\
\mathrm{T}_{\mathrm{w}}\end{array}$ \\
\hline
\end{tabular}




\section{Results}

\subsection{Measured and Modeled Water Temperature Changes}

Comparison of measured water temperatures at Bonneville Dam for 1938 to 1952 and 2004 to 2018 show an increase in average annual temperature of $1.2 \pm 0.2^{\circ} \mathrm{C}$ between these two periods (Figure 23). Seasonally, the largest measured increase occurs in the fall and early winter months, while the smallest increase and even slight decrease in water temperature occurs in the spring. A similar comparison between water temperatures between 1855 to 1875 and 1938 to 1952 suggests a change of $0.76 \pm 0.1^{\circ} \mathrm{C}$ (Figure 24). As mentioned previously, the water temperature measurements for the 1850 s originates from Astoria that have been corrected to approximate Bonneville water temperatures. Because there are no raw temperature measurements from Bonneville prior to 1938, additional error is introduced into results that rely on this data. To quantify this error, I calculated the daily root-mean-squared difference between the true Bonneville and estimated Bonneville measurements from 1950 to 1982 to be $0.95^{\circ} \mathrm{C}$. This is an estimate on the random error that is introduced by using Astoria water temperatures for the Historical model. On a monthly basis, the lowest RMSE of about $0.84^{\circ} \mathrm{C}$ occurs in the spring time (March to April). This result might be explained by a combination of increasing river flows at this time of year and the warming of the river temperature to be more similar to ocean temperatures. Both of these factors indicate why temperatures at Bonneville would be similar to Astoria and thus ultimately produce a lower RMSE. From the estimated Bonneville temperature measurements, I found that between the $1850 \mathrm{~s}$ and $1940 \mathrm{~s}$, the 
seasonal changes in temperature appear somewhat homogenous with all times of the year showing a similar increase in temperature (Figure 24).
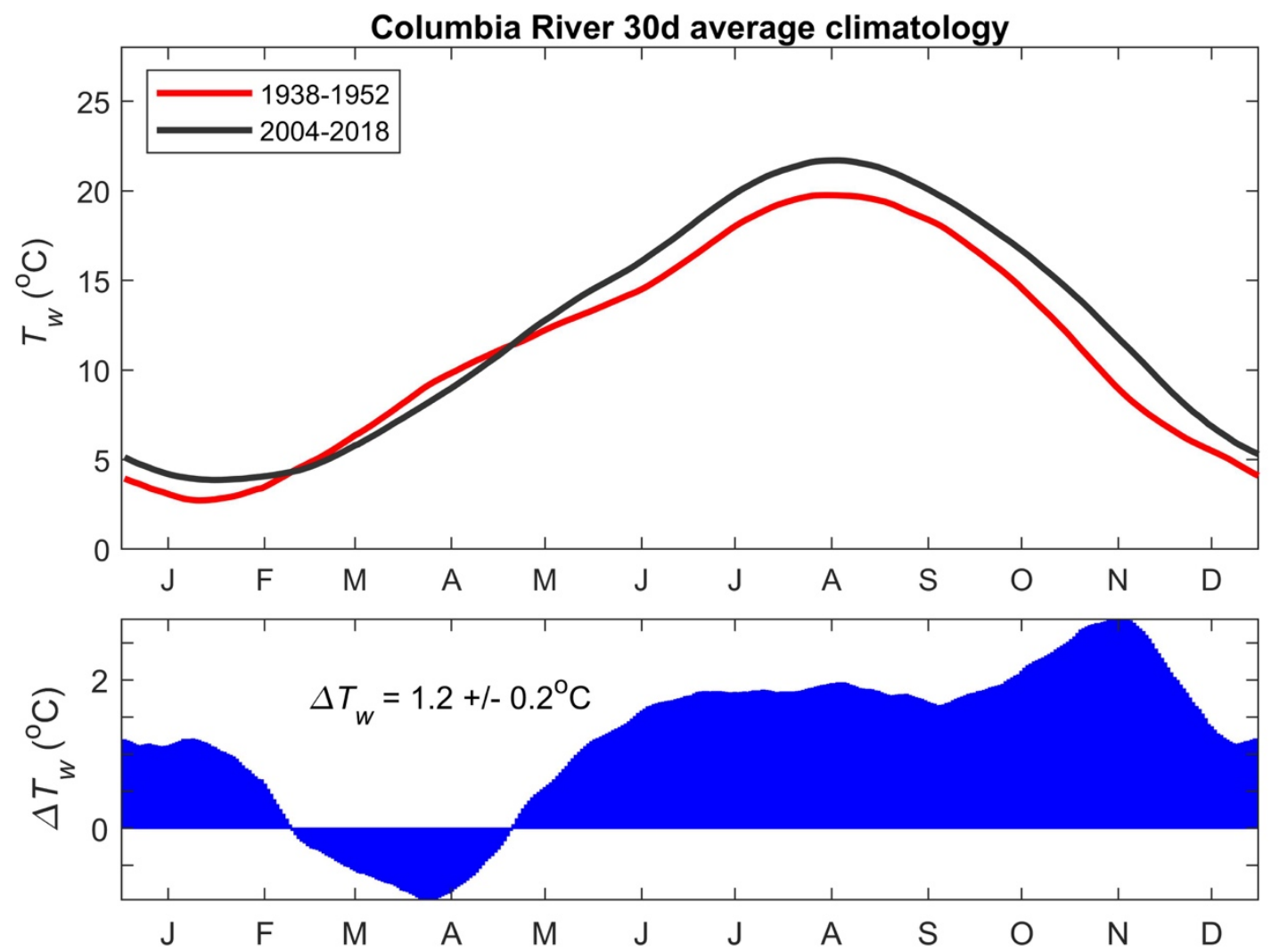

Figure 23: Measured change in water temperature at Bonneville between 1938 and 2018. A river climatology was calculated based on thirty-day averaged temperature between 1938 to 1952 (red line) and 2004 to 2018 (black line). The estimated change in temperature is based on the difference between the specified time periods. 

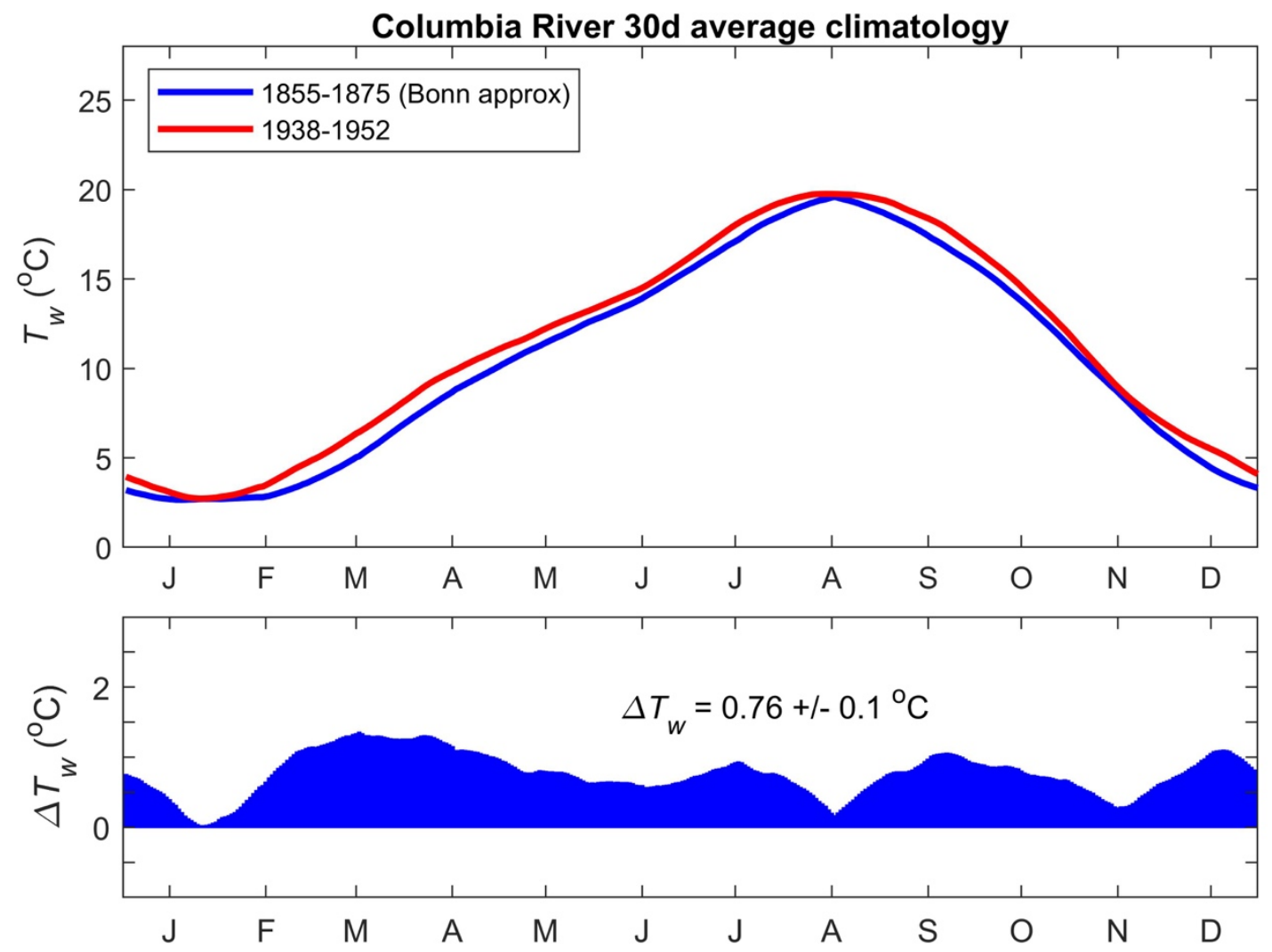

Figure 24: Estimated measured change in water temperature at Bonneville between 1855 to 1952. A river climatology was calculated based on thirty-day averaged temperature between 1855 to 1875 (blue line) and 1938 to 1952 (red line). The data from the 1800s is estimated Bonneville temperatures based on measured water temperature data from Astoria. The estimated change in temperature is based on the difference between these two time periods.

The model results shown below are for the Vancouver composite model because it had the longest air temperature record for one location and allowed for a mostly consistent airwater temperature relationship; however I also did the same analysis for the Spokane, Portland, and EOF composite models. To avoid a plethora of figures, I have only included those for the Vancouver composite model, as a sample of my results. The error bars on trend estimates shown below represent the standard error of the regression coefficients 
from the line fitted to the model results. In other words, it is the uncertainty in the trend derived from the model results.

Based on a linear trend fit to the data, the Vancouver composite model estimated about a $1.3 \pm 0.1^{\circ} \mathrm{C}$ increase in water temperature per century (Figure 25). Using this rate of change, the modeled change over 81 years is $1.05 \pm 0.1^{\circ} \mathrm{C}$, while the measured change over the same length of time is $1.2^{\circ} \mathrm{C}$ (Figure 23). The model prediction, therefore, slightly underestimates the measured difference. A possible explanation for this is the non-linearity of measured annual water temperature trends. Based on visual observation, temperatures have been warming more quickly over time rather than at a constant rate (Figure 25). By fitting a trend line to the entire model period, I may not be capturing the trends occurring on a smaller time scale as accurately, which might explain why the model is underestimating the measured changes. $3^{\text {rd }}$ and $4^{\text {th }}$ order polynomials were then fitted to a smoothed annual mean water temperature model for comparison to the linear fit. The approximate change over the same 81 years for the $3^{\text {rd }}$ and $4^{\text {th }}$ order polynomials were 1.2 $\pm 0.1^{\circ} \mathrm{C}$ and $1.3 \pm 0.1^{\circ} \mathrm{C}$ increases, respectively. These higher order curve fits are a slight improvement from the linear fit, likely because they are able to capture the smaller scale changes.

Using the simple linear trend, I applied it to the years from 1850 to 2018 (168 years), and found the modeled change in water temperature was $2.2 \pm 0.2^{\circ} \mathrm{C}$. The annual minimum temperature model trend is the same as the annual mean trend at $1.3 \pm 0.3^{\circ} \mathrm{C} /$ century, while the annual maximum trend is slightly larger at $1.6 \pm 0.3^{\circ} \mathrm{C} /$ century, indicating annual 
maximum temperatures may be warming faster than the mean and minimum (Figure 25). The primary statistic used to measure the performance of the models was the root mean squared error (RMSE). This statistic represents how close the modeled results were to the measured data. The RMSE for the annual mean Vancouver composite model was $0.51{ }^{\circ} \mathrm{C}$ (Figure 25). The RMSE for the annual minimum and maximum Vancouver composite models was $1.17^{\circ} \mathrm{C}$ and $0.94^{\circ} \mathrm{C}$, each (Figure 25).
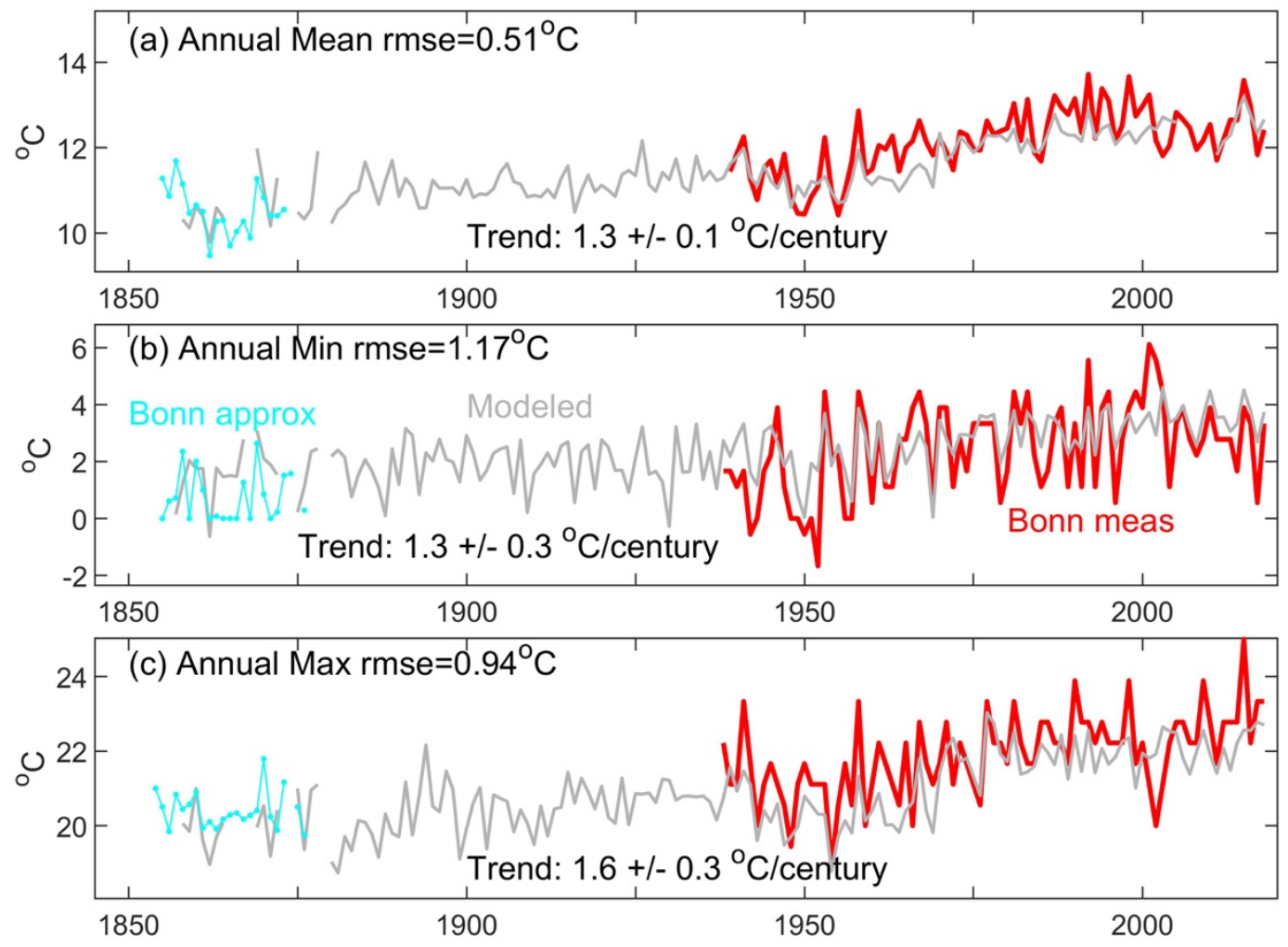

Figure 25: Annual mean, minimum, and maximum water temperature trends are shown. The red line is the measured data from Bonneville, the grey line is the modeled water temperature, and the cyan line is the estimated water temperatures at Bonneville based on data from Astoria. 
Seasonally, the largest modeled increase in temperature occurs during the fall and early winter months, and the smallest modeled increase occurs in the spring (Figure 26). These trends can be better understood by considering seasonal changes in air temperature and river flow. The magnitude of spring freshet flows has been reduced through flow regulation and irrigation withdrawals, resulting in less snowmelt running down the river in the summer to early fall months (Figure 2 and Naik and Jay 2011). Additionally, one of the largest seasonal increases in air temperature for the Columbia River Basin has occurred during the fall months, providing further explanation for the increase in water temperature during the fall time (Figure 29). These compounding factors likely play a role in the $2.0 \pm$ $0.2^{\circ} \mathrm{C} /$ century increase in fall/early winter river temperatures. With respect to native salmon species, these changes may be of concern because adults of many stocks such as fall Chinook salmon migrate upriver in the summer and fall (Figure 26d, Figure 26e).

The smallest seasonal modeled increase in water temperature occurs in the spring, with an increase of about $0.04 \pm 0.2^{\circ} \mathrm{C}$ per century between March and April (Figure 26). This trend might be explained once again by the changes in annual river flow. While the spring freshet flows have been reduced, the flows during the winter time have increased (Figure 2). This increase in river flow might help explain the minimal increase in modeled water temperatures in the spring, because the two factors are known to be negatively correlated (Gu et al 1998, Overman 2017). A minimal temperature change in the spring may be beneficial for juvenile salmon, many of which migrate out to the ocean at this time of year (Figure 26b). Adult spring Chinook salmon also migrate upriver from March to May. 
Another contributing factor to the large river temperature increases in the fall is that the capacitance of the river system has increased. The river stays above $20^{\circ} \mathrm{C}$ longer in the year now due to its increased "memory" (Figure 27), which is associated with the reservoir system and reduced mean flows. While river flow and air temperature have not changed dramatically in the winter, the models show a large increase in river temperature for this time of year. There have been, however, more dramatic changes to river flow and air temperatures in the late summer and early fall. Because of the river's increased "memory," environmental changes in the fall time likely affect the river's winter temperatures. This same argument could be used to explain why the spring time does not show as much warming as other times of the year; water temperatures are slower to respond to changes in seasonal air temperature compared to previously. Furthermore, the observed air temperature change for the springtime is small, providing additional explanation for the small modeled spring water temperature change (Figure 29). While I only included air temperature and river flow in my model, it is important to note there are many other factors that affect river temperature as well such as irrigation withdrawals and returns, logging, and urbanization. Any of these could also be contributing to the seasonal changes, and more work would need to be done to determine the effects of each. 

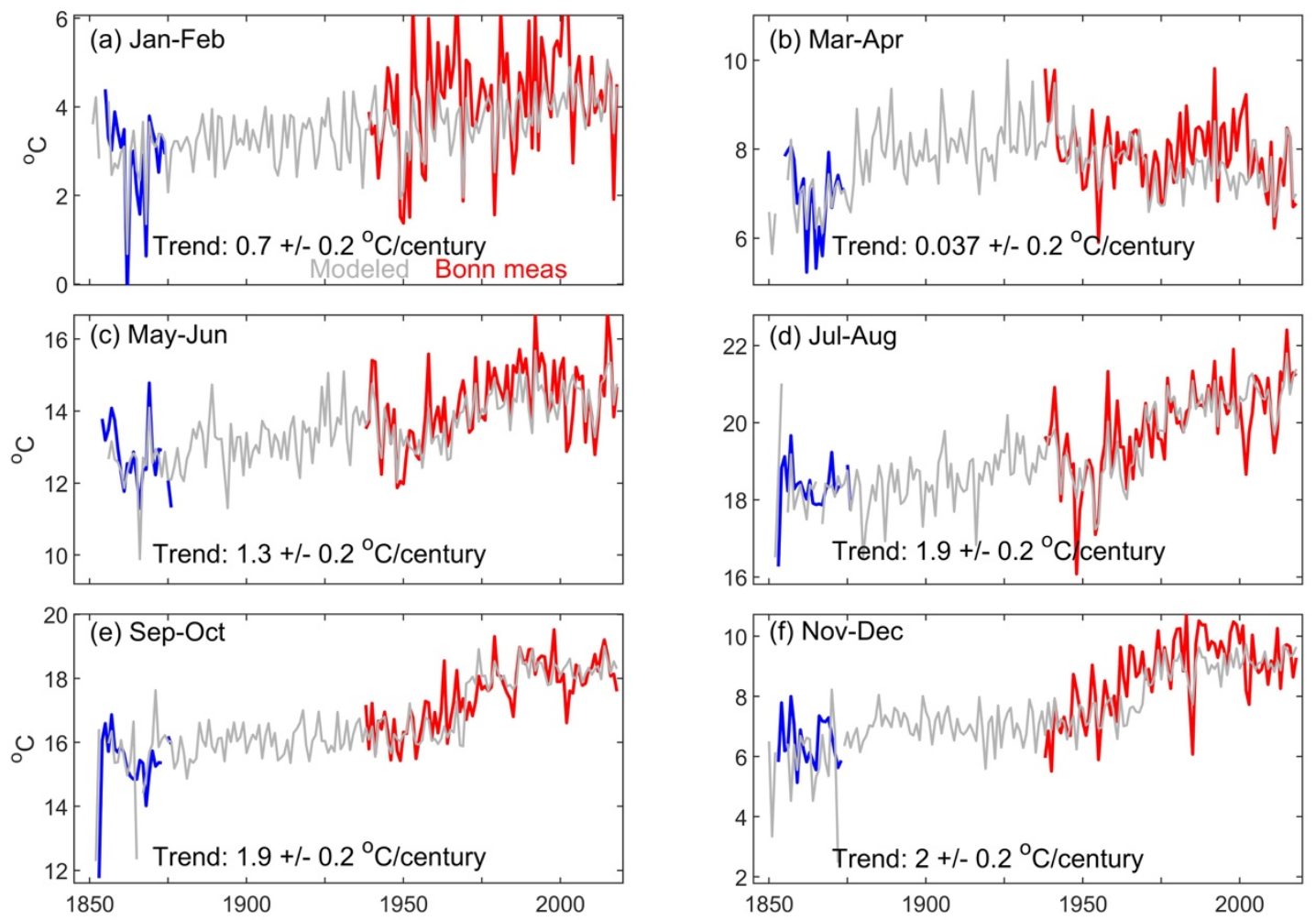

Figure 26: Annual seasonal trends are shown. The red line is the measured data from Bonneville and the grey line is the modeled result. The measured water temperature from the 1800s shown in blue is estimated Bonneville temperatures based on measurements from Astoria.

I also modeled the occurrence of temperatures above and below various thresholds, because of the relevance of these thresholds to the health of salmon and other cold-water species. The yearly maximum water temperature comes earlier in the year than it used to (Figure 27). This has potential consequences for migrating species such as anadromous fish. Furthermore, the magnitude of the warmest annual water temperature is increasing and the number of days over $20^{\circ} \mathrm{C}$ has increased since the 1800 s. So, the river is not only warmer but also warmer for a longer amount of time each year. This result suggests there is more thermal stress placed on cold-water species (Figure 27). 


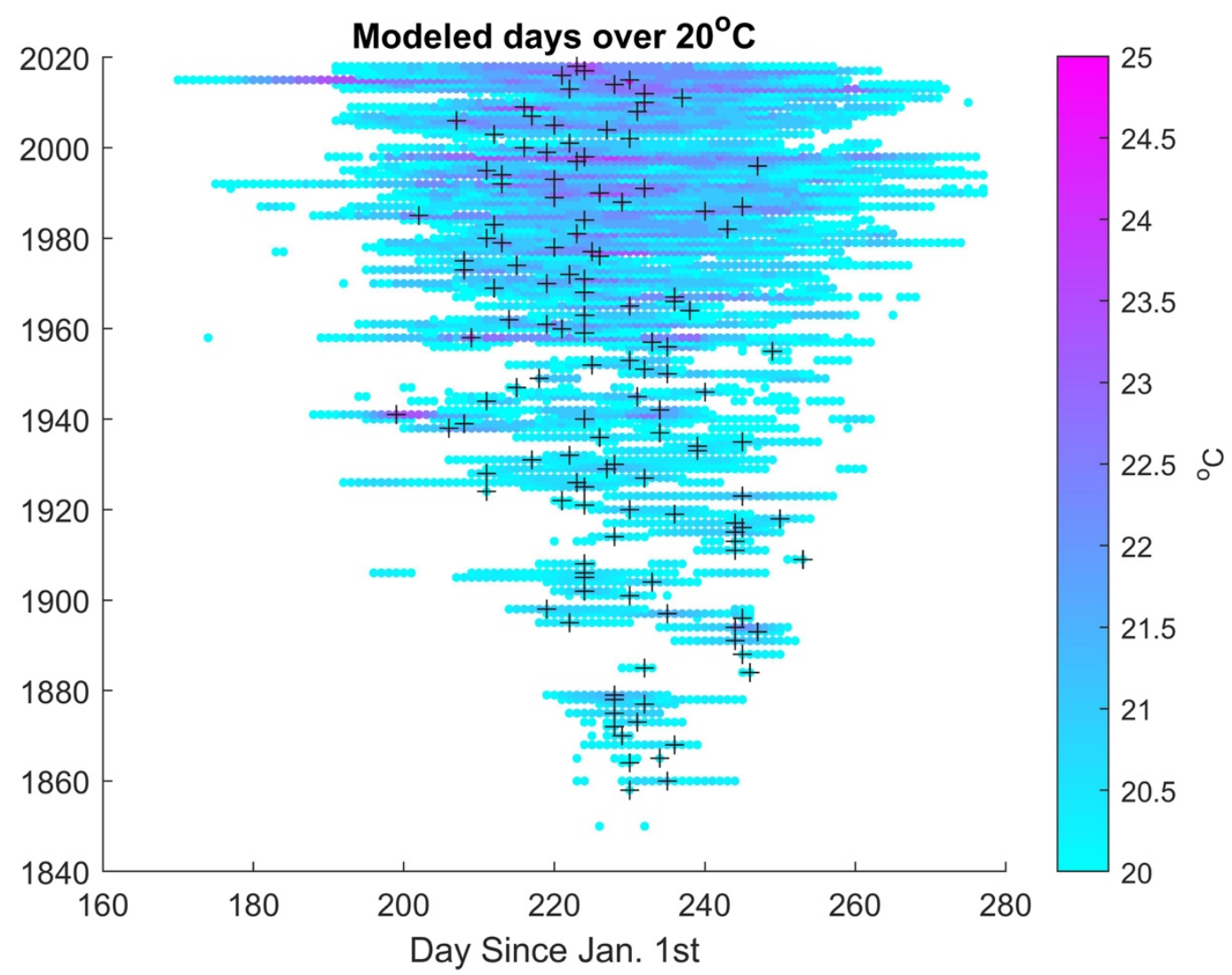

Figure 27: Modeled number of days over $20^{\circ} \mathrm{C}$ for water temperature. The + sign indicates when the maximum water temperature for the year occurred.

The number of days per year over $18^{\circ} \mathrm{C}$ and over $20^{\circ} \mathrm{C}$ have each increased by about 40 days per year since the mid-1800s (Figure 28). Currently, there are about 100 days per year over $18^{\circ} \mathrm{C}$ and 60 days per year over $20^{\circ} \mathrm{C}$. While the number of days per year above $22^{\circ} \mathrm{C}$ has increased by much less (about 10 days), this change is still significant because of the negative ecological implications of these temperatures; the upper threshold for healthy functioning in salmonids is about 19 to $20^{\circ} \mathrm{C}$ and temperatures become lethal around $22^{\circ} \mathrm{C}$ (Carter et al. 2006). Moreover, days above $22^{\circ} \mathrm{C}$ appear to have been absent prior to about 1940. An increased number of warm days poses an environmental threat to these cold- 
water species that are unable to adapt as quickly as the rapid rate of change induced by human activities (Quinn and Adams 1996). Additionally, the number of days per year that is less than $2^{\circ} \mathrm{C}$ has noticeably decreased since the mid-1800s to zero (Figure 28). This modeled result is supported by the historical fact that the Columbia River used to freeze over during some winters, but rarely does now (Spranger 1996).

Lastly, the modeled number of days over $20^{\circ} \mathrm{C}$ is noticeably lower than the measured number of days over $20^{\circ} \mathrm{C}$ between the 1950 s and 1970s (Figure 28b). This difference likely indicates the effect of the Hanford Nuclear Site which was most active during this time period. 
Water temperature above/below a threshold
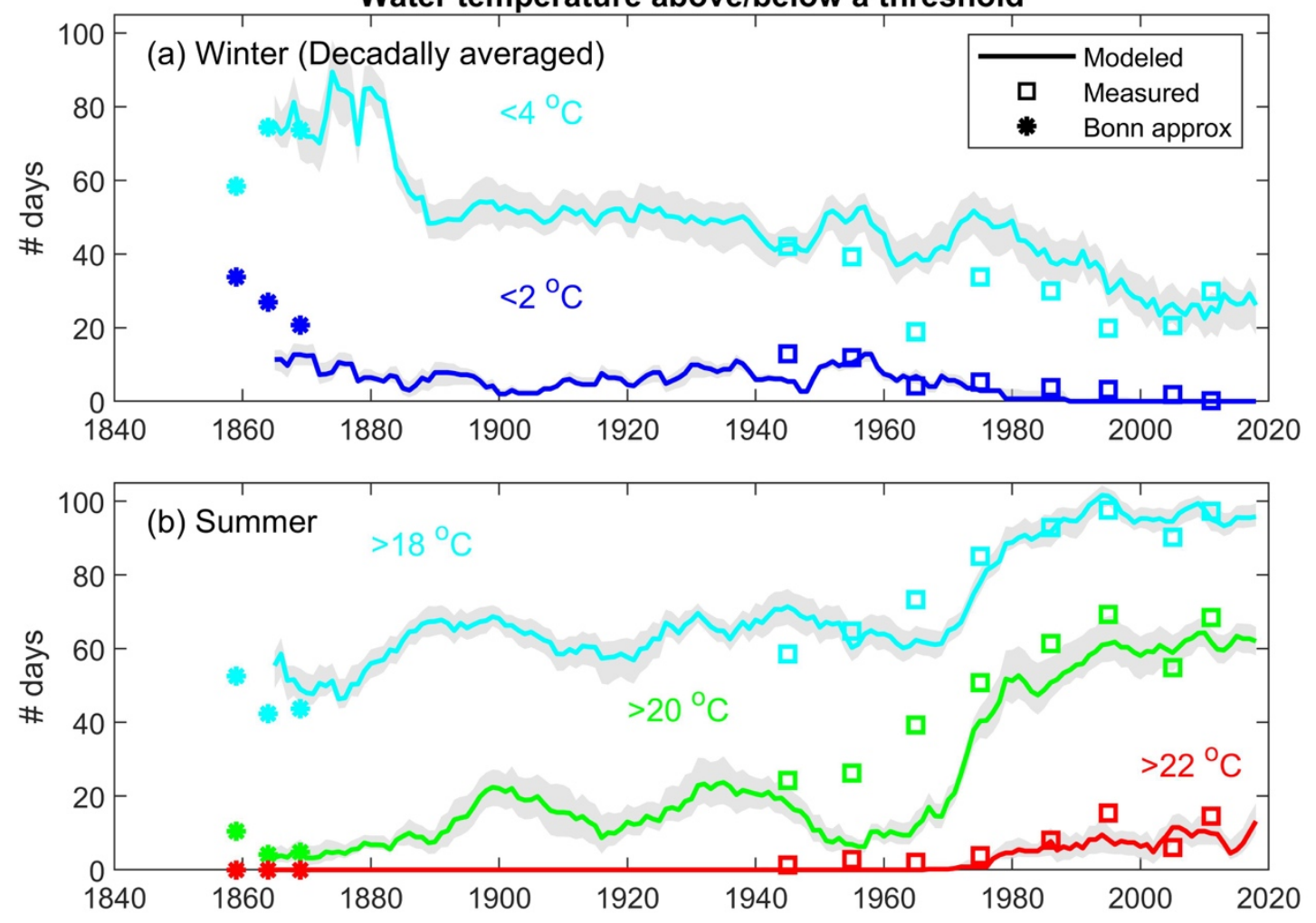

Figure 28: The decadally averaged number of days above and under various thresholds. (a) shows the number of cold days (below 2 and $4{ }^{\circ} \mathrm{C}$ ) is decreasing. (b) shows the number of warm days (above 18, 20, and $22^{\circ} \mathrm{C}$ ) is increasing. The ridged circles indicate Bonneville approximated measurements, the squares indicate true Bonneville measurements. 


\subsection{Causes of Temperature Change}

Based on air temperature climatology for 1880 to 1910 and 1988 to 2018 for Vancouver

WA, the estimated increase in water temperature due to climate change (i.e., increased air temperature) is about $0.4 \pm 0.02^{\circ} \mathrm{C}$ (Figure 29). Seasonally, the largest increases in water temperature due to changes in air temperature occur during late winter and late summer to fall with a maximum of about a $1^{\circ} \mathrm{C}$ increase. Spring and early winter show the least amount of change at less than $0.25^{\circ} \mathrm{C}$ on average (Figure 29).

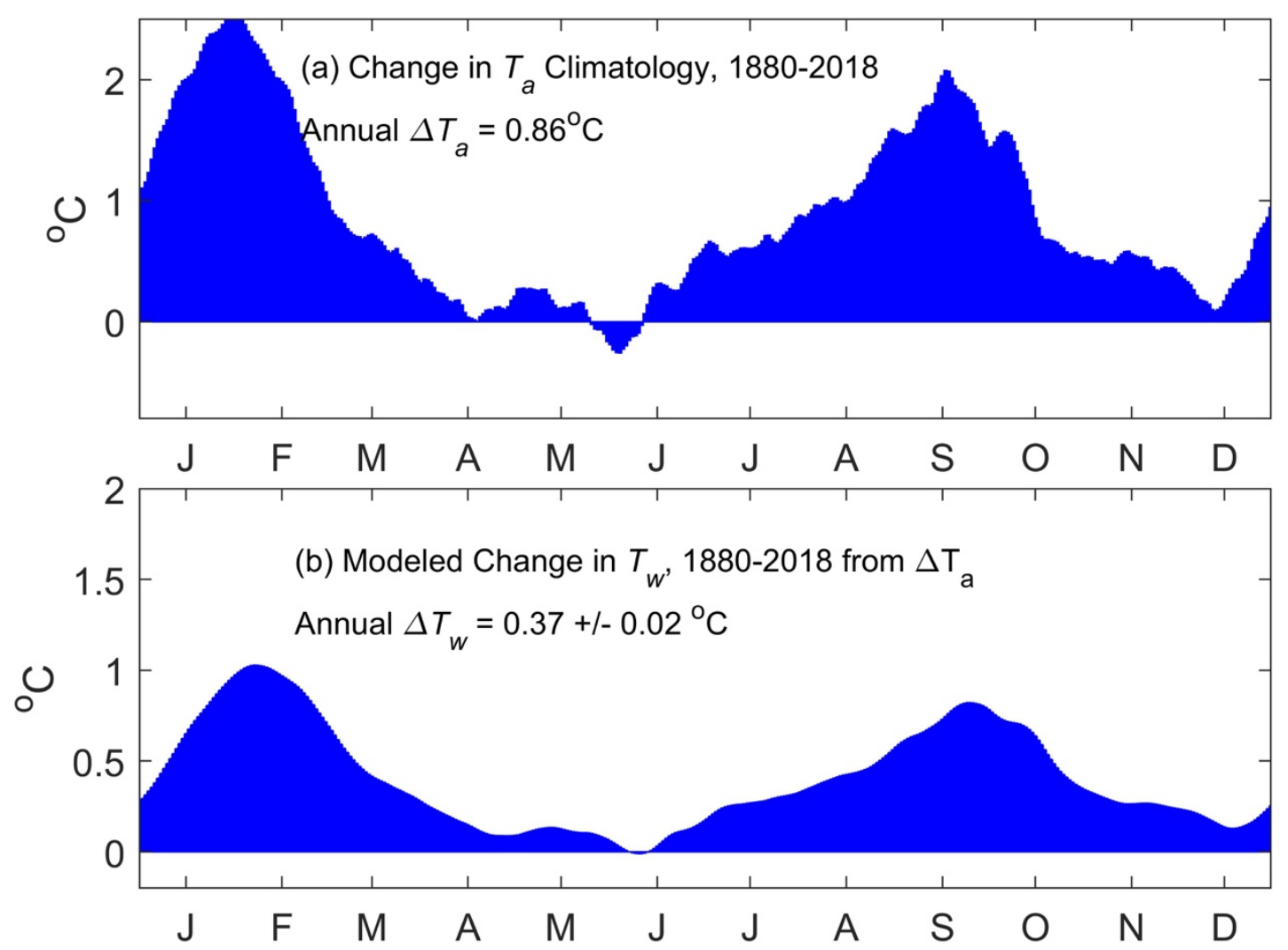

Figure 29: The modeled change in water temperature based solely on the changing climate (air temperature). We used the 1940s (historical) Vancouver model for this simulation. (a) The change in air temperature climatology from 1880 to 1910 and 1988 to 2018. (b) The modeled change in water temperature from 1880 to 2018. 
To isolate and estimate the effects of the hydropower system and reservoirs, I applied both the Pre-Dam and Modern models to the years 2000 to 2018, thus keeping air temperature and river flow consistent, and calculated the difference in model results. Based on the difference between the 1940s Vancouver model and the 2000s Vancouver model, the estimated average increase in water temperature due to reservoir management was about $0.8 \pm 0.4^{\circ} \mathrm{C}$ between 1938 to 1952 and 2000 to 2018 (Figure 30). Seasonally, the largest increase occurs in the fall, with a maximum change exceeding $2^{\circ} \mathrm{C}$. The smallest increase (and even some decrease) occurs in the spring (Figure 30). These seasonal trends are also reflected in the total water temperature change, which suggests the reservoir system is an important factor.

Other studies that have estimated thermal effects of dams on rivers have found similar warming patterns in the late summer and fall (Rounds 2010). However, unlike the results shown here, it has been found, particularly for deep storage reservoirs, that they have a cooling effect in mid-summer. Because the taller dams often release water from deeper in the pool, that water is cooler than water near the surface. Then in late summer and fall, as larger amounts of water are released to free up storage capacity, the warmer water near the surface gets pulled downstream as well, resulting in a warming effect (Rounds 2010). It is important to note that temperature effects tend to be specific to the structure of individual dams and the residence time of water behind it. While deep storage reservoirs may produce a cooling effect in mid-summer, run-of-the-river reservoirs characteristic of the Columbia River may not have this same effect. However, despite seasonal differences, the overall 
effects of flow impoundments are increased water temperature due to increased water residence time, regardless of the type or size of reservoir. Previous research has shown that even relatively shallow, run-of-the-river reservoirs have contributed to warming trends, a finding which agrees with the results shown here (Yearsley et al. 2001).

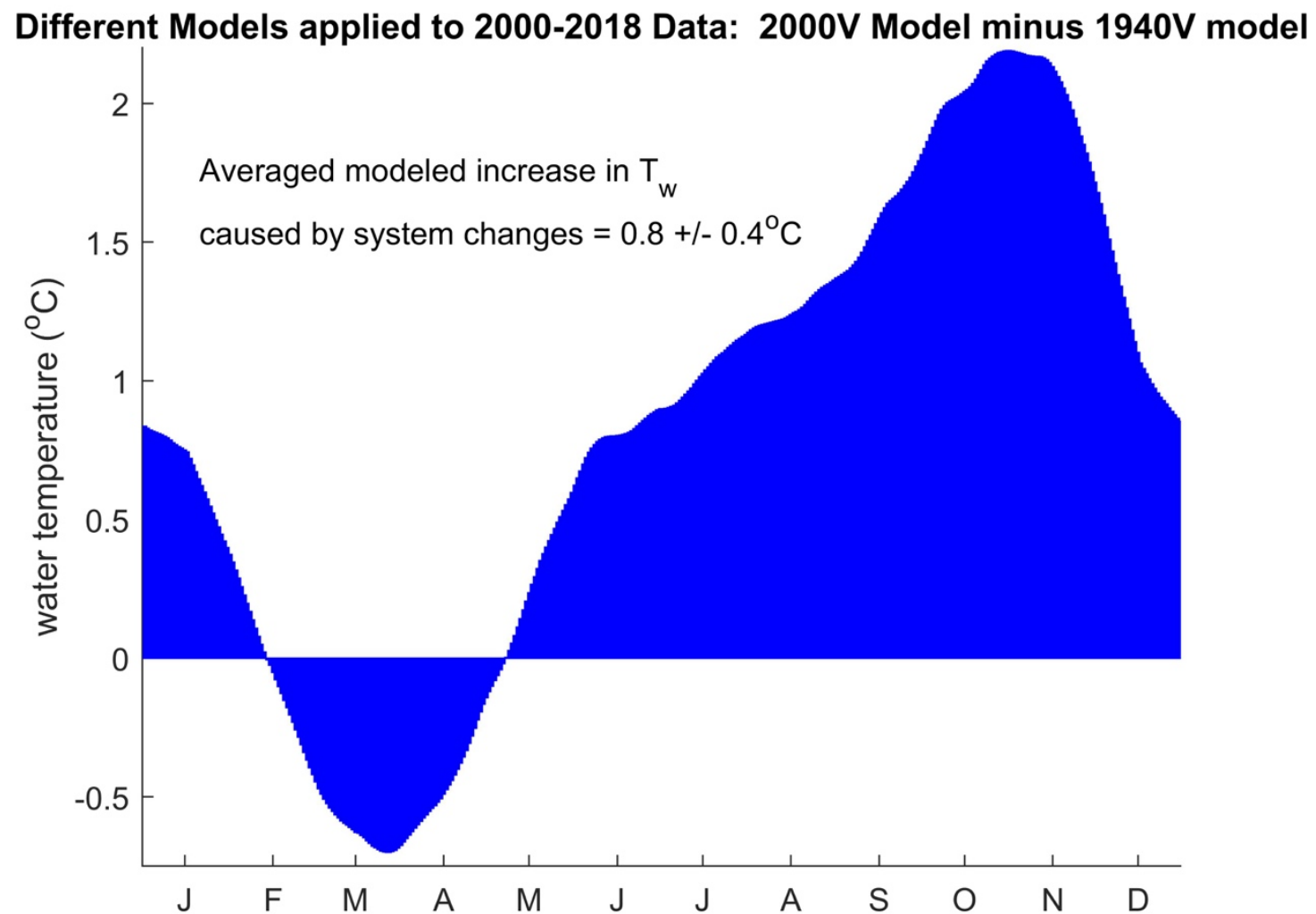

Figure 30: The estimated modeled change in water temperature based solely on changes to the river due to the reservoir system. This figure shows the difference in the Pre-Dam Vancouver model (1940V) and Modern Vancouver model (2000V) when applied to the same set of air temperature and river flow data.

Another important factor to address is the change in amount of annual flow. The scenario I ran to estimate the hydropower system's impact involved changing only the model coefficients (i.e. the relationships between $T_{a}, Q$, and $T_{w}$ ), but this does not necessarily 
account for the change in the total amount of flow per year (Figure 2). The primary drivers of this change are irrigation withdrawal and climate change. The annual mean water temperature increase due to decreased mean flows was estimated to be $\sim 0.15 \pm 0.05^{\circ} \mathrm{C}$. This result was obtained by taking the difference between the previous scenario explained (see Figure 30), and a scenario that used constant air temperature with changing flows and model coefficients. In reality, the impacts of the dams, reservoirs, and irrigation withdrawals are likely interconnected and accurately separating out the individual effects can be challenging. These results provided are simple estimates of a rather complex issue, based on a linear decomposition.

The estimated change in water temperature due to increased air temperatures was based on the period 1880 to 2018 , while the estimated change due to reservoir management was for 1938 to 2018 (Figure 29 and Figure 30). Prior to 1938, the effects on the river due to reservoir management were minimal since Rock Island Dam was the only other existing dam along the mainstem during this time period. Using the assumption then, that there were no significant reservoir effects between 1880 and 1938, the combined estimated change in temperature due to climate change, reservoir management, and irrigation was an increase of $1.4^{\circ} \mathrm{C} \pm 0.4^{\circ} \mathrm{C}$ between 1880 and 2018 , which is the sum of the individual effects; $1.4^{\circ} \mathrm{C}=0.4^{\circ} \mathrm{C}+0.8^{\circ} \mathrm{C}+0.2^{\circ} \mathrm{C}$.

Using the linear trend of $1.3 \pm 0.1^{\circ} \mathrm{C}$ per century from Figure 25 , the total modeled water temperature change between 1880 and 2018 is $1.8 \pm 0.1{ }^{\circ} \mathrm{C}$. While this result is $\sim 0.4^{\circ} \mathrm{C}$ larger than the summed result from climate and reservoir effects, there are numerous other 
ways in which humans have affected water temperature since the $19^{\text {th }}$ century. Thus, this $0.4^{\circ} \mathrm{C}$ difference is likely attributable to factors not directly modeled here, e.g., to land use practices such as logging, agriculture, and additional climate change factors. To convert these values into percentages, I calculated the ratio between the change from each isolated effect and the total change. For example, about $20 \%$ of the total change is due to climate change (where $0.4^{\circ} \mathrm{C} / 1.8^{\circ} \mathrm{C} \sim 0.2$ ); about $45 \%$ of the total change is due to the reservoirs and their management $\left(0.8^{\circ} \mathrm{C} / 1.8^{\circ} \mathrm{C} \sim 0.45\right)$; about $10 \%$ is due to irrigation withdrawals $\left(0.2^{\circ} \mathrm{C} / 1.8^{\circ} \mathrm{C} \sim 0.1\right)$, and the remaining $25 \%$ is due to the various other human-related activities such as logging and deforestation $\left(0.4^{\circ} \mathrm{C} / 1.8^{\circ} \mathrm{C} \sim 0.25\right)$. It is important to note that these are rough estimates of attribution and don't account for any non-linear effects within the river system.

I also explored how and why temperature dynamics have changed by evaluating and comparing water temperatures from Rock Island Dam (1933 to 2018). Interestingly, the difference in temperature between Bonneville Dam and Rock Island Dam has increased over time (Figure 31). From 1939 to 1952 Rock Island and Bonneville temperatures follow each other closely, with an average difference of $0.5^{\circ} \mathrm{C}$ noted, despite a $495 \mathrm{~km}$ difference in location. In the $1950 \mathrm{~s}$ to $1960 \mathrm{~s}$, this temperature difference increases to $2.4^{\circ} \mathrm{C}$, likely because of the heating caused at the Hanford nuclear site. However, the 1950s difference persisted after Hanford operations stopped, and remains $2.5^{\circ} \mathrm{C}$ for the 2010 to 2018 decade. Thus, there is more heating that occurs between Rock Island and Bonneville than historically, and/or the tributaries between the two locations are warmer than they were historically. Tributary dams and irrigation diversion are possible reasons for the tributary 
warming. As dam construction and reservoir management are one of the primary changes that have occurred since the 1950 s, this finding suggests that the reservoir system may contribute to the majority of this $2.5^{\circ} \mathrm{C}$ difference.

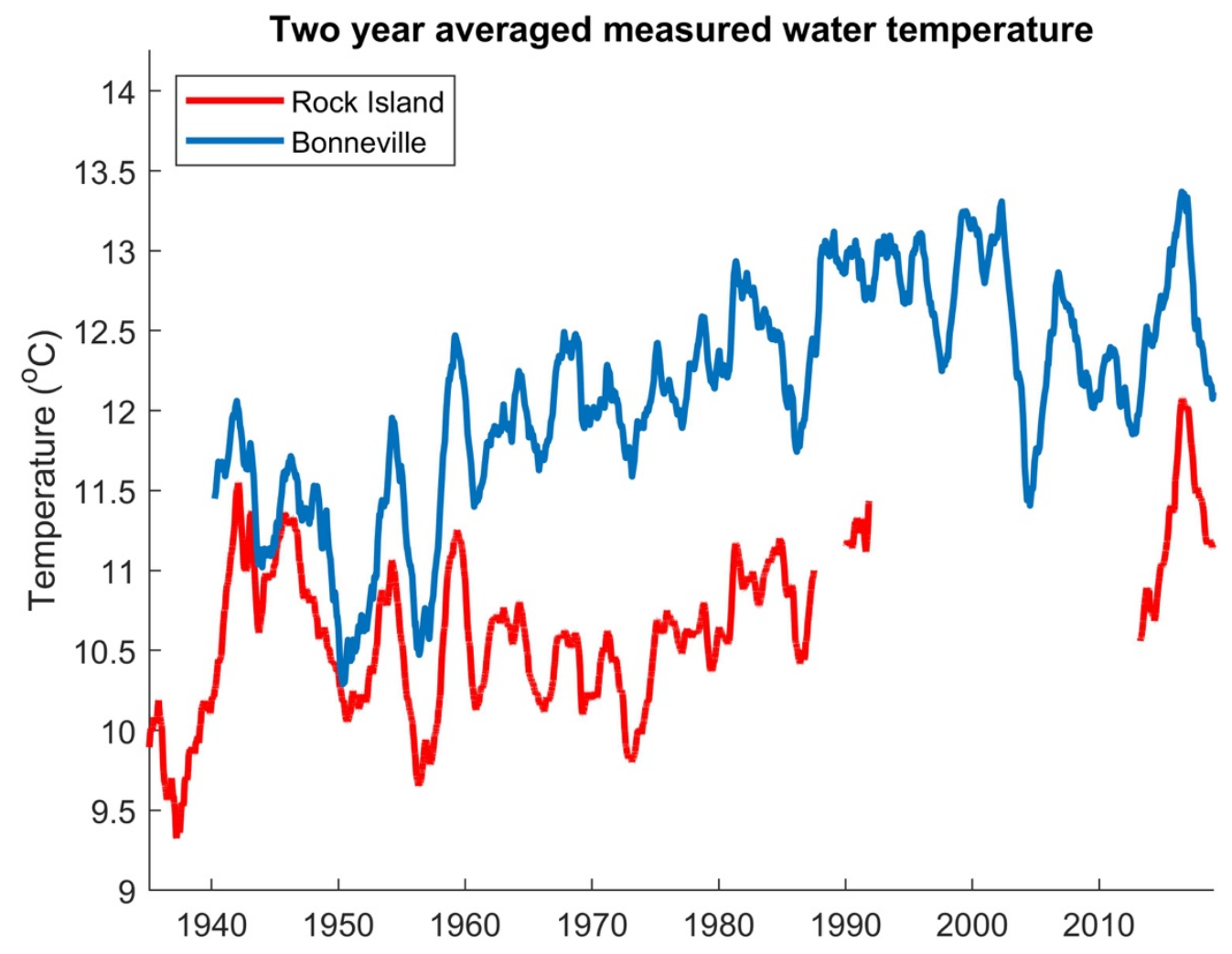

Figure 31: Measured water temperatures from Rock Island Dam (blue) and Bonneville Dam (orange) over time. The measurements are averaged over a two year time period. 


\subsection{River System "Memory"}

Plotting the air temperature regression coefficients against the corresponding time lags showed that the river system "memory" has changed over time (Figure 32). The coefficients from the 1940s Vancouver model indicate that air and water temperature became decorrelated more quickly when compared with the coefficients from the 2000 s Vancouver model. Thus, water temperatures are more strongly correlated with air temperatures further back in time in the Modern model (Figure 32). In the Pre-Dam 1940s model, it takes about 12 days for the air and water temperature correlation to reach about $1 / 3$ of its maximum. In the Modern 2000s model, a similar decorrelation takes about 22 days. This change is likely attributable to the reservoir system throughout the Columbia River Basin. The reservoirs hold water and release it later based on human needs, which means the water in the lower Columbia River at a given time could originally be from weeks or months prior but that had only just been released upstream. It is also noteworthy that the maximum magnitude of the coefficients has decreased from the Pre-Dam model to the Modern model (Figure 32). This effect is also likely attributable to the reservoir system because it shows that air and water temperatures are not as highly correlated as they used to be. A weaker $T_{a}-T_{w}$ correlation implies that the modern river system is not as sensitive to short term fluctuations and synoptic weather patterns. Consequently, it takes longer for the river to heat in the spring and longer to cool in the fall. This result supports the seasonal changes observed in water temperature (Figure 23 and Figure 26). 
The river depth has also changed, due to construction of reservoirs and navigation channels. Based on reports from the early 1900's of the Cascade Locks, located just upstream of Bonneville Dam today, average depths have increased by about 10 to 20 meters since the dam was built. Before the dam, the approximate river depth ranged from 3 to 15 meters annually, while today, the depth is closer to 20 to 25 meters (U.S. Army 1892, 1911). The current river depth is also much less variable over the year compared to the system prior to the dams and reservoirs due to flow regulation. The observed changes in the river "memory" may be further explained by the changes in river depth as the depth is known to be directly related to time lags (Stefan and Preud'homme 1993). Using Stefan and Preudhomme's (1993) approach for obtaining estimates of daily time lags based on the river depth, the time lags for the pre-dam system would have ranged from about 6 to 30 days, depending on the time of year, while the corresponding time lags for the modern system are around 45 to 50 days. This simple theoretical exercise not only helps show that river depth and time lags are directly correlated, but it also supports the results from the statistical model that the water in the modern system has a longer "memory" than that of the pre-dam system (Figure 32). 

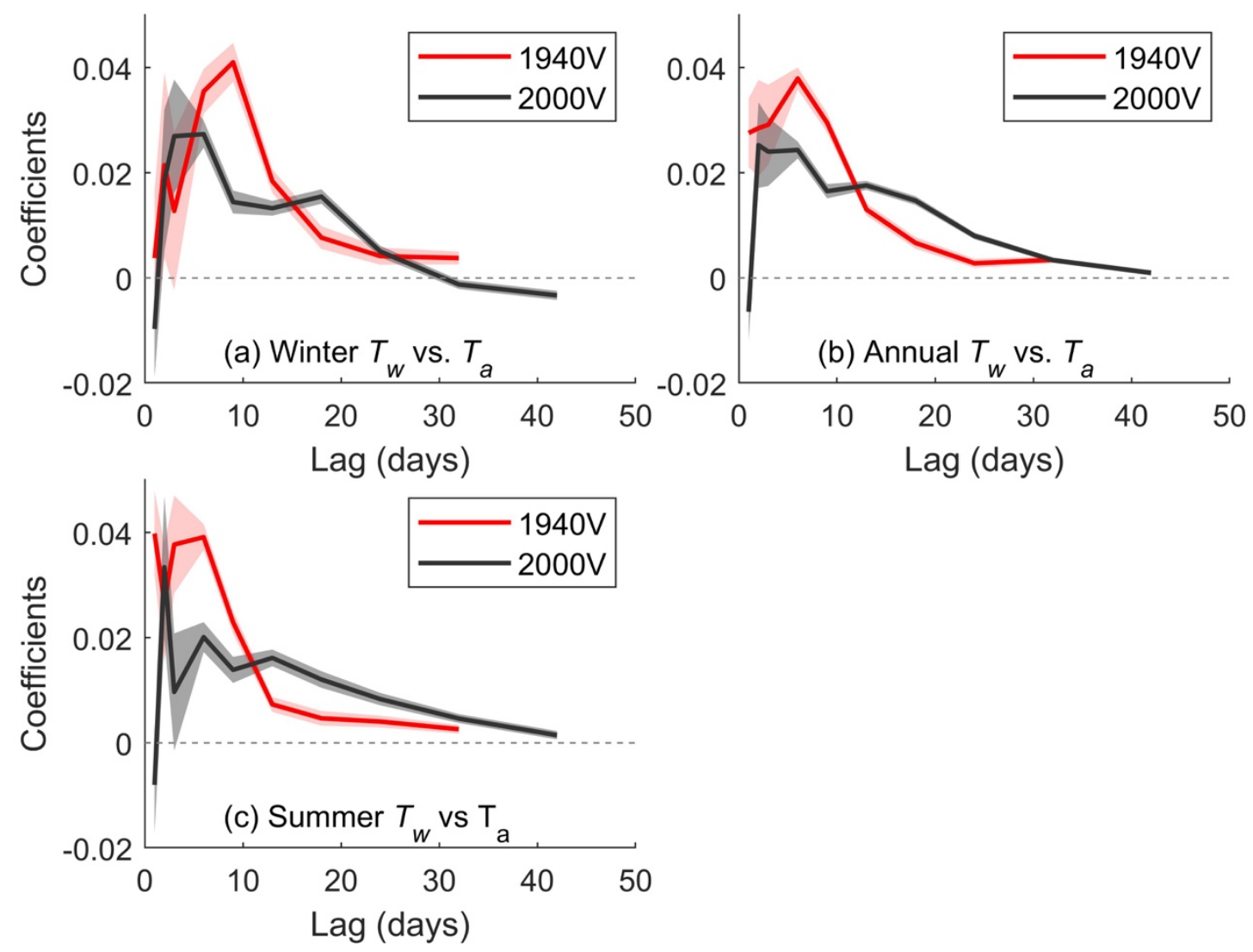

Figure 32: The air temperature coefficients plotted as a function of number of days lagged. The change in the magnitude of coefficients from 0 lag days to 60 lag days shows how the correlation between air temperature and water temperature decreases as the time between measurements increases. The red line is the 1940s Vancouver (1940V) decorrelation structure and the black line is the 2000s Vancouver (2000V) correlation structure. 


\subsection{Multiple Model Comparison and an Average Model}

Lastly, I computed an average model based on multiple models that used air temperatures from various locations throughout the Columbia River Basin (Table 1 and Figure 33). All previously shown results stem from the Vancouver models and provide a sample analysis framework; however I also ran similar analyses for additional models in order to obtain more robust results. The average of all models, based on different air temperature data sets, shows that while individual models agree with the overall increasing trends in water temperature, there is still quite a bit of variability among models. Additionally, there are also some time periods where the models in general don't perform as well based on the measured data. From the mid-1950s to the mid-1970s, the measured water temperature was consistently warmer than the modeled results. This difference can be most likely explained by the activity from the Hanford Site. Another period of discrepancy between the measured data and modeled results was from the 1980s to the early 2000s. Once again, the measured data are consistently warmer than many of the modeled results. One possible explanation for this is that the data collection methods changed in the mid-1990s. Prior to this point, temperatures were recorded at one of Bonneville Dam's turbine intake, while afterwards temperatures were taken from the forebay (Isaak et al. 2018); moreover, the time of day when the measurements were taken was changed from 0800 to 1200 in 1992 . Considering the scale of temperature difference between the modeled average and measured data (for this time period), it is certainly possible that these changes could explain the discrepancy. 


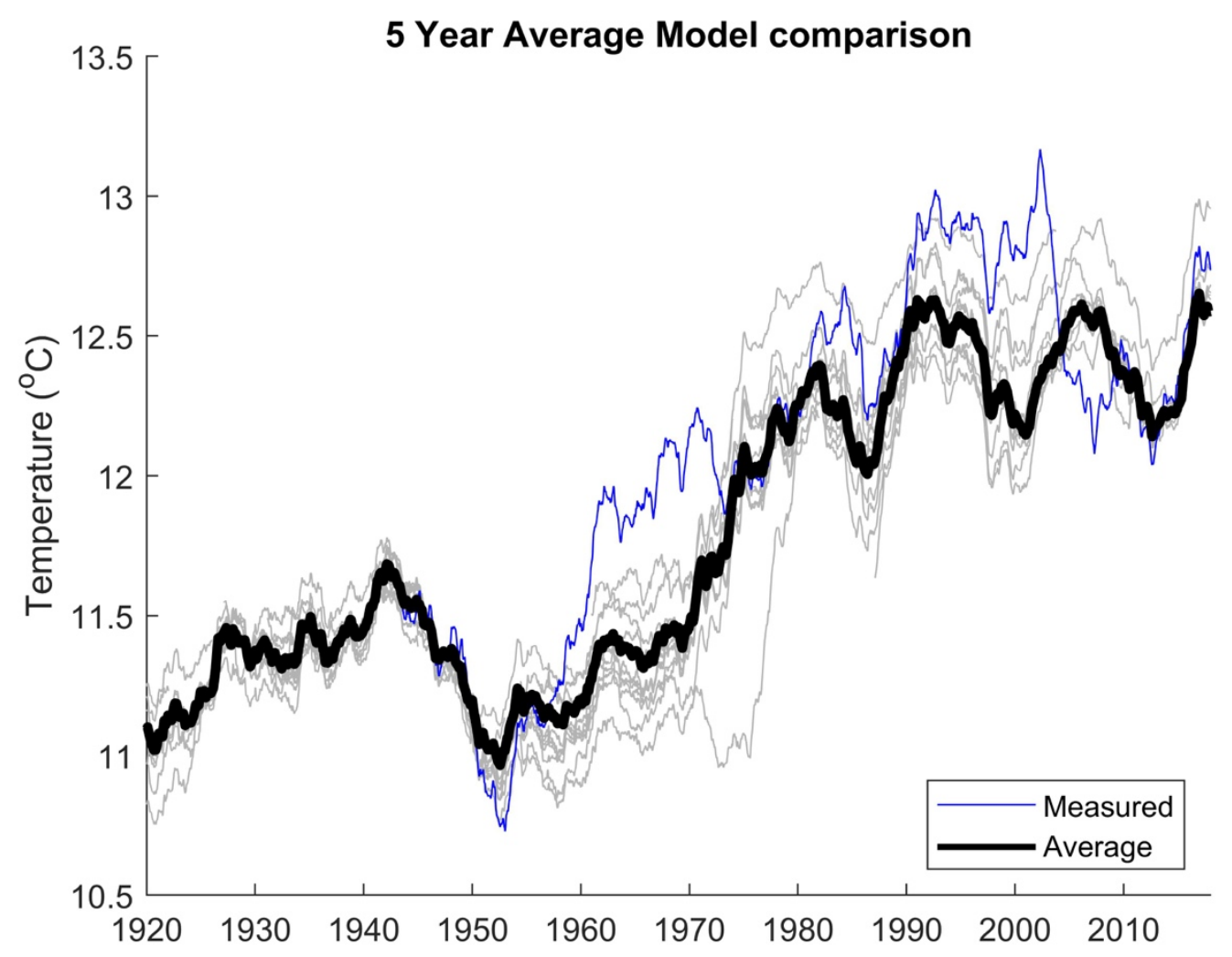

Figure 33: Five-year averaged modeled water temperature from various models (light grey lines) compared with the ensemble average of all model results (black line) and five-year averaged measured water temperature (blue line). The various models shown used different air temperature inputs from different locations (Table 1).

For the years between 1938 and 2018, I calculated the change per decade for all individually modeled and measured data by fitting a linear trend to the data (Table 5). The different model results ranged from $0.10^{\circ} \mathrm{C} /$ decade to $0.27^{\circ} \mathrm{C} /$ decade, with the average of all model results being $0.21^{\circ} \mathrm{C} /$ decade. The daily RMSE for the composite models, excluding the Hanford period (1957 to 1976), ranged from 0.85 to $1.38^{\circ} \mathrm{C}$, with an average of $0.96^{\circ} \mathrm{C}$ (Table 5). This performance is fairly good considering the length of the dataset, which included daily temperatures for approximately 80 years. The model that used EOF analysis to incorporate multiple air temperatures in a single model appeared to perform 
slightly better than most others. The daily RMSE for this model was $0.85^{\circ} \mathrm{C}$, which was the lowest value of all models by $0.01^{\circ} \mathrm{C}$, suggesting the use of EOF analysis can slightly, but measurably improve model performance.

Table 5: The RMSE statistic and estimated change per decade statistic are shown below for each composite model using different $T_{a}$ inputs. All models used $T_{a}$ from NOAA's NCEI unless otherwise noted.

\begin{tabular}{|c|c|c|c|}
\hline Model & Daily RMSE $\left({ }^{\circ} \mathrm{C}\right)$ & $\mathbf{R}^{2}$ & ${ }^{\circ} \mathrm{C}$ increase/decade \\
\hline PDX Airport & 0.86 & 0.98 & $0.23+/-0.02$ \\
\hline Vancouver, WA & 0.89 & 0.98 & $0.22+/-0.02$ \\
\hline $\begin{array}{r}\text { Vancouver, WA } \\
\text { (Berkeley Earth) }\end{array}$ & 0.91 & 0.97 & $0.25+/-0.02$ \\
\hline $\begin{array}{r}\text { Spokane, WA } \\
\text { (Berkeley Earth) }\end{array}$ & 0.87 & 0.98 & $0.22+/-0.02$ \\
\hline Spokane, WA & 1.29 & 0.95 & $0.24+/-0.02$ \\
\hline Portland, OR & 0.86 & 0.98 & $0.12+/-0.02$ \\
\hline Kalispell, MT & 0.91 & 0.98 & $0.21+/-0.02$ \\
\hline Moscow, ID & 0.91 & 0.98 & $0.19+/-0.02$ \\
\hline Payette, ID & 1.02 & 0.98 & $0.10+/-0.02$ \\
\hline Priest Rapids, ID & 0.91 & 0.97 & $0.22+/-0.02$ \\
\hline Heppner, OR & 0.88 & 0.98 & $0.21+/-0.02$ \\
\hline Odessa, WA & 1.38 & 0.95 & $0.26+/-0.02$ \\
\hline Porthill, ID & 0.94 & 0.98 & $0.25+/-0.02$ \\
\hline EOF model & 0.85 & 0.98 & $0.27+/-0.02$ \\
\hline Measured $\mathbf{T}_{\mathbf{w}}$ & & & $0.25+/-0.02$ \\
\hline
\end{tabular}




\section{Discussion and Conclusions}

In this study, I examined the evolution of water temperatures in the lower Columbia River from the 1850s forward. I used an empirical approach and created a statistical model in order to estimate daily historical water temperatures preceding existing measurements, as well as to gain a deeper understanding of how the river as a system has changed since the $19^{\text {th }}$ century. Using daily air temperature and daily river flow measurements as inputs to models and daily water temperature measurements from Astoria for 185?to 1876 in the calibration process, I was able to model daily water temperatures at Bonneville Dam from 1850 to 2018. Furthermore, I sought to identify and quantify some of the causes of these long-term changes by distinguishing how much of the water temperature changes are due to climate effects and how much of the changes are due to the reservoir system and its management.

I found that there has been about a $2.2 \pm 0.2^{\circ} \mathrm{C}$ increase in water temperature at Bonneville Dam from 1850 to 2018, which agrees well with existing literature (Figure 25). Bottom et al. (2011) estimated a 2 to $3^{\circ} \mathrm{C}$ increase between May and December from 1890 to 2014 , and Overman (2017) found a $1.5^{\circ} \mathrm{C}$ increase between 1938 and 2003. Additionally, an EPA report draft estimated a $1.5 \pm 0.5^{\circ} \mathrm{C}$ increase in the lower Columbia River since about the 1960s (U.S. EPA 2018). These results together suggest that the majority of the river's warming has occurred within the last 50 to 60 years. 
There are multiple lines of evidence that point to warming air temperatures and changes in precipitation in the coming decades, which have implications for the lower Columbia River temperature regime. I have found in this study that river temperatures have already increased around $2^{\circ} \mathrm{C}$ in the late summer and early fall over the past century. Other studies have also shown the most warming occurs during this time of year (U.S. EPA 2018). Between predictions of more winter precipitation falling as rain, drier summers, and increasing air temperatures, it is expected that summer river temperatures will become even warmer (U.S. EPA 2018). Isaak et al. (2018) estimated summer water temperatures in the Columbia River will increase by about $2.0^{\circ} \mathrm{C}$ by the end of the century. Summer water temperatures have already changed significantly, and future projections only suggest further detrimental changes for cold water fish in the Columbia River.

One of the primary difficulties in this study was dealing with the biases in the long-term daily air temperature data. Because one of the goals of this study was to develop a statistical model starting in the $19^{\text {th }}$ century, I needed weather stations that had air temperature measurements over a century or more. While there are a few stations that met this criterion, specifically Vancouver, WA, Portland, OR and Spokane, WA, all stations had changed location and elevation over time. By changing the elevation at which the temperature readings occurred, an unavoidable bias was introduced into the data because temperature changes with elevation, known as a temperature lapse rate. Furthermore, the stations that had long records of data were subject to multiple location changes, which adds some complexity in determining the bias. One solution to this problem was to use data from the Berkeley Earth project. As mentioned previously, this gridded air temperature dataset had 
been corrected for individual station bias. Another way to minimize the influence of individual station bias was to incorporate many different stations' air temperature into a single regression model. Not only does this reduce individual station bias, it also theoretically captures the climate of the basin more accurately. This was the primary motivation for using EOF analysis. Through this analysis, I was able to include about $95 \%$ of the total variance of eight different stations, while only including two independent air temperature variables in the model. It also produced the lowest RMSE of all tested models, which supports the notion that using multiple $T_{a}$ stations better represents the climate of the basin as a whole.

In addition to air temperature data, the water temperature data also presented some limitations. Because the river temperature measurements start only after some of the dams had already been built, I am limited in how I can describe the historical, or pre-reservoir, Columbia River system. The method of data collection is an additional source of uncertainty. The specific location of temperature measurements at Bonneville Dam changed in 1997 from one of the dam's powerhouse turbine intake to the dam forebay (Isaak et al. 2018). Also, the timing of daily measurements shifted from 8:00 am to 12:00 am after 1992, introducing additional discontinuity in data collection methods. The personnel recording the measurements and exactly how they made the recordings have certainly also changed over the course of the 80 year data record. Such changes can create misleading trends in water temperature that may not exist in reality. It also makes determining the performance of my statistical model more difficult if there are biases in the original data. 
There are also some limitations inherent to linear regression analysis. For example, the models may not capture extreme temperatures as well as the average temperature. This can be beneficial for determining mean trends in the data but not for looking at trends in threshold — or extreme - temperatures. Another limitation of a model such as this one is that it does not capture the spatial variability in water temperature. Because this model relies on water temperature data from primarily one measurement location (Bonneville Dam), it is most likely successful at predicting temperatures only for that location. This has ecological significance because one point in the river channel may not be representative of the entire river channel and thus may not be the temperature that fish and other species experience. While I assumed that the river is well mixed, this assumption doesn't account for river temperatures throughout the length of the channel, which undoubtedly changes as the water flows downstream. This point is also important with regards to my estimates of the reservoir effects. The models are based on data near Bonneville Dam and therefore are mainly applicable to this portion of the Columbia River. Also, the estimated reservoir effects presented here are likely not representative of other river systems.

While there are multiple sources of error and bias in my statistical model, I am confident that the general trends captured are quite accurate. By using temperature data from many locations and sources, I confirmed there are obvious air and river temperature warming trends, despite any individual biases that may exist in each record. I also attempted to attribute the causes of the river temperature changes to various factors (climate change, reservoir management and water withdrawal), but only a broad-brush treatment is possible. The interaction between different causes of the change is complex and can be difficult to 
accurately distinguish. The lower Columbia River has changed in more ways than just the addition of dams and reservoirs. For example, the bathymetry, shading, and vegetation in and around the river has been altered significantly, along with significant irrigation diversion. There are also more indirect causes such as urbanization. While the combination of many factors such as these makes it difficult to differentiate the causes of change, it is nonetheless a critical step in initiating changes in conservation management.

In conclusion, my statistical model provides important insights into the evolution of the water temperature regime of the lower Columbia River. By making use of the available air and water temperature data that date back to the 1850 s, I was able to create a continuous model back to this point in time and therefore gain a more complete understanding of how the water temperature has changed under the influence of humans. Furthermore, creating a daily model allowed for more accurate estimation of the number of days above threshold temperatures-which are important to native salmonid species-and allowed for estimation of the change in the number of days over these threshold temperatures. A model like this one, covering a lengthy time span, can provide valuable information to any project - ecological, civil, or otherwise - that requires an understanding of not only what conditions are like now, but also what they used to be and how and why they have changed. 


\section{References}

Benyahya L., D. Caissie, A. St-Hilaire, T.B.M.J. Ouarda, and B. Bobée. 2007. A Review of statistical water temperature models. Canadian Water Resources Journal. 32(3): 179-192.

Bottom, D. L., C. A. Simenstad, J. Burke, A. M. Baptista, D. A. Jay, K. K. Jones, E. Casillas, and M. H. Schiewe. 2005. Salmon at river's end: The role of the estuary in the decline and recovery of Columbia River salmon. U.S. Dept. of Commerce, NOAA Tech. Memo., NMFS-NWFSC-68.

Bottom, D., A. Baptista, J. Burke, L. Campbell, E. Casillas, S. Hinton, D. A. Jay, M. A. Lott, G. McCabe, R. McNatt, M. Ramirez, G. C. Roegner, C. A. Simenstad, S. Spilseth, L. Stamatiou, D. Teel, and J. E. Zamon. 2011. Estuarine habitat and juvenile salmon: Current and historical linkages in the Lower Columbia River and estuary. Final report, 2002-2008. Report of the National Marine Fisheries Service to the U.S. Army Corps of Engineers. Portland, Oregon. Available at https://www.nwfsc.noaa.gov/publications/index.cfm

Butler, N. L. 2015. Water temperature modeling in streams to support ecological restoration. Doctoral dissertation, University of California Berkeley, Berkeley.

Caissie, D., N. El-Jabi, and A. St-Hilaire. 1998. Stochastic modelling of water temperatures in a small stream using air to water relations. Canadian Journal of Civil Engineering. 25: 250-260.

Caissie, D., N. El-Jabi, and M. G. Satish. 2001. Modelling of maximum daily water temperatures in a small stream using air temperatures. Journal of Hydrology. 251: $14-28$.

Caissie, D., B. L. Kurylyk, A. St-Hilaire, N. El-Jabi, and K. T. B. MacQuarrie. 2014. Streambed temperature dynamics and corresponding heat fluxes in small streams experiencing seasonal ice cover. Journal of Hydrology. 519: 1441-1452.

Caissie, D., and C. H. Luce. 2017. Quantifying streambed advection and conduction heat fluxes. Water Resources Research. 53: 1595-1624.

Caldwell, R.J., S. Gangopadhyay, J. Bountry, Y. Lai, and M.M. Elsner. 2013. Statistical modeling of daily and subdaily stream temperatures: Application to the Methow River Basin, Washington. Water Resources Research. 49: 4346 - 4361. 
Carter, K. 2005. The effects of temperature on Steelhead trout, Coho salmon, and Chinook salmon biology and function by life stage. California Regional Water Quality Control Board, North Coast Region.

Columbia Riverkeeper v. Pruitt, 337 F. Supp. 3d 989 (W.D. Wash., 2018).

Erickson, T. R., H. G. Stefan, and Members of ASCE. 2000. Linear air/water temperature correlation for streams during open water periods. Journal of Hydrologic Engineering. 5(3): 317-321.

Foster, R. F. 1971. Effects of Hanford Reactors on Columbia River and adjacent land areas. United States. BNWL-SA-3679. doi: 10.2172/4035801.

Gu, R. 1998. A simplified river temperature model and its application to streamflow management. Journal of Hydrology (NZ). 37(1): 35-54.

Gu, R., S. Montgomery, and T. Al Austin. 1998. Quantifying the effects of stream discharge on summer river temperature. Hydrological Sciences Journal. 43(6): 885-904.

Hannachi, A. 2004. A primer for EOF Analysis of Climate Data. Scientific Report. Department of Meteorology, University of Reading.

Isaak, D.J., S. Wollrab, D. Horan, and G. Chandler. 2012: Climate change effects on stream and river temperatures across the northwest U.S. from 1980-2009 and implications for salmonid fishes. Climatic Change. 113: 499 - 524.

Isaak, D. J., C. H. Luce, D. L. Horan, G. L. Chandler, S. P Wollrab, and D. E. Nagel. 2018. Global warming of salmon and trout rivers in the northwestern U.S.: road to ruin or path through purgatory? Transactions of the American Fisheries Society. 147: $566-587$.

ISAB (Independent Scientific Advisory Board). 2011. Columbia River food webs: Developing a broader scientific foundation for fish and wildlife restoration. ISAB 2011-1. Northwest Portland and Conservation Council, Portland, OR, USA. Available at https://www.nwcouncil.org/reports

Jackman, A. P. and N. Yotsukura. 1977. Thermal loading of natural streams. U.S. Geological Survey, Professional Paper 991. doi: 10.3133/pp991

Jarvis, C.S. et al. 1936. Floods in the United States: Magnitude and Frequency. U.S. Geological Survey Water Supply Paper 771. 
Johnson, S. L. 2004. Factors influencing stream temperatures in small streams: substrate effects and a shading experiment. Canadian Journal of Fisheries and Aquatic Sciences. 61: 913-923.

Keefer, M. L., C. A. Peery, and C. C. Caudill. 2008. Migration timing of Columbia River spring Chinook salmon: effects of temperature, river discharge, and ocean environment. Transactions of the American Fisheries Society. 137: 1120-1133.

Kothandaraman, V. 1971. Analysis of water temperature variations in large river. ASCE, Journal of the Sanitary Engineering Division. 91(SA1): 19-31.

Laizé, C. L. R., C. B. Meredith, M. J. Dunbar, and D. M. Hannah. 2017. Climate and basin drivers of seasonal river water temperature dynamics. Hydrology and Earth System Sciences. 21: 3231-3247.

McCullough, D. A., and 15 others. 2009. Research in thermal biology: burning questions for coldwater stream fishes. Reviews in Fisheries Science. 17(1): 90-115.

Mohseni, O. and H. G. Stefan. 1999. Stream temperature/air temperature relationship: a physical interpretation. Journal of Hydrology. 218: 128-141.

Moore, A. M. 1968. Water temperatures in the lower Columbia River. U.S. Geological Survey, Circular 551. doi: 10.3133/cir551

Naik, P. K. and D. A. Jay. 2005. Estimation of Columbia River virgin flow: 1879 to 1928. Hydrological Processes. 19(9): 1807-1824.

Naik, P. K. and D. A. Jay. 2011. Human and climate impacts on Columbia River hydrology and salmonids. River Research and Applications. 27: 1270-1276.

National Research Council. 2004. Managing the Columbia River: Instream Flows, Water Withdrawals, and Salmon Survival. Washington, DC: The National Academies Press. https://doi.org/10.17226/10962.

Neumann, D. W., B. Rajagopalan, and E. A. Zagona. 2003. Regression model for daily maximum stream temperature. Journal of Environmental Engineering, ASCE. 129(7): 667-674.

Overman, C.C.M. 2017. A statistical investigation of Lower Columbia River water temperature, 1915-2003. BS Thesis, Portland State University, Portland.

PRISM Climate Group, Oregon State University, obtained 5, November, 2019. http://www.prism.oregonstate.edu/comparisons/anomalies.php 
Quinn, T. P. and D. J. Adams. 1996. Environmental changes affecting the migratory timing of American Shad and Sockeye Salmon. Ecology. 77(4): 1151-1162.

Rohde, R.,R. Muller, R. Jacobsen, S. Perlmutter, A. Rosenfeld, J. Wurtele, J. Curry, C. Wickham, and S. Mosher. 2013. Berkeley Earth Temperature Averaging Process. Geoinformatics and Geostatistics: An Overview. 1(2).

Rounds, S.A., 2010, Thermal effects of dams in the Willamette River basin, Oregon: U.S. Geological Survey Scientific Investigations Report 2010-5153, 64 p.

Sauter, S. T., J. McMillan, and J. Dunham. 2001. Issue paper 1: Salmonid behavior and water temperature: prepared as part of EPA Region 10 Temperature water quality criteria guidance development project. EPA 910-D-01-001.

Sherwood, C.R., D.A. Jay, R.B. Harvey, P. Hamilton, and C.A. Simenstad. 1990. Historical changes in the Columbia River estuary. Progress in Oceanography 25: 299-352.

Sinokrot, B. A. and H. G. Stefan. 1993. Stream temperature dynamics: measurements and modeling. Water Resources Research. 29(7): 2299-2312.

Sinokrot, B. A. and J. S. Gulliver. 2000. In-stream flow impact on river water temperatures. Journal of Hydraulic Research. 38(5): 339-349.

Sonnichsen, Jr, J. C., D.A. Kottwitz, and R.T. Jaske. 1970. Dispersion Characteristics of the Columbia River Between River Miles 383 and 355. United States. BNWL 1477. doi:10.2172/4095066.

Spranger, Michael S. 1996. Columbia Gorge: A Unique American Treasure. Diane Publishing Co.

Stefan, H. G. and E. B. Preud'homme. 1993. Stream temperature estimation from air temperature. Water Resources Bulletin. 29(1): 27-45.

Talke, S. A., A. Mahedy, D.A. Jay, P. Lau, C. Hilley, A. Hudson. 2020. Sea level, tidal and river flow trends in the Lower Columbia River Estuary, 1853-present, Journal of Geophysical Research-Oceans. doi.org/10.1029/2019JC015656

U.S. Army. 1892. Annual report of the chief of engineers to the secretary of war for the year 1892. In four parts and atlas (H. Ex. Doc 1. part 2, vol. II, part 1, Serial Set 3078). Washington D.C.: Government Printing Office. 
U.S. Army. 1911. Annual Report of the Chief of Engineers. In three parts. (part 3. vol II, Doc. no. 401). Washington D.C.: Government Printing Office.

U.S. Department of the Interior, Bureau of Reclamation. 2016. West-wide climate risk assessment Columbia River basin Climate Impact Assessment Final Report. Available at https://www.usbr.gov/watersmart/baseline/

U.S. Department of Commerce, National Oceanic and Atmospheric Administration, National Marine Fisheries Service. 2015. 2015 Adult sockeye salmon passage report. Available at https://www.westcoast.fisheries.noaa.gov/publications/hydropower/fcrps/

U.S. Environmental Protection Agency. 2003. Columbia River Preliminary Draft Temperature TMDL.

U.S. Environmental Protection Agency. 2018. Assessment of climate change impacts on temperatures of the Columbia and Snake rivers.

van Vliet, M. T. H., F. Ludwig, J. J. G. Zwolsman, G. P. Weedon, and P. Kabat. 2011. Global river temperatures and sensitivity to atmospheric warming and changes in river flow. Water Resources Research. 47(3): W02544.

Wagner, R. W, M. Stacey, L. R. Brown, and M. Dettinger. 2011. Statistical models of temperature in the Sacramento-San Joaquin delta under climate-change scenarios and ecological implications. Estuaries and Coasts. 34: 544-556.

Webb, B. W., P. D. Clack, and D. E. Walling. 2003. Water-air temperature relationships in a Devon river system and the role of flow. Hydrological Processes. 17: 30693084.

Webb, B. W. and F. Nobilis. 2007. Long-term changes in river temperature and the influence of climatic and hydrological factors. Hydrological Sciences Journal. 52(1): 74-85.

Webb, B. W., D. M. Hannah, R. D. Moore, L. E. Brown, F. Nobilis. 2008. Recent advances in stream and river temperature research. Hydrological Processes. 22: 902-918.

Weitkamp, L. A. 1994. A review of the effects of dams on the Columbia River Estuarine environment, with special reference to salmonids. Report of the National Marine Fisheries Service to the Bonneville Power Administration. Portland, Oregon. Available at https://www.nwfsc.noaa.gov/publications/index.cfm 
Whiteman, C. D. 2000. Mountain Meteorology: Fundamentals and Applications. Oxford University Press.

Wu, H., J. S. Kimball, M. M. Elsner, N. Mantua, R. F. Adler, and J. Stanford. 2012. Projected climate change impacts on the hydrology and temperature of Pacific Northwest rivers. Water Resources Research. 48, W11530.

Yearsley, J., D. Karna, S. Peene, and B.Watson. 2001. Application of a 1-D heat budget model to the Columbia River system. EPA Region 10. EPA 910-R-01-004. Seattle, WA. 